\title{
Homogeneous Catalysis by Organometallic Polynuclear Clusters
}

\author{
Nielsen, Mathias Thor; Padilla Paz, Rosa Maria; Nielsen, Martin
}

Published in:

Journal of Cluster Science

Link to article, DOI:

$10.1007 / \mathrm{s} 10876-019-01635-3$

Publication date:

2020

Document Version

Peer reviewed version

Link back to DTU Orbit

Citation (APA):

Nielsen, M. T., Padilla Paz, R. M., \& Nielsen, M. (2020). Homogeneous Catalysis by Organometallic Polynuclear Clusters. Journal of Cluster Science, 31, 11-61. https://doi.org/10.1007/s10876-019-01635-3

\section{General rights}

Copyright and moral rights for the publications made accessible in the public portal are retained by the authors and/or other copyright owners and it is a condition of accessing publications that users recognise and abide by the legal requirements associated with these rights.

- Users may download and print one copy of any publication from the public portal for the purpose of private study or research.

- You may not further distribute the material or use it for any profit-making activity or commercial gain

- You may freely distribute the URL identifying the publication in the public portal

If you believe that this document breaches copyright please contact us providing details, and we will remove access to the work immediately and investigate your claim. 
HOMOGENEOUS CATALYSIS BY ORGANOMETALLIC POLYNUCLEAR CLUSTERS

Mathias T. Nielsen, ${ }^{1}$ Rosa Padilla, ${ }^{1}$ Martin Nielsen*1

Martin Nielsen, marnie@kemi.dtu.dk

${ }^{1}$ Department of Chemistry, Technical University of Denmark, DK-2800 Kgs. Lyngby, Denmark.

\begin{abstract}
Homogeneous polynuclear metal clusters constitute a broad class of coordination compounds with important applications in catalysis. The current interest of synthetic chemistry in this field demands the exploration of new strategies to develop catalytic methods that work under mild conditions and maximize atom utilization. This review covers the application of polynuclear clusters of nuclearity $\geq 3$ in homogeneous catalytic processes, with focus on providing an array of examples of various reaction types within cluster catalysis.
\end{abstract}

Keywords: polynuclear cluster $\cdot$ ligand scaffold $\cdot$ homogeneous catalysis 


\section{LIST OF CONTENTS}

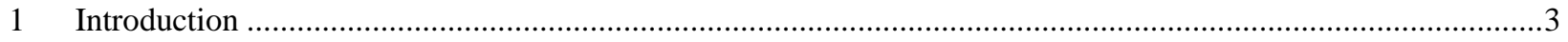

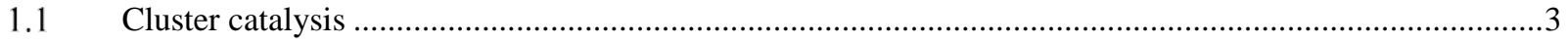

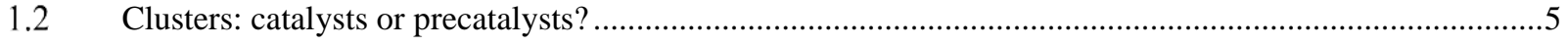

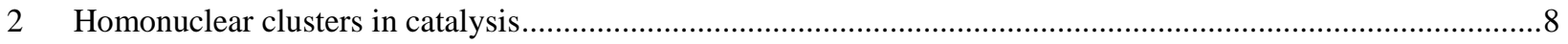

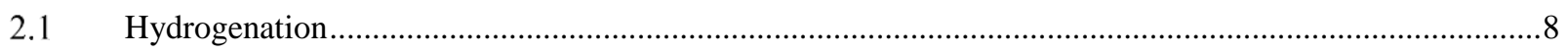

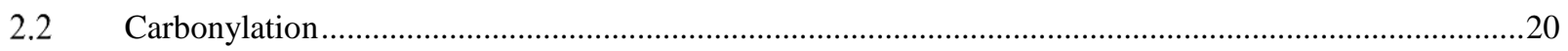

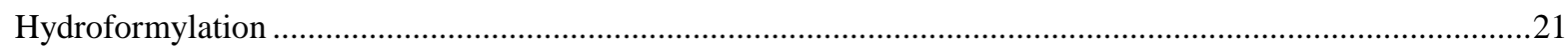

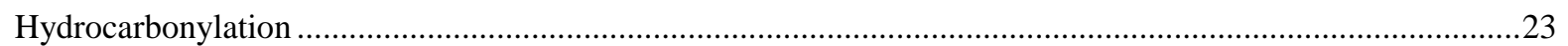

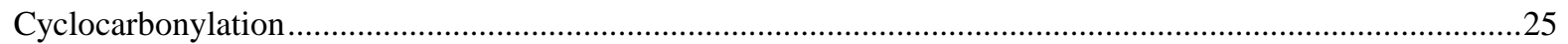

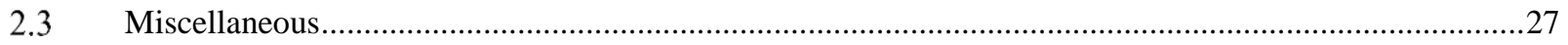

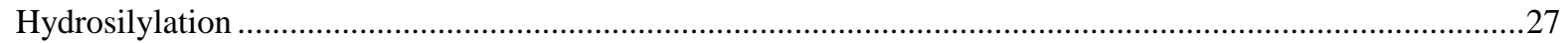

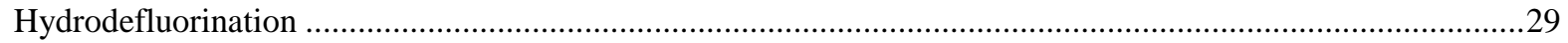

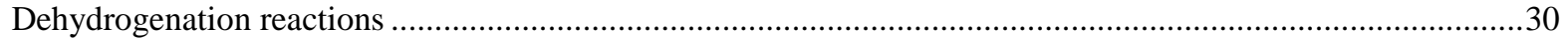

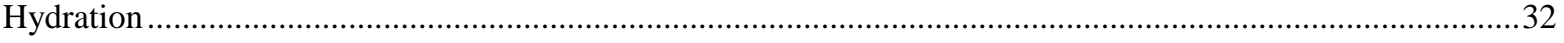

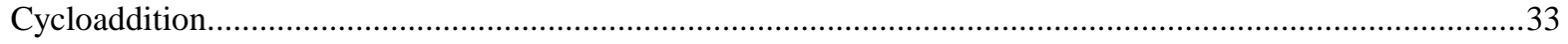

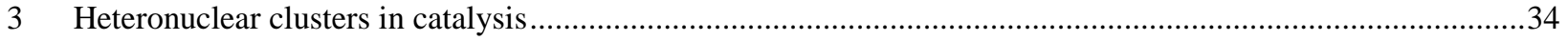

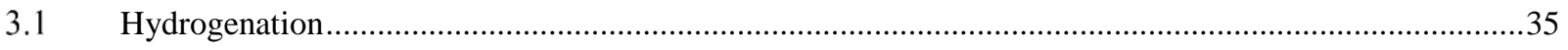

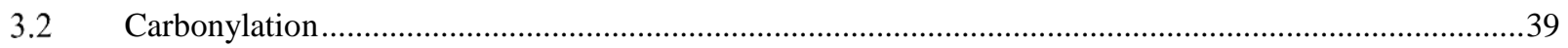

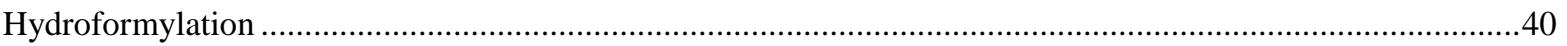

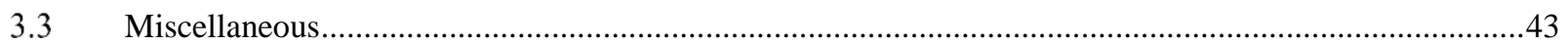

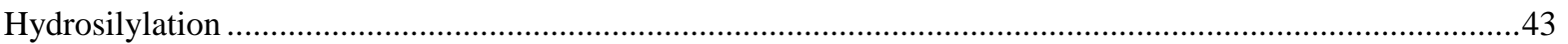

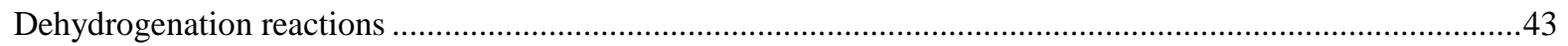

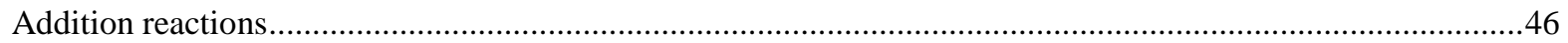

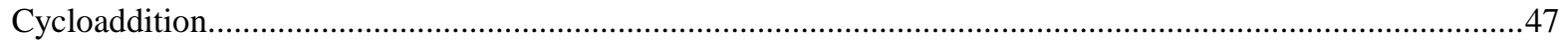

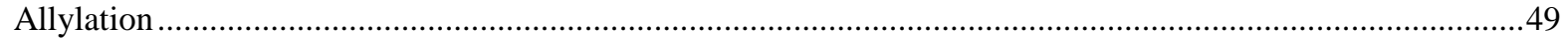

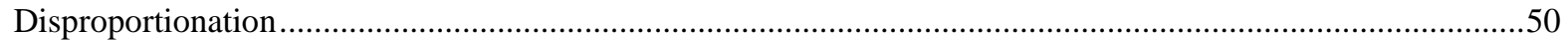

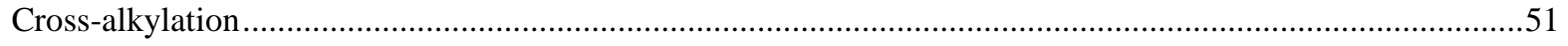

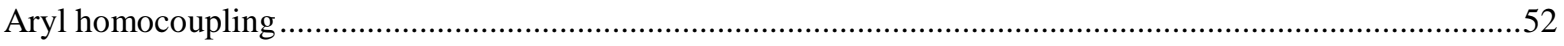

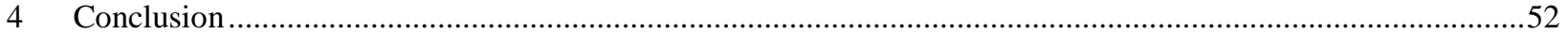

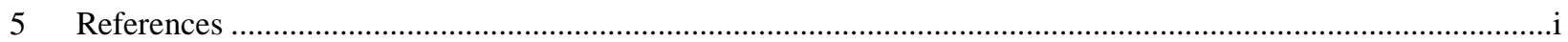




\section{INTRODUCTION}

Polynuclear metal clusters constitute a broad class of coordination compounds with numerous applications in catalysis. As is true for traditional mononuclear organometallic catalysis, polynuclear clusters may perform complex transformations in homogeneous solution. The principal objective of both fields is the exploration of new strategies to develop novel catalytic atom-efficient transformations that work under mild conditions. The typical approach towards this goal is to employ a transition metal or -ion with specific fundamental features, and then fine-tune the catalytic behavior by proper modification of the ligand scaffold. In this regard, compared to mononuclear complexes, the study of polynuclear cluster catalysis offers the potential of tuning an entirely new dimension, namely the interaction between several transition metals.

The chemistry involved in activation of small molecules, such as alkenes, alkynes, $\mathrm{CO}$, and $\mathrm{H}_{2}$, by metal(hydrido)carbonyl clusters is well reported [1-5]. The binding of substrate to these clusters varies from analogous to monometallic complexes, to simultaneous interactions of the substrate with multiple metal centers resulting in unique chemo-, regio- and stereoselectivities, see for example Scheme 1 [6-8]. These scenarios provide many opportunities for novel transformations and, as such, demonstrate that the combined application of more than one metal offers appealing new opportunities for the synthetic community.

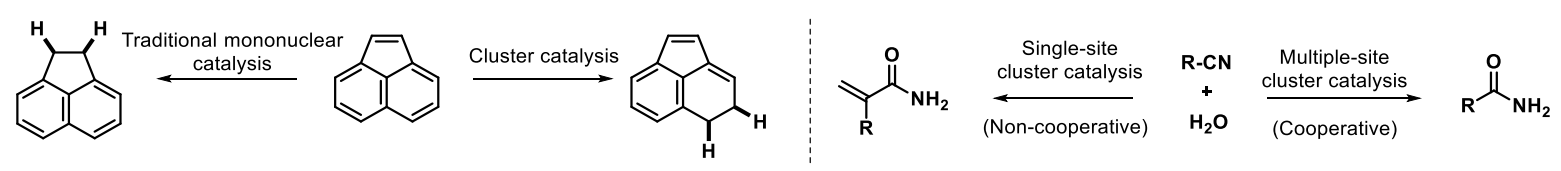

Scheme 1. Examples of unique cluster catalyzed transformations compared to traditional mononuclear catalysis (left scheme) and between different types of cluster catalysis (right scheme), [6-8].

In this review, we focus on catalysis based on homogeneous polynuclear transition metal clusters with nuclearities of three or higher. We do so because dinuclear clusters have recently been extensively discussed in excellent reviews [9, 10]. In the course of analyzing the definitions and criteria discussed below, we have sought to provide pertinent literature, which serves to deliver excellent illustrations on current state-of-the-art within cluster catalysis.

\subsection{Cluster catalysis}

The term cluster was introduced in 1964 by F. A. Cotton to designate a finite number of metal atoms held together to a certain extent, either by metal-metal interactions or metal-nonmetal bonds [11-13]. The nuclearity defines the total number of metal atoms comprising the cluster, and further classification is made with respect to the number of different metals. For example, a hexanuclear bimetallic cluster refers to a complex comprising of six metals of two different

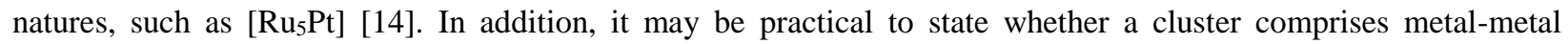
interactions [15]. The proximity between metal centers permits unique substrate transformations as multiple binding sites are available, and each metal center potentially provides additional redox-active electrons.

A given cluster's electronic properties and catalytic proficiency largely relate to three parameters, namely, (i) electronic properties of the parent metals, (ii) the combination of metal and ligand, and (iii) the extent of metal-metal interactions. Cluster frameworks consisting of early-transition metals predominantly comprise high valent metals combined with $\sigma / \pi$-donating ligands, such as halides and chalcogenides (high valent clusters) [16, 17]. The ligands act as a source of electrons that promote bonding interactions between the metals, as well as stabilizing the positive oxidation states. Such electropositive clusters often act as potential Lewis acidic catalysts. Contrary, late-transition metal clusters mainly comprise low valent metals combined with $\pi$-accepting ligands (low valent clusters) [18]. Hereof, $\mathrm{CO}$ represents the more common ligand albeit other examples of $\pi$-accepting ligands have been reported, such as phosphines, alkenes, alkynes, and heteroaromatics. These typically redox-active compounds may undergo oxidative addition and can catalyze reactions such as hydrogenation, hydroformylation and $\mathrm{C}-\mathrm{H}$ bond activation.

The propensity to form M-M bonds increases when going from $3 d$, through $4 d$, to $5 d$ metals, which reflects the increased possible $d-d$ orbital overlap when going down a transition metal triad. A range of [ $\left.\mathrm{MRu}_{2}\right], \mathrm{M}=\mathrm{Ni}, \mathrm{Pd}, \mathrm{Pt}$, clusters work to demonstrate the effect on catalysis when substituting one metal for another in a triad. Thus, for the 
catalytic oxidation of benzylic alcohol to benzaldehyde, the activity was observed to increase up to five-fold when substituting either $\left[\mathrm{PdRu}_{2}\right]$ or $\left[\mathrm{PtRu}_{2}\right]$ with [NiRu$\left.{ }_{2}\right]$ [19]. Interestingly, the effect of substituting Pt with $\mathrm{Ni}$ was also reflected in the structures of the cluster cores. As such, the $\mathrm{NiRu}_{2}$ core in $\left[\mathrm{NiRu}_{2}\right]$ is asymmetric with $\mathrm{Ni}-\mathrm{Ru}$ bond lengths of 2.90 and $3.12 \AA$, respectively, whereas in $\left[\mathrm{PtRu}_{2}\right]$ the $\mathrm{PtRu}_{2}$ core is symmetric with equidistant $\mathrm{Pt}-\mathrm{Ru}$ bond lengths of $3.16 \AA$.

Clusters containing first-row transition metals are significantly more affected by ligation than the corresponding second and third row metals. Perturbation of the $d$-orbital splitting and the properties derived hereof, thus relates to the ligand, and whether this induces a low field-splitting (weak field), or a large field-splitting (strong field) environment. However, the majority of cluster catalysts comprises $4 d$ and $5 d$ metals coordinated by strong-field ligands.

Laine proposed a three-level scale to reflect the involvement of a given cluster in the catalytic cycle as schematized in Figure 1 [20]. The highest level of sophistication necessitate that at least two of the cluster's metal centers are mechanistically required for the transformation. The combination of multiple metals (identical or different in chemical nature) typically leading to a distinct chemo-, regio- and stereoselectivity, as well as a significantly different activity from a mere additive effect, is considered as synergism or cooperativity. In this regard, specific combinations of various transition metals can afford clusters with unique stereoelectronic environments to satisfy a certain set of criteria for reactivity. On the other hand, a single metal center may mechanistically account for the transformation, while interacting with vicinal centers. The other metal thus acts as an extended ligand. The nature of this interaction may be explained from both a steric and an electronic perturbation of the center bound to the substrate, and thereby enhance the overall catalytic performance. Finally, the lowest level of sophistication suggests a cluster be required in at least one of the catalytic steps.

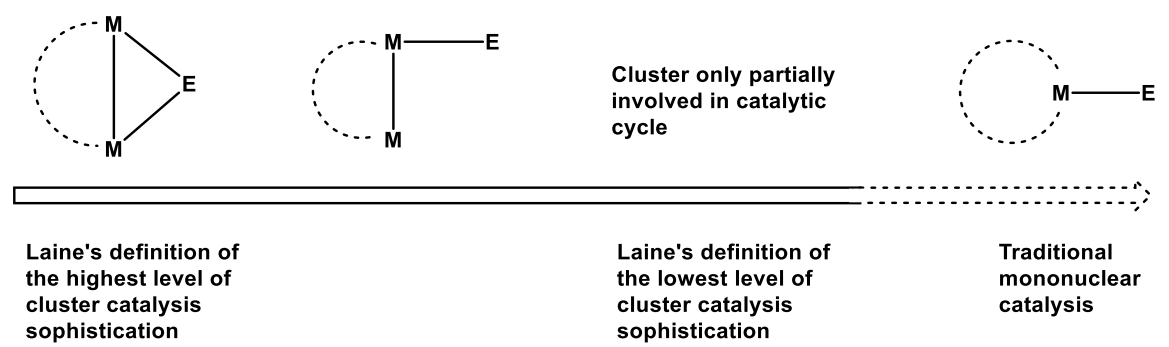

Figure 1. Three levels of sophistication a) multiple metal interactions with a substrate, b) a metal-substrate interaction is influence by a vicinal metal center either electronic, sterically or both, and c) single metal-substrate interaction, [20].

Laine's three-level scale of sophistication provides the basis for the following separate five criteria, also proposed by Laine, that suggest cluster mediated catalysis as:

1. An increasing amount of added catalysts results in a corresponding increase in turnover frequency (TOF).

2. Differences in product selectivity due to the use of a cluster catalyst (precursor), which mechanistically cannot be justified by a mononuclear compound.

3. A change in reaction conditions, or change in the catalyst, which favors metal-metal bond formation, induces an increased catalytic activity.

4. Mixed-metal cluster catalysis is suggested given a combination of at least two different metals enhance the rate of reaction or change product selectivity, which either fails to provide alone.

5. Chiral induction achieved employing asymmetric metal cluster (pre)catalysts. Chirality may reside on the basic skeletal- or metal-framework.

While these criteria provide an indirect indication of cluster catalysis, supplementary measurements are often required to ascertain the true nature of the catalyst. Such further measurement can include testing for agglomeration of colloids and nanoparticles, for example by a $\mathrm{Hg}(0)$ poisoning test. In addition, a catalyst (precursor) inhibition test, as well as recovery and recycling experiments, may provide even further insights into the nature of the true catalyst [21].

\section{P. 3 of 52}


Moreover, it is important to emphasize that no methods alone should form the conclusion on the nature of the true catalyst, as immature conclusions may potentially be drawn [22].

\subsection{Clusters: catalysts or precatalysts?}

Polynuclear cluster catalysts are more often isolated as their corresponding precatalyst rather than as one of the catalytically active intermediates because of the high reactivity of the latter. Thus, the binary metal carbonyl dodecacarbonyl triruthenium, $\mathrm{Ru}_{3}(\mathrm{CO})_{12}$, has been extensively used in small molecule activation, for example of $\mathrm{H}_{2}$ [23-25] or CO [26-30], as well as more complex transformations, such as (cyclo)carbonylation [31-34] and C-H bond activation [35-38]. However, while highly active systems have been reported, mechanistic studies on these $\mathrm{Ru}_{3}(\mathrm{CO})_{12}$ catalyzed reactions strongly suggest that the cluster acts a precatalyst and transforms into the active species prior to catalysis.

At high pressures of $\mathrm{CO}, \mathrm{Ru}_{3}(\mathrm{CO})_{12}$ is in equilibrium with its monomeric congener $\mathrm{Ru}(\mathrm{CO})_{5}$, see Scheme 2 [39]. This equilibrium has been shown to be highly accelerated by the presence of chloride [40]. Geoffroy and Dombek reported various nuclearity ruthenium structures resulting from different equilibria depending on temperature, $\mathrm{CO}$ pressure and the nature of a halide additive [41]. Thermal treatment afford tetranuclear butterfly structures in presence of chloride and bromide, whereas iodide promotes loss of $\mathrm{CO}$ resulting in a triruthenium- $\left(\mu_{3}-\mathrm{I}\right)$ species.

Treating $\mathrm{Ru}_{3}(\mathrm{CO})_{12}$ with dppe resulted in formation of the mononuclear species $\mathrm{Ru}(\mathrm{CO})_{3}(\mathrm{dppe})$ [42]. Interestingly, work by Dyson and Duckett demonstrates that, in polar solvents, the $\left[\mathrm{Ru}_{3}\right]$-core stays intact despite the presence of phosphine, whereas apolar solvents induce cluster fragmentation, forming $\mathrm{Ru}(\mathrm{H})_{2}(\mathrm{CO})_{2}\left(\mathrm{PPh}_{3}\right)_{2}$ [43, 44]. Krische was able to isolate a mononuclear $\mathrm{Ru}$-metallacycle from the fragmentation of $\mathrm{Ru}_{3}(\mathrm{CO})_{12}$ in presence of $\mathrm{PCy}_{3}$. [45] Chatani found that, under carbonylation of $\mathrm{C}-\mathrm{H}$ bonds, fragmentation of the precatalyst $\mathrm{Ru}_{3}(\mathrm{CO})_{12}$ into mononuclear $\mathrm{Ru}$ complexes occurs [46-48]. Beller reported precatalytic amounts of $\mathrm{Ru}_{3}(\mathrm{CO})_{12}$ mixed with phosphine ligands in-situ forms a mononuclear species [49-51]. Thus, there is significant evidence suggesting that $\mathrm{Ru}_{3}(\mathrm{CO})_{12}$ behaves as a precatalyst for a variety of catalytically active mononuclear Ru-species.

In a similar fashion, treatment of $\mathrm{Fe}_{3}(\mathrm{CO})_{12}$ with amine in THF was reported by Periasamy to fragment into two different compounds, a dinuclear $\mathrm{Fe}_{2}(\mathrm{CO})_{8}$ and an amine- $\mathrm{Fe}(\mathrm{CO})_{4}$ species [52-54]. Chini and Martinengo reported that the binary tetrarhodium carbonyl cluster, $\mathrm{Rh}_{4}(\mathrm{CO})_{12}$ undergoes thermal decomposition $\left(130-140{ }^{\circ} \mathrm{C}\right)$ under $\mathrm{N}_{2}$, affording $\mathrm{Rh}_{6}(\mathrm{CO})_{16}$ [55]. This decomposition was also observed to occur slowly in $\mathrm{MeOH}$. The reaction of either tetra- or hexarhodium cluster with $\mathrm{PPh}_{3}$ under a $\mathrm{CO}$ atmosphere afforded the dirhodium compound, $\mathrm{Rh}_{2}(\mathrm{CO})_{4}\left(\mathrm{PPh}_{3}\right)_{4}$. Chini later reported that $\mathrm{Rh}_{4}(\mathrm{CO})_{12}$ forms an array of clusters varying in nuclearity at increasingly reducing conditions under a $\mathrm{CO}$ atmosphere [56]. Likewise, $\mathrm{Rh}_{6}(\mathrm{CO})_{16}$ reacts with $\mathrm{CO}$ under reducing conditions to form anionic compounds of lower nuclearities, namely $\left[\mathrm{Rh}_{4}(\mathrm{CO})_{11}\right]^{2-}$ and $\left[\mathrm{Rh}(\mathrm{CO})_{4}\right]^{-}$[57]. Fragmentation of $\mathrm{Rh}_{4}(\mathrm{CO})_{12}$ was corroborated by Matsuda, who reported degradation under silylformylation of terminal alkynes using $\mathrm{Rh}_{4}(\mathrm{CO})_{12}$ as precatalyst [58]. Longoni demonstrated that the transformation of tetracobalt dodecacarbonyl, $\mathrm{Co}_{4}(\mathrm{CO})_{12}$, to a dicobalt compound, $\mathrm{Co}_{2}(\mathrm{CO})_{8}$, is feasible at room temperature under approximately 1 bar of $\mathrm{CO}$ in ${ }^{i} \mathrm{PrOH}$ [59]. The equilibrium was further pushed towards the dicobalt in the presence of halide ions. These findings corroborate previously established decomposition patterns of the tetracobaltate clusters $\left[\mathrm{Co}_{4}(\mathrm{CO})_{11} \mathrm{X}\right]^{-}, \mathrm{X}=\mathrm{Br}$, I, or SCN, in Lewis-basic solvents. 


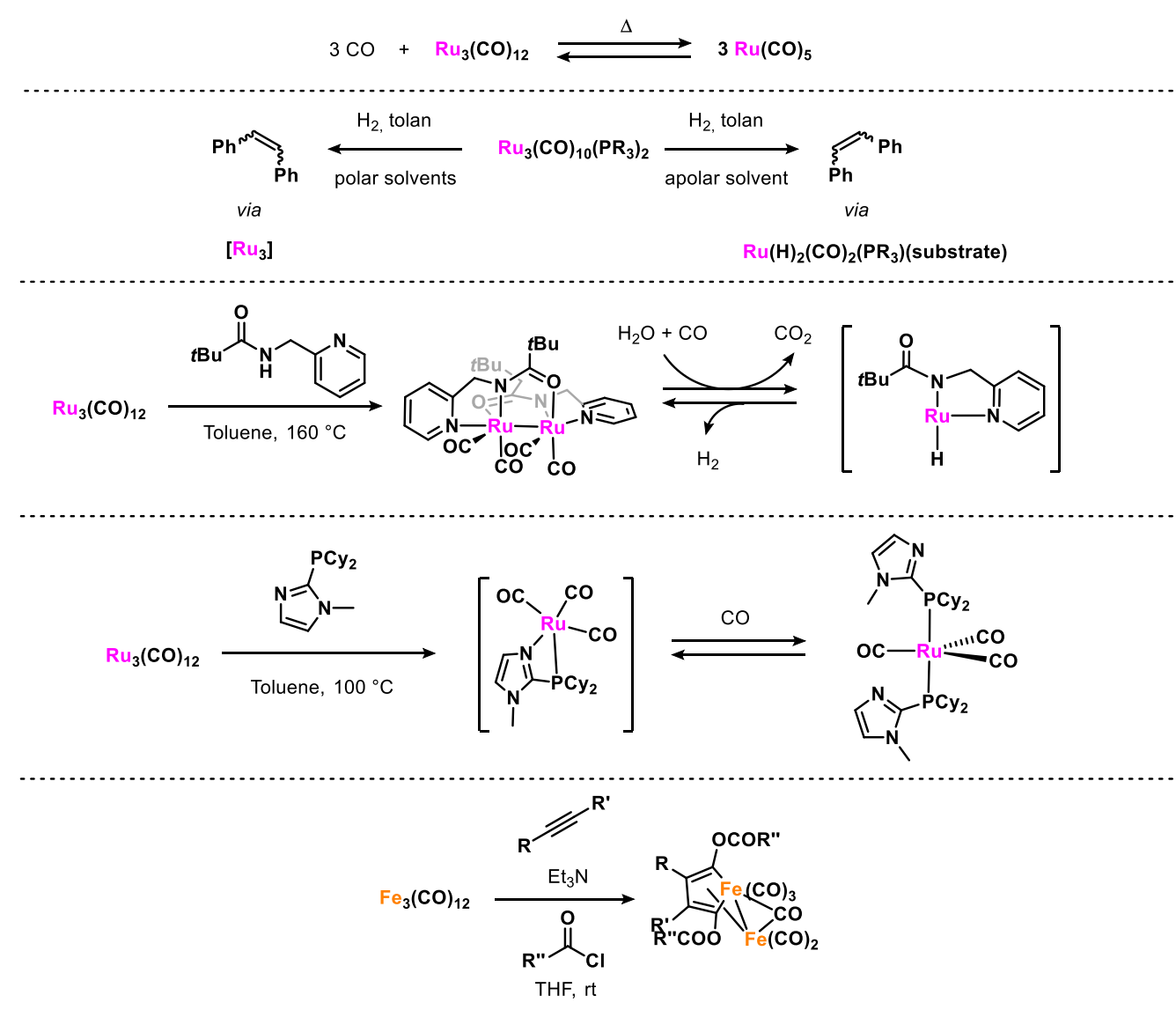

Scheme 2. Selected examples of fragmentations for catalyst precursors $\mathrm{Ru}_{3}(\mathrm{CO})_{12}$ and $\mathrm{Fe}_{3}(\mathrm{CO})_{12}$. Starting from the top, through the bottom, the reactions follow [39], [43, 44], [46-48], [49-51], and [52-54], respectively.

Watanabe studied various Ru-complexes as (pre)catalysts for the hydroacylation of olefins with an array of aldehydes [60]. The authors were able to recover $\mathrm{Ru}_{3}(\mathrm{CO})_{12}$ from the reaction mixture where mononuclear complexes, such as $\mathrm{Ru}(\mathrm{COD})(\mathrm{COT})$ and $\mathrm{Ru}(\mathrm{COD})_{2}$, had been employed as precatalysts. Among the screened potential catalysts, $\mathrm{Ru}_{3}(\mathrm{CO})_{12}$ showed the best activity with $95 \%$ conversion and $50 \%$ yield. Moreover, changing the composition of the atmosphere significantly affected the amount of recovered $\mathrm{Ru}_{3}(\mathrm{CO})_{12}$. Approximately 50 bar of Ar afforded a merely $5 \%$ recovery, whereas 20 bar of $\mathrm{CO}$ resulted in $60 \%$ recovery. The authors suggest that $\mathrm{CO}$ stabilize $\mathrm{Ru}(\mathrm{CO})_{5}$ and $\mathrm{Ru}_{3}(\mathrm{CO})_{12}$, either of which may be the active catalyst.

Similarly, Moore investigated the acylation of pyridine with $\mathrm{CO}$ and olefins $\mathbf{1}$ using $\mathrm{Ru}_{3}(\mathrm{CO})_{12}$ as precatalyst, Scheme 3 [61]. Under 10.3 bar of $\mathrm{CO}$ pressure and at $150{ }^{\circ} \mathrm{C}, 65 \%$ of a $13: 1$ mixture of $\boldsymbol{n - 2}$ and iso-2 was produced. During their studies, they observed that the ortho-metalated compound $\mathbf{3}$ decomposed to $\mathrm{Ru}_{3}(\mathrm{CO})_{12}$ under the given reaction conditions albeit in the absence of an olefin. Thus, even though $\mathbf{3}$ was not observed in the catalytic reaction mixture, they inferred that the catalytic cycle is based on a triruthenium hydride species. They further corroborated their finding by performing kinetic studies that showed a first-order rate dependence on the $\mathrm{Ru}_{3}(\mathrm{CO})_{12}$ concentration.

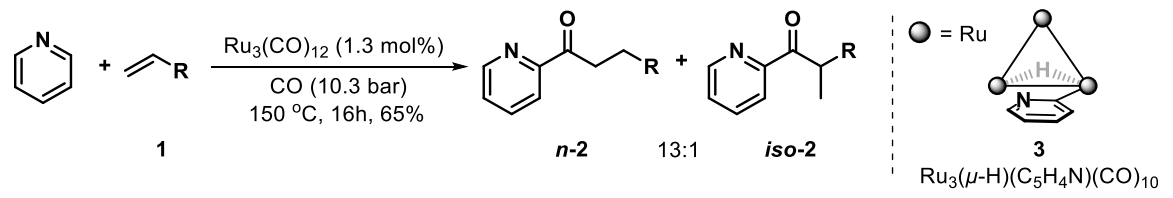

Scheme 3. Acylation of pyridine using $\mathrm{Ru}_{3}(\mathrm{CO})_{12}$ as precatalyst, [61].

Related transformations exploiting chelate assisted $\mathrm{C}-\mathrm{H}$ bond activation using $\mathrm{Ru}_{3}(\mathrm{CO})_{12}$ as (pre)catalyst has since been reported by the groups of Murai and Chatani. This includes the reaction of 1,2-dimethylimidazole with $n$-hexene 
(1a) under CO affording catalytic acylation of the imidazole with yields up to $77 \%$ of predominantly the linear product (up to >99:1) [62]. Interestingly, the authors propose the left triruthenium species $\mathbf{4}$ in Figure $\mathbf{2}$ to be a key component in the catalytic cycle. However, it could not be ruled out that the monoruthenium complex $\mathbf{5}$ is catalytically active as well. Moreover, the two structures were suggested from a related triosmium cluster, $\mathrm{Os}_{3}(\mathrm{C})_{10}\left(\mathrm{CH}_{3} \mathrm{CN}\right)_{2}$ [63], as well as the ortho-metalated species discussed by Moore in Scheme 3, to rationalize for the observed products.

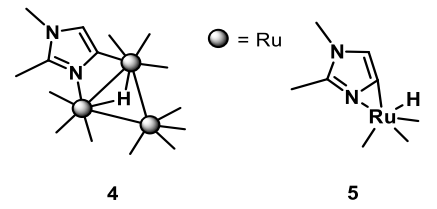

Figure 2. Two compounds with different nuclearity assumed to be central for the activation of $\mathrm{C}-\mathrm{H}$ bond activation in 1,2-dimethylimidazole. Terminal CO molecules have been omitted for clarity, [62].

The general difficulty in ascertaining the true nature and nuclearity of the catalysts in various reactions is reflected in discussions in several subsequent reports using $\mathrm{Ru}_{3}(\mathrm{CO})_{12}$ as precatalyst. One examples is the $N$-directed Ru-catalyzed carbonylation at a $\mathrm{C}-\mathrm{H}$ bond in pyridylbenzenes, where analyses suggest the mononuclear species to be the catalytically active species [64]. Another example is the cyclocarbonylation of yne-aldehydes forming bicyclic $\alpha, \beta$-unsaturated $\gamma$-butyrolactones, where the catalyst was merely defined as a Ru dihydride species [65]. In a third example, both $\mathrm{Ru}_{3}(\mathrm{CO})_{12}$ and $\mathrm{Rh}_{4}(\mathrm{CO})_{12}$ were found active in catalytic carbonylation at olefinic pyridylolefins via chelate assisted $s p^{2} \mathrm{C}-\mathrm{H}$ bond activation [66]. In this study, the reactivity patterns of the precatalysts were rationalized based on a previously reported triosmium structure 6 shown in Figure 3 [67]. Likewise, Ru-catalyzed carbonylation of imidazoles via $s p^{2} \mathrm{C}-\mathrm{H}$ bond activation adjacent to the $s p^{2} N$ proceeds in high yields (up to $96 \%$ ) and excellent linear selectivity (up to >99:1). The authors rationalize the observed products via an ortho-metalated trinuclear Rucluster as in 4 [68]. Finally, Ru-catalyzed carbonylation of aza-heterocycles provided C-H bond activation $\beta$ to a directing nitrogen proceeding via 5 [69].

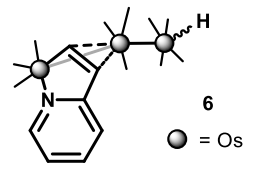

Figure 3. 5-membered metallacycle obtained from reaction of $\mathrm{Os}_{3}(\mathrm{CO})_{10}\left(\mathrm{CH}_{3} \mathrm{CN}\right)_{2}$ with 2-vinylpyridine. Terminal CO molecules have been omitted for clarity, [67].

In this context, Chatani found that carbonylation of pyridin-2-ylmethylene $N$-substituted aromatic amides using $\mathrm{Ru}_{3}(\mathrm{CO})_{12}$ as precatalyst produced a diruthenium complex with the substrate providing a chelating $N, N$-coordination environment to one of the Ru-centers [70]. While catalytically active, the compound was attributed as the resting state, as the presence of $\mathrm{H}_{2} \mathrm{O}$ was necessary for a significant reactivity. As such, merely $16 \%$ product was observed after 3 days without the presence of $\mathrm{H}_{2} \mathrm{O}$, which should be compared to $55 \%$ after the same time span in the presence of two equivalents of $\mathrm{H}_{2} \mathrm{O}$. Moreover, the authors rationalized that the dinuclear species reacted under water-gas-shift conditions. A similar dinuclear species, also attributed as the resting state, was found in later studies on carbonylation of aromatic amides [46-48]. This compound, too, was fragmented in the presence of water, forming the mononuclear species.

Interestingly, work by Murai and Chatani on alkylation and vinylation of aromatic compounds revealed a catalyst nuclearity influence on the product regioselectivity [71]. Thus, as shown in Scheme 4, $\mathrm{Ru}(\mathrm{H})_{2}(\mathrm{CO})\left(\mathrm{PPh}_{3}\right)_{3}$ provides $\mathrm{C}-\mathrm{C}$ bond formation ortho to the acetyl group of $\mathbf{7}$ leading to $\mathbf{9 a}$, whereas $\mathrm{Ru}_{3}(\mathrm{CO})_{12}$ affords a selectivity ortho to the imine leading to $\mathbf{9 b}$. Hence, even though no further detailed mechanistic investigation were carried out, these observation suggest cluster catalysis based on, at least, the second criterion according to Laine. 


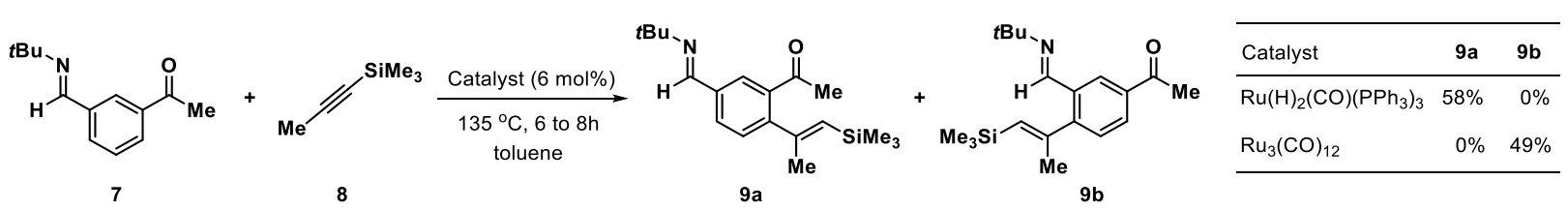

Scheme 4. Catalyst nuclearity affect the regioselectivity in vinylation of functionalized benzenes, [71].

These examples are meant to demonstrate the need for thorough mechanistic investigations to account for cluster catalysis and, if cluster catalysis is indicated, to elucidate the structure of the catalytically active cluster(s). Moreover, a trend is that polydentate ligands provide means of stabilizing a cluster framework during the catalytic cycle. They do so by enabling sufficient structural fluxionality for the various bond cleavages and formations throughout the catalytic transformation while retaining cluster integrity.

\section{HOMONUCLEAR CLUSTERS IN CATALYSIS}

\subsection{Hydrogenation}

Cabeza provided an example of a well-defined triruthenium cluster active in catalysis, where the preformed complex 10 catalyzes the hydrogenation of tolan (11a) to stilbene (12a), as shown in Scheme 5 [72, 73]. The authors emphasize that the ampy-NH moiety affords a substrate coordination-wise regioselectivity towards the cis position to the $\mathrm{NH}$ coordinated ruthenium center, as $\mathrm{CO}$ substitution was consistently observed at this site. To elucidate the catalytic cycle, varying pressures of $\mathrm{H}_{2}$ were used to establish rate-order dependence of substrate/catalyst ratio. At low $\mathrm{H}_{2}$ pressures (low substrate to catalyst ratios), 10 undergoes $\beta$-hydride elimination to yield 10c, followed by dissociation of tolan leading to $10 d$. Subsequently, 10e is formed by oxidative addition of $\mathrm{H}_{2}$ to $10 d$, followed by a fast hydrogenation of an incoming 11a. Contrary, at high $\mathrm{H}_{2}$ pressures (high substrate to catalyst ratios), 10 rearranges to 10a, which then undergoes oxidative addition of $\mathrm{H}_{2}$ forming $10 \mathbf{b}$. Hydride transfer and loss of 12a with subsequent association of 11a then leads to 10c. Finally, a 1,2-migratory insertion completes the cycle. A later study of a structurally related cationic ruthenium cluster, $\left.\left[\mathrm{Ru}_{3}(\mu-\mathrm{H})\left(\mu_{3}-\mathrm{ampy}\right)\left(\mu, \eta^{1}, \eta^{2}-\mathrm{PhCH}=\mathrm{CHPh}\right)(\mathrm{CO})_{8}\right)\right]^{+}$, was reported by Cabeza as a catalyst precursor that promotes homogeneous catalytic hydrogenation of 11a as well [74]. From kinetic studies indicating a first order rate-dependence with respect to the cluster, as well as spectroscopic analyses corroborating a trinuclear ruthenium complex as the only species in solution, the authors suggest a catalytic scheme analogous to the right hand side of Scheme 5.

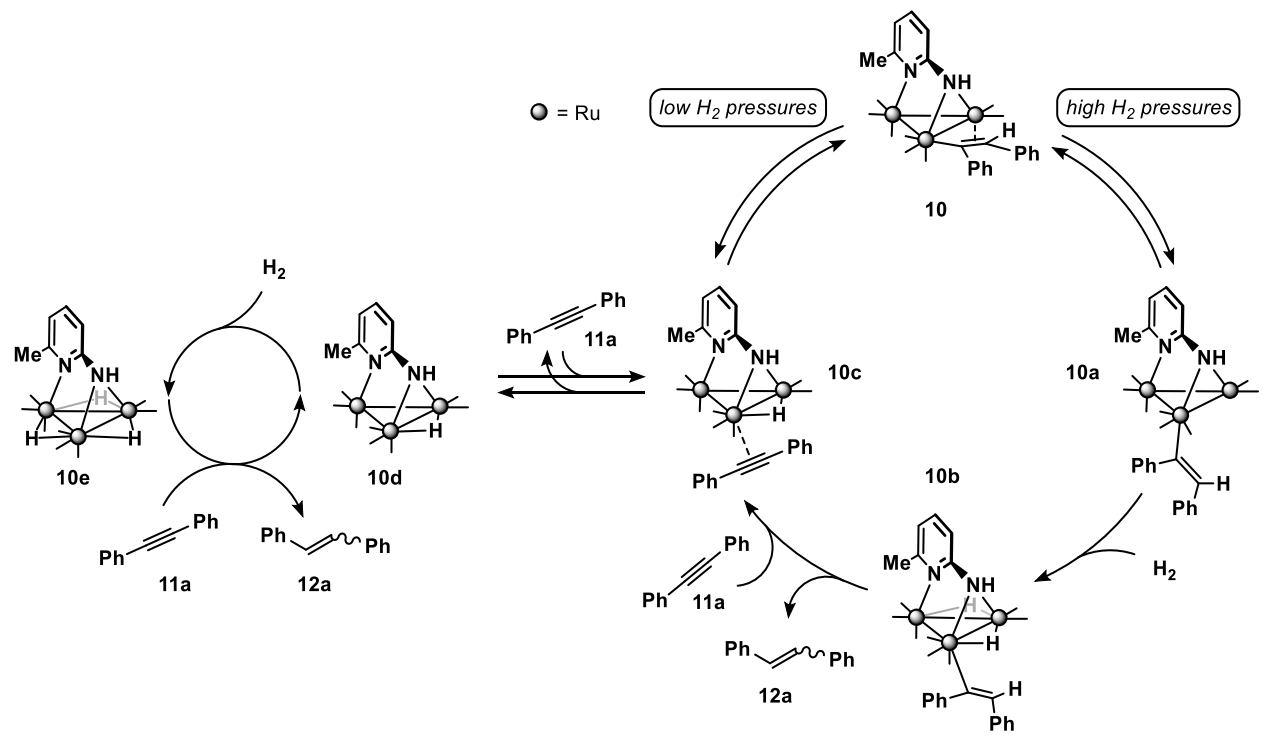

Scheme 5. Proposed mechanism by Cabeza of the hydrogenation of tolan (11a) to stilbene (12a) catalyzed by 10 . Terminal CO molecules have been omitted for clarity, [72, 73]. 
Sappa investigated a series of face-capping phosphinidene-bridged triiron clusters 13, Scheme 6, as catalysts for the hydrogenation of 11a as well as isomerization of cis-12a [75]. The catalytic activities of one of these clusters, $\mathrm{Fe}_{3}(\mathrm{CO})_{9}\left(\mu_{3}-\mathrm{P} t \mathrm{Bu}\right)_{2}(\mathbf{1 3 c})$, was compared with that of a shape-wise similar tetraruthenium cluster, $\mathrm{Ru}_{4}(\mathrm{CO})_{13}\left(\mu_{3}-\mathrm{PPh}\right)$ (14), which showed that for hydrogenation of 11a, 14 is greater than one order of magnitude more active albeit with loss of trans-12a selectivity. Thus, whereas the iron-based $13 \mathrm{c}$ had a TOF $(1 \mathrm{~h})$ of $5 \mathrm{~h}^{-1}$ with a trans-/cis-12a ratio of 1.5:1, the ruthenium-based 14 showed a TOF $(1 \mathrm{~h})$ of approximately $130 \mathrm{~h}^{-1}$ with a ratio of close to $1: 1$. It is difficult to assess the precise role and effect of the metal core due to the difference in nuclearities. However, the use of phosphinidene-bridging ligands demonstrates the cluster stabilizing power of $\mu_{3}$-bridging $\mathrm{X}_{2} \mathrm{~L}$-type ligands.

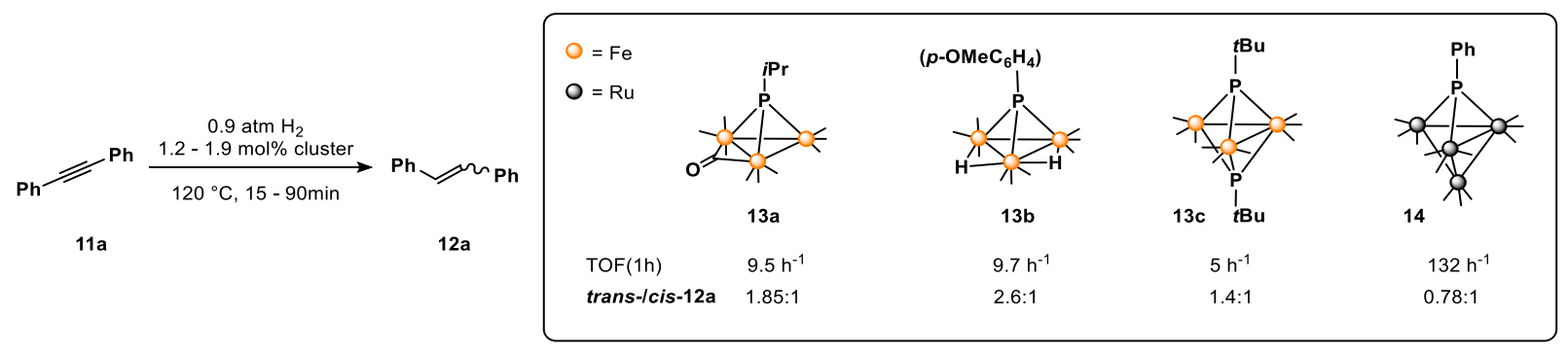

Scheme 6. Three structurally related face-capped triiron cluster compared to a face-capped tetraruthenium cluster for the hydrogenation of 11a to trans-12a and cis-12a. Terminal CO molecules have been omitted for clarity, [75].

More recently, Algarra, Llsuar, and Basallote reported the incomplete cubane-type $\mathrm{Mo}_{3} \mathrm{~S}_{4}$ cluster 15, Scheme 7, as catalyst for the partial hydrogenation of alkynes (11) [76]. The authors rationalize a mechanism based on experimental and computational studies, which invoke transformation via the edge-bridging sulfur groups rather than at the metal centers. A dithiolene adduct (15a) is formed between two of the bridging sulfurs and the alkyne, analogous to adsorption to $\mathrm{MoS}_{2}$ surfaces. The remaining edge-bridging sulfur cleaves the $\sigma$-bond in $\mathrm{H}_{2}$, resulting in intermediate 15b with one $(\mu-\mathrm{S})-\mathrm{H}$ and a $\mathrm{C}-\mathrm{H}$ bond. Two competing pathways account for formation of either of the $(E)$ or $(Z)$ alkene. The former undergoes an isomerization step and subsequently reductive elimination, whereas the latter forms without prior isomerization. Using $12 \mathrm{~mol} \%$ of the catalyst for 65 hours under 100 bars pressure of $\mathrm{H}_{2}$ at $150{ }^{\circ} \mathrm{C}$ in $\mathrm{CH}_{3} \mathrm{CN}$ resulted in $62 \%$ conversion of $\mathbf{1 1 a}$, of which $85 \%$ was $\boldsymbol{c i s - 1 2 a}$.
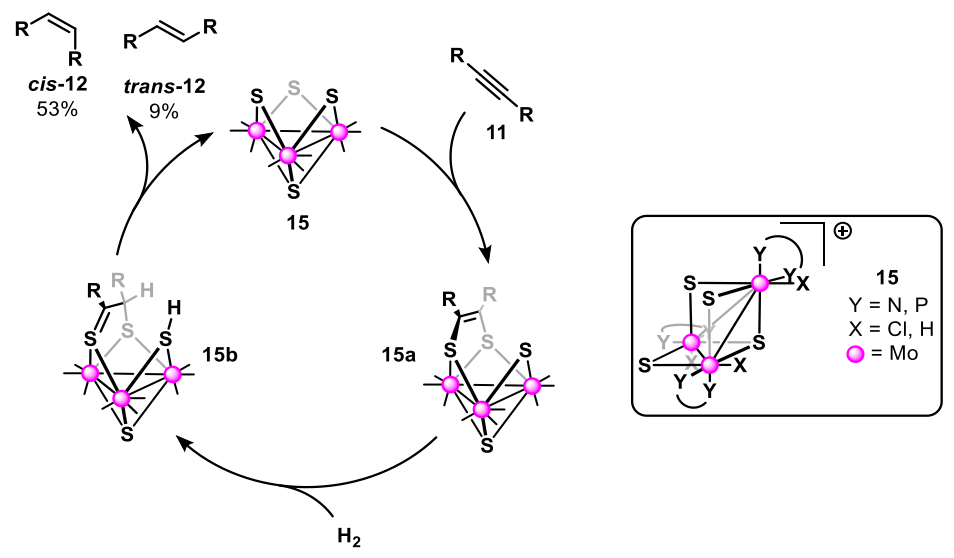

Scheme 7. Partial hydrogenation of $\mathbf{1 1}$ via bridging sulfur atoms, rather than the metals of $\mathbf{1 5}$. Terminal CO molecules have been omitted for clarity, [76].

Bonnet studied chalcogenide face-capped triruthenium hydrido clusters, $(\mu-\mathrm{H})_{2} \mathrm{Ru}_{3}\left(\mu_{3}-\mathrm{Y}\right)(\mathrm{CO})_{5}(\mathrm{dppm})_{2} \mathrm{Y}=\mathrm{O}(\mathbf{1 6 O})$, $\mathrm{S}(\mathbf{1 6 S})$, as precatalysts for the hydrogenation of 1 to alkanes 17 as seen in Scheme 8 [77]. The authors discuss possible mechanisms for the observed products, and suggests a transient species, $160 \mathrm{a} 1$ and $160 \mathrm{a} 2$, wherein a Ru-Ru bond is broken to accommodate alkene coordination. While substitution of $\mu_{3}-\mathrm{O}$ with $\mu_{3}-\mathrm{S}$ did not increase catalytic activity, they did not provide sufficient framework stability as some fragmentation product was observed. However, no fragmentation was observed for the clusters where the one or two of the edges was bridged by a dppm-ligand. As such, 
the authors conclude a synergism between the face-capping atom and the phosphine ligand, resulting in both increased stability of the cluster, and an increased catalytic activity. Furthermore, the authors propose a catalytic scheme invoking the breaking of a $\mathrm{Ru}-\mathrm{Ru}$ bond, which is rationalized from kinetic studies showing a first order ratedependence with respect to alkene, in addition to an isotopic labelling study, showing that a single hydride is transferred to the olefin.

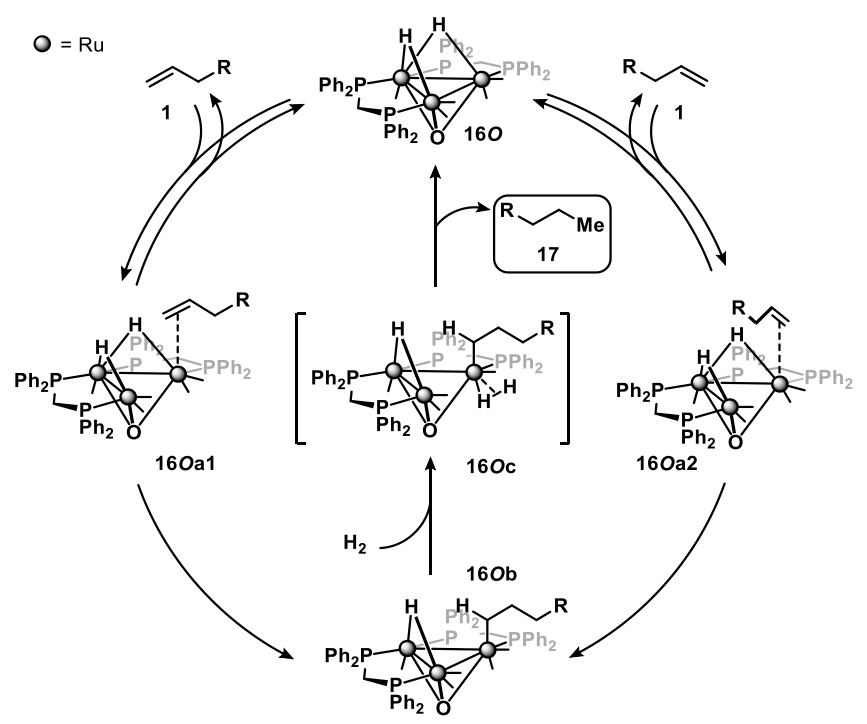

Scheme 8. Face-capping oxygen and dppm ligands of $16 O$ provide positive interactions that ensures the cluster integrity throughout the catalytic hydrogenation of olefins as proposed by Bonnet. Terminal $\mathrm{CO}$ molecules have been omitted for clarity, [77].

Haupt reported that the treatment of dirhenium complexes, $\mathrm{Re}_{2}\left(\mu-\mathrm{P}\left(p-\mathrm{XC}_{6} \mathrm{H}_{4}\right)_{2}\right)(\mathrm{CO})_{8}, \mathrm{X}=\mathrm{H}, \mathrm{F}$, with $\mathrm{H}_{2}$ afforded triand tetranuclear rhenium clusters (18 and 19, respectively) [78]. These were found to be active catalysts in both hydrogenation and isomerization of $\mathbf{1 a}$, of which a distinct selectivity for hydrogenation was observed for the fluorinesubstituted arenes (18b and 19b), Table 1. Ligand substitution for $p-\mathrm{FC}_{6} \mathrm{H}_{4}$ resulted in an increase in TON along with suppression of isomerization reaction. Cluster $\mathbf{1 8 b}$ and $\mathbf{1 9 b}$ are evidently stronger Lewis acids, thus resulting in a more facile coordination to 1a. The authors suggest cluster catalysis based on the recovered amount of intact clusters. A catalytic cycle was rationalized based on their observations, and comparing the reactivity to that of the known triosmium cluster, $\mathrm{Os}_{3}(\mu-\mathrm{H})_{2}(\mathrm{CO})_{10}$ [4]. As such, the proposed cycle proceeds analogously to traditional mononuclear catalysis; ( i) formation of cluster-alkene $\pi$-complex, (ii) alkene insertion into the $(\mu$-H)-Re bond, (iii) oxidative addition of $\mathrm{H}_{2}$, and finally (iv) reductive elimination of $\mathbf{1 7 a}$.

Table 1. Treatment of 1a with $\mathrm{H}_{2}$ is affected by electronic properties of the organic ligand in $\mathbf{1 8}$ and 19. Terminal $\mathrm{CO}$ molecules have been omitted for clarity, [78].

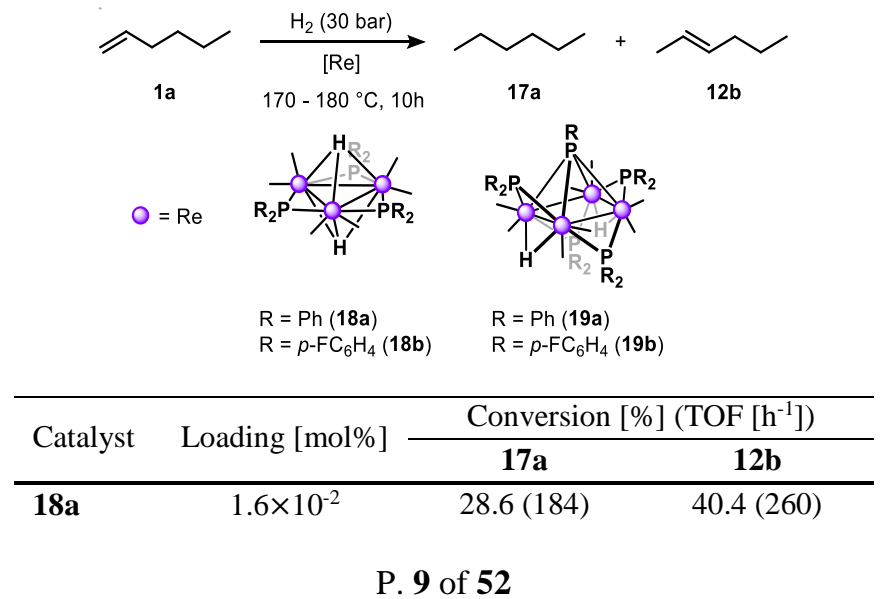




\begin{tabular}{cccc} 
19a & $8.3 \times 10^{-3}$ & $23.8(288)$ & $39.6(480)$ \\
$\mathbf{1 8 b}$ & $9.0 \times 10^{-3}$ & $56.4(630)$ & $8.3(92)$ \\
$\mathbf{1 9 b}$ & $8.5 \times 10^{-3}$ & $63.5(750)$ & $21.1(250)$ \\
\hline
\end{tabular}

Araujo investigated the selectivity in the catalytic partial hydrogenation of 1,5-cyclooctadiene (20) employing a range of tetrairidium clusters [25]. While bulk iridium as well as mononuclear $\operatorname{IrCl}(\mathrm{CO})\left(\mathrm{PPh}_{3}\right)_{2}$ afforded full hydrogenation to cyclooctane (23), $\operatorname{Ir}_{4}(\mathrm{CO})_{11} \mathrm{PPh}_{2} \mathrm{H}(\mathbf{2 4})$ and $\operatorname{Ir}_{4}(\mathrm{CO})_{12}$ afforded partial hydrogenation to 21 and 22 with up to $58 \%$ selectivity albeit at a lower conversion, Table 2 . Kinetic measurements established a first-order rate-dependency with respect to 20, whereas the various iridium clusters had a similar value $\left(\sim 0.0015 \mathrm{~min}^{-1}\right)$ suggesting a transformation of the catalyst precursors. The lack of nanoparticles, a lack of change in reactivity in presence of $\mathrm{Hg}$, and an observed product selectivity difference, work in support of cluster catalysis.

Table 2. Hydrogenation of $\mathbf{2 0}$ using various Ir catalyst precursors. Terminal CO molecules have been omitted for clarity, [25].

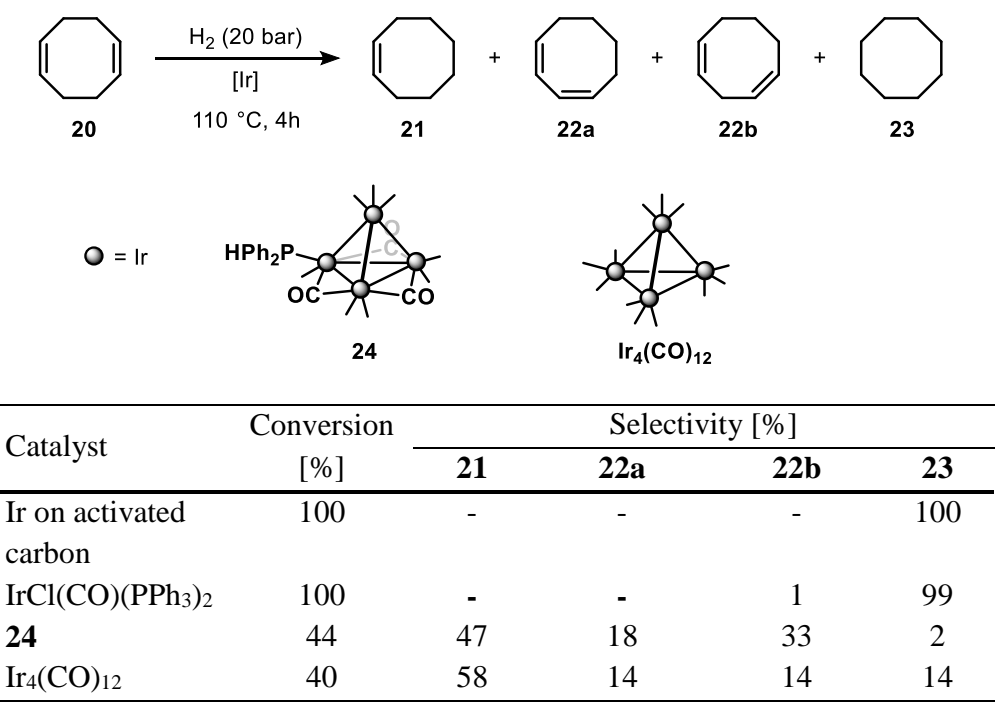

From Wangelin's studies on $\mathrm{Fe}(\mathrm{hmds})_{2}$, hmds $=\mathrm{N}\left(\mathrm{SiMe}_{3}\right)_{2}$, for the catalytic hydrogenation of alkenes, discrete metal clusters ranging from four to seven in nuclearity were obtained, each containing metal-metal bonds, Scheme 9 [79]. Preliminary reactions demonstrated that $\mathbf{2 5}$ afforded catalytic hydrogenation of $\alpha$-methylstyrene $\mathbf{1 b}$ to the alkane $\mathbf{1 7} \mathbf{b}$ of merely $5 \%$. However, under reducing conditions ( $5 \mathrm{~mol} \%$ DIBAL-H) $25 \%$ yield was achieved, which in presence of additional reductant resulted in $>99 \%$ yield.

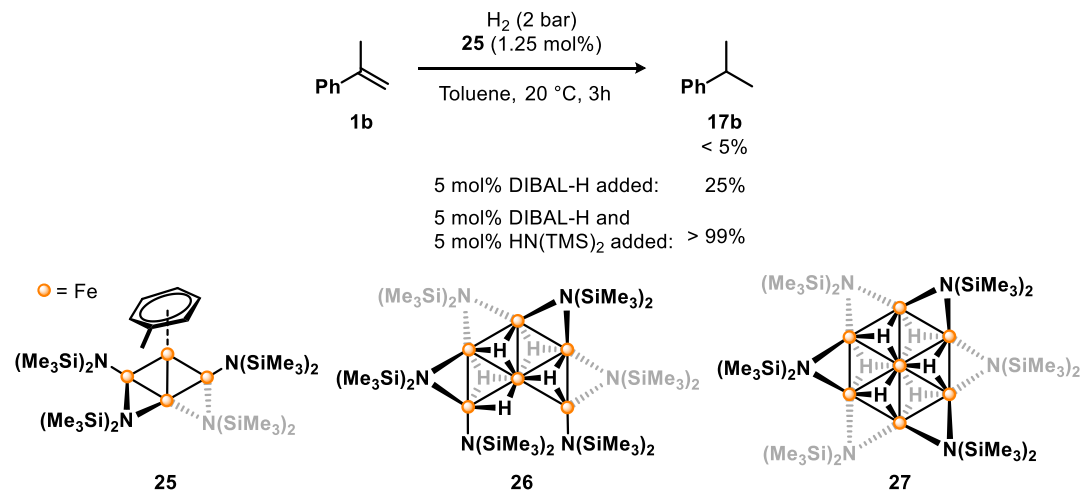

Scheme 9. Low-valent heteroleptic iron clusters varying in nuclearity, resulting from treatment of $\mathrm{Fe}(\mathrm{hmds})_{2}$ with DIBAL-H, [79]. 
Wangelin synthesized a low-valent 2D heteroleptic planar $\mathrm{Mn}_{6}$ cluster 28, and provided an account on its catalytic properties for the hydrogenation of alkenes, alkynes and imines under reducing conditions [80]. Preparation of the cluster, or in-situ formation, afforded the same yields of $\mathbf{1 7 b}(97 \%)$ from $\mathbf{1 b}$ using equimolar amount of the reductant DIBAL-H:Mn in $n$-hexane at $20{ }^{\circ} \mathrm{C}$. On the contrary, hydrogenation of sterically encumbered alkenes (or alkynes), such as 21a to 23a, was achieved using reductant/Mn in 2:1, Table 3. Moreover, it was unclear whether the cluster or a mononuclear Mn species was responsible for the catalysis.

Table 3. 2D heteroleptic planar $\mathrm{Mn}_{6}$ cluster 28 as catalyst for the hydrogenation of $\mathbf{1 b}$ and 21a, [80].

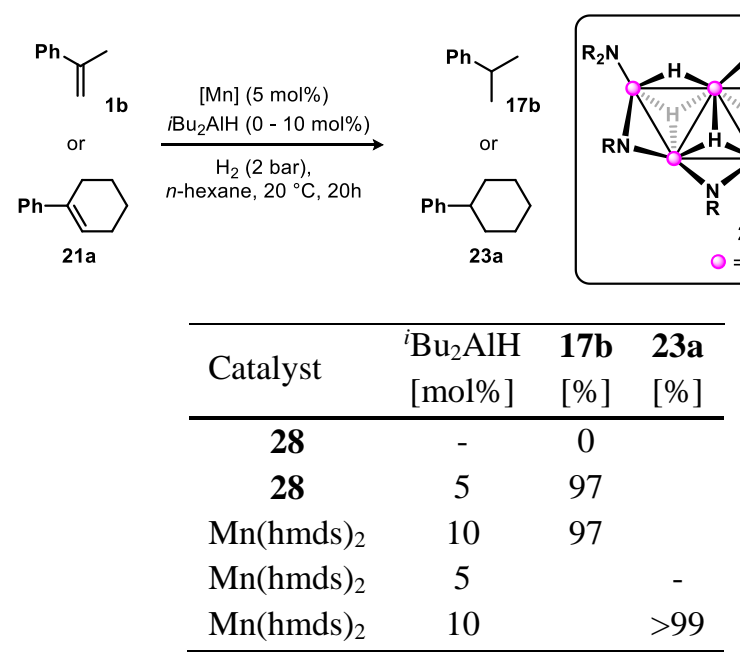

Matteoli investigated the influence of two different chiral phosphine-ligated tetraruthenium clusters in asymmetric hydrogenation of olefins, as well as $\alpha, \beta$-unsaturated acids $\mathbf{2 9}$, such as tiglic acid (29a) and $\mathbf{2 9}$ b, and their corresponding esters, such as 31a [81]. The difference in electronic properties of the substrates was sought to provide mechanistic insight, such as competing isomerization reactions, enhanced substrate-catalyst interactions, and steric congestion. The structures of the precursors were determined by both single-crystal $\mathrm{X}$-ray diffraction, as well as ${ }^{1} \mathrm{H}$ and ${ }^{31} \mathrm{P}$ NMR, which demonstrated a $P, P$-coordination environment at a single Ru center, 32, Table 4. Based on these experimental findings, the authors emphasize that the presence of a carboxylic moiety in the substrate enhances the substrate-catalyst interaction. Moreover, they conclude the BINAP ligated cluster (32a) in general affords the better properties, and the presence of an additional ligand may increase catalytic activity. No elaborate studies on nuclearity and retention hereof were reported, nor was any tentative mechanism proposed. 
Table 4. Asymmetric hydrogenation of 29a, 29b, and 31a using tetraruthenium clusters 32 or 33 having chiral ligands as catalysts. Terminal CO molecules have been omitted for clarity, [81-84].
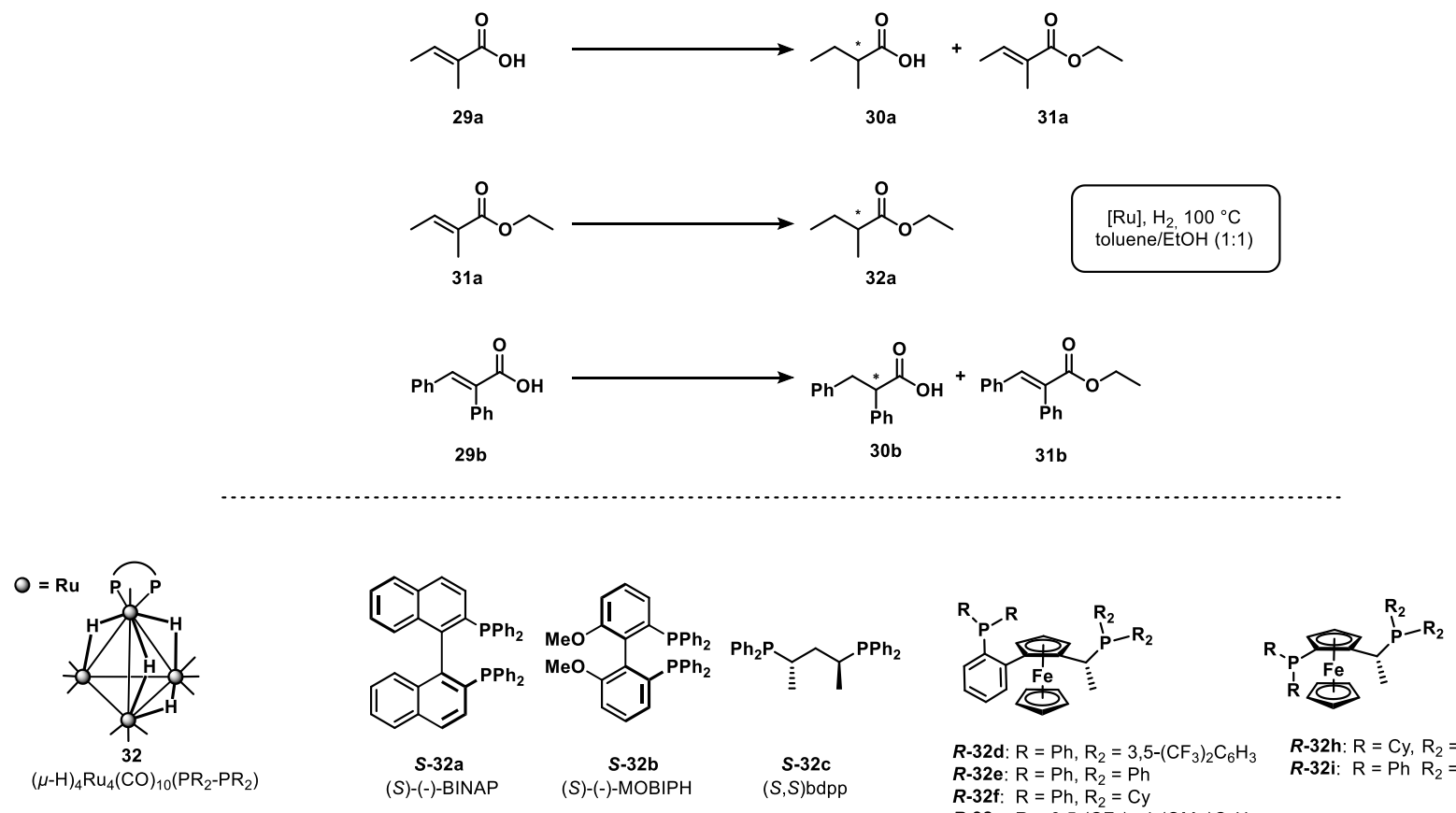
$\boldsymbol{R}-32 \mathrm{~d}: \mathrm{R}=\mathrm{Ph}, \mathrm{R}_{2}=3,5-\left(\mathrm{CF}_{3}\right)_{2} \mathrm{C}_{6} \mathrm{H}_{3}$
$\boldsymbol{R}-32 \mathrm{e}: \mathrm{R}=\mathrm{Ph}, \mathrm{R}_{2}=\mathrm{Ph}$ $R$-32f: $\mathrm{R}=\mathrm{Ph}, \mathrm{R}_{2}=\mathrm{Cy}$ R-32g: $\mathrm{R}=3,5-\left(\mathrm{CF}_{3}\right)_{2}-4-(\mathrm{OMe}) \mathrm{C}_{6} \mathrm{H}_{2}$

R-32h: $R=C y, R_{2}=C y$

$(\mu-\mathrm{H})_{4} \mathrm{Ru}_{4}(\mathrm{CO})_{10}\left(\mathrm{PR}_{2}-\mathrm{PR}_{2}\right)$

$$
\begin{gathered}
\text { s-32a } \\
(S)-(-)-\text { BINAP }
\end{gathered}
$$

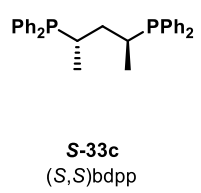

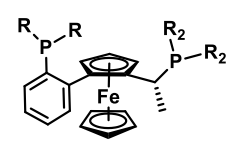

$R$-33a: $\mathrm{R}=\mathrm{Ph}, \mathrm{R}_{2}=3,5-\left(\mathrm{CF}_{3}\right)_{2} \mathrm{C}_{6} \mathrm{H}_{3}$ $R-33 b: R=P h, R_{2}=P h$

$R$-33d: $\mathrm{R}=\mathrm{Ph}, \mathrm{R}_{2}=\mathrm{Cy}$

R-33e: $\mathrm{R}=3,5-\left(\mathrm{CF}_{3}\right)_{2}-4-(\mathrm{OMe}) \mathrm{C}_{6} \mathrm{H}_{2}$ $\mathrm{R}_{2}=3,5-\left(\mathrm{CF}_{3}\right)_{2} \mathrm{C}_{6} \mathrm{H}_{3}$

\begin{tabular}{|c|c|c|c|c|c|c|c|c|c|}
\hline Substrate & $\begin{array}{c}\text { Catalyst } \\
\text { (loading }[\mathrm{mol} \%] \text { ) }\end{array}$ & $\begin{array}{c}\mathrm{H}_{2} \\
\text { pressure } \\
{[\text { bar] }}\end{array}$ & $\begin{array}{l}\text { Reaction } \\
\text { time }[\mathrm{h}]\end{array}$ & $\begin{array}{c}\text { Conversion } \\
{[\%]}\end{array}$ & Product & $\begin{array}{c}\text { Selectivity } \\
\text { [\%] }\end{array}$ & $\begin{array}{c}\text { Yield } \\
{[\%]}\end{array}$ & $\begin{array}{l}e e \\
{[\%]}\end{array}$ & Configuration \\
\hline 29a & $S$-32a $(0.05)$ & 130 & 93 & 91 & 30a & - & 85 & 29 & $(R)$ \\
\hline $29 \mathbf{a}$ & $S-32 \mathbf{b}(0.05)$ & 130 & 72 & 100 & 30a & - & 94 & 17 & $(S)$ \\
\hline $31 \mathbf{a}$ & $S$-32a $(0.05)$ & 130 & 234 & 87 & 32a & - & 87 & 3 & $(R)$ \\
\hline $31 \mathbf{a}$ & $S-32 \mathbf{b}(0.05)$ & 130 & 253 & 100 & 32a & - & 100 & 2 & $(S)$ \\
\hline $29 \mathbf{a}$ & $\boldsymbol{R}-32 \mathrm{c}(0.1)$ & 50 & 48 & 85 & 30a & 94 & - & 45 & $(R)$ \\
\hline $29 \mathbf{a}$ & $S-32 \mathrm{c}(0.1)$ & 50 & 48 & 75 & 30a & 92 & - & 43 & $(S)$ \\
\hline 29a & $\boldsymbol{R}-33 \mathbf{c}(0.4)$ & 50 & 48 & 100 & 30a & 95 & - & 42 & $(R)$ \\
\hline 29a & $S-33 \mathrm{c}(0.4)$ & 50 & 48 & 100 & 30a & 92 & - & 44 & $(S)$ \\
\hline $29 \mathbf{a}$ & $\boldsymbol{R}-\mathbf{3 2 d}(0.4)$ & 50 & 24 & 100 & 30a & 100 & - & 93 & $(S)$ \\
\hline $29 a$ & $\boldsymbol{R}-33 \mathbf{a}(0.4)$ & 50 & 24 & 99 & 30a & 99 & - & 82 & $(S)$ \\
\hline $29 \mathbf{a}$ & $\boldsymbol{R} \mathbf{- 3 3 a}(0.4)+\mathrm{Hg}(0)$ & 50 & 24 & 100 & 30a & 100 & - & 87 & $(S)$ \\
\hline $29 \mathbf{a}$ & $\boldsymbol{R}$-33b $(0.4)$ & 50 & 24 & 100 & 30a & 100 & - & 58 & $(S)$ \\
\hline $29 \mathbf{a}$ & $\boldsymbol{R} \mathbf{- 3 3 b}(0.4)+\mathrm{Hg}(0)$ & 50 & 24 & 100 & 30a & 100 & - & 62 & $(S)$ \\
\hline $29 b$ & $\boldsymbol{R}$-33a $(0.4)$ & 50 & 24 & 100 & $30 \mathrm{~b}$ & 90 & - & 66 & $(R)$ \\
\hline $29 \mathrm{~b}$ & $\boldsymbol{R}-\mathbf{3 3 b}(0.4)$ & 50 & 24 & 100 & 30b & 83 & - & 63 & $(R)$ \\
\hline $29 a$ & $\boldsymbol{R}-\mathbf{3 3 d}(0.4)$ & 50 & 24 & 99 & 30a & 100 & - & 54 & $(R)$ \\
\hline $29 a$ & $\boldsymbol{R}-33 \mathbf{e}(0.4)$ & 50 & 24 & 87 & 30a & 100 & - & 77 & $(S)$ \\
\hline $29 a$ & $\boldsymbol{R}-\mathbf{3 3 f}(0.4)$ & 50 & 24 & 100 & 30a & 90 & - & - & - \\
\hline $29 a$ & $\boldsymbol{R}-33 g(0.4)$ & 50 & 24 & 100 & 30a & 96 & - & - & - \\
\hline
\end{tabular}


Nordlander investigated two sets of stereoenriched tetraruthenium clusters, $(\mu-\mathrm{H})_{4} \mathrm{Ru}_{4}(\mathrm{CO})_{10}\{\mu-1,1-(R / S, R / S)$ bdpp $\}\left(\boldsymbol{R}-32 c\right.$ or $S$-32c, respectively) and $(\mu-\mathrm{H})_{4} \mathrm{Ru}_{4}(\mathrm{CO})_{10}\{1,2-(R / S, R / S)$-bdpp $\}(\boldsymbol{R}-33 \mathbf{c}$ or $\boldsymbol{S}$-33c, respectively), as catalysts for the asymmetric hydrogenation of 29a under milder conditions [82]. Lowering the pressure of $\mathrm{H}_{2}$ from 130 to 50 bar resulted in three distinct observations: high conversion $(75-100 \%)$, interconversion from the bridging $33 \mathbf{c}$ to the chelating 32c, and a product distribution strongly affected by the ligand enantiomer; $(R, R)$ forms $(R)$, likewise $(S, S)$ resulting in $(S)$. As the activities of $S / \boldsymbol{R}-\mathbf{3 3 c}$ were nearly identical to $S / \boldsymbol{R}-\mathbf{3 2 c}$, and the recovered cluster was of the latter structure, cluster catalysis by structure $S / R-32 \mathbf{c}$ was argued. While the possibility of lower-nuclearity species forming from degradation is not excluded, the activity of these being responsible for the conversion is unlikely. The authors argue that in such a scenario, the activity of $\left[\mathrm{H}_{4} \mathrm{Ru}_{4}(\mathrm{CO})_{12}\right]$-systems would be independent of the ligands, whereas they find the opposite to be true. Despite not having determined the exact sequence of elementary steps, a tentative account on the experimental findings is presented in Scheme 10. Starting from 32cg, the oxidative addition of $\mathrm{H}_{2}$ is discussed to be stereoselective due to the orientation of $P$-phenyl substituents. Accordingly, introduction of 29a to the coordination-sphere of 32c follows either of two pathways: (i) ligand substitution forming 32ce, or (ii) homo or heterolytic cleavage of a Ru-Ru bond forming 32ca, permitting coordination of 29a, resulting in 32cb. Stepwise hydride insertion is followed by reductive elimination, regenerating 32c. The latter route is argued to be more probable because of a low $\mathrm{CO}$ pressure makes reassociation unlikely.

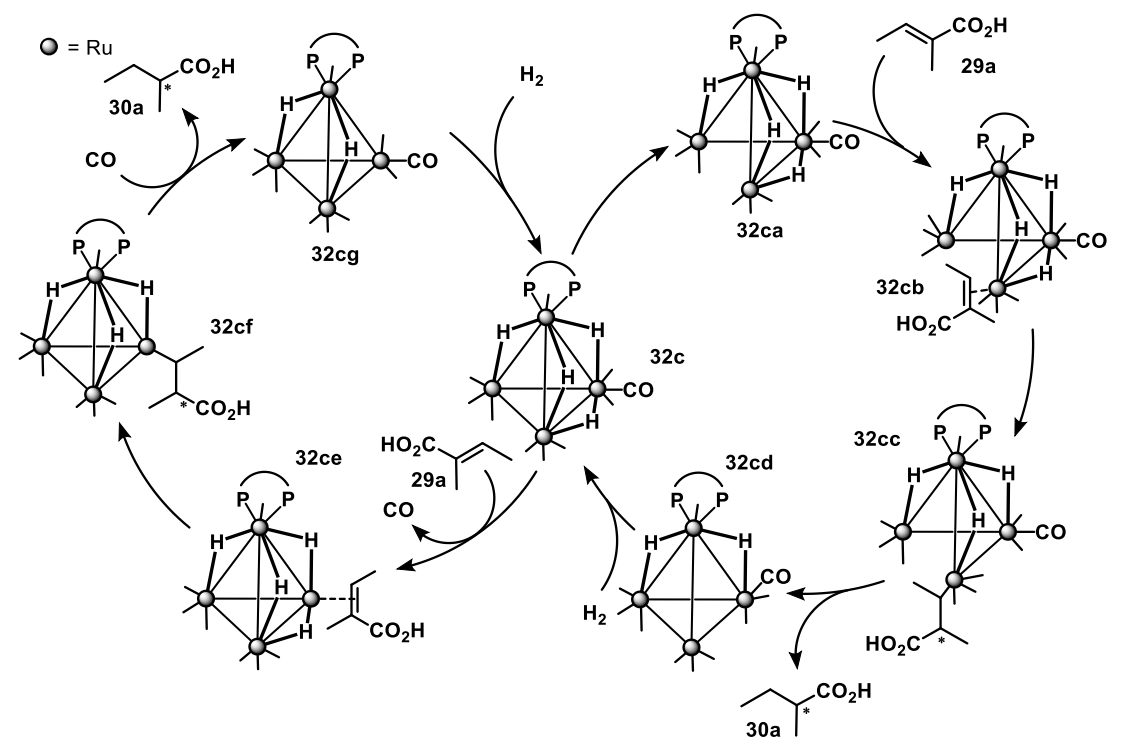

Scheme 10. Catalytic cycles involved in hydrogenation of 29a leading to 30a by cluster 32c as proposed by Nordlander. The low CO pressure is suggested to disfavor the left hand pathway, as CO reassociation is unlikely. Remaining terminal CO molecules have been omitted for clarity, [82].

Continued work by Nordlander investigated the changes in cluster stability and activity in the asymmetric hydrogenation of 29a induced by various chiral phosphine ligands [85]. While improvement was observed over the parent hydrido cluster, $(\mu-\mathrm{H})_{4} \mathrm{Ru}_{4}(\mathrm{CO})_{12}$, the authors noted varying conversion $(70-95 \%)$, with poor increase in enantioselectivity (up to $23 \% e e$ ), along with thermal decomposition. Cluster catalysis is invoked, as the decomposition products were insufficient in providing similar catalytic activity, as well as provided different products than those observed. The authors relate these findings to their prior study, and suggest that a better enantioselectivity can be achieved by employing ligands with a significant steric bulk proximal to the substrate. To this end, Nordlander prepared Walphos substituted tetraruthenium clusters (33a,b) and reported up to excellent enantioselectivity (30 93\% ee) in the hydrogenation of various $\alpha, \beta$-unsaturated carboxylic acids [83]. From spectroscopical and single-crystal $\mathrm{X}$-ray diffraction analysis, an unusual bonding of the phosphine ligand was found; one coordinates equatorially whilst the other axially, resulting in chiral cluster frameworks and thus potential diastereomeric mixtures. Nevertheless, NMR analysis corroborates the presence of only a single diastereomer. $\mathrm{A} \mathrm{Hg}(0)$ poisoning test and recovery experiment suggest (small amounts of) cluster fragmentation albeit the authors dismiss the significance of the colloidal 
material, due to the significantly difference observed in catalyst activity with respect to yield and selectivities. Moreover, the authors emphasize an interconversion of isomers of chelating and bridging diphosphines during catalysis, and they suggest suppressing this interconversion may result in even higher stereoselectivity.

A series of tetraruthenium hydrido clusters was substituted with Josiphos- (32h, $\mathbf{i}$ and $\mathbf{3 3 f}, \mathbf{g})$ and Walphos phosphines (32d, e, f, $\mathbf{g}$ and 33d, e) to assess the steric and electronic influence of the ligand on the hydrogenation of 29a [84]. Whereas the Josiphos substituted clusters demonstrated poor catalytic properties as well as degradation, the Walphos clusters demonstrated both excellent conversion $(99-100 \%)$, product selectivity $(99-100 \%)$, and enantioselectivity (92\% ee), Table 4. Interestingly, an interconversion opposite to that previously established was observed, transforming the 1,1-chelating into 1,2-bridging diphosphines ( $\mathbf{3 2}$ to $\mathbf{3 3}$ ). This observation is argued by the authors to origin in strain relief transitioning from a nine membered "dimetallacycle" ring to the eight membered ring. Suppression of this isomerization is suggested to result in an increased enantioselectivity. While spectroscopic analyses and catalyst poisoning tests demonstrated that the combination of cluster, hydrogen pressure and temperature afforded the majority of the transformation, the free ligand was found to promote the reaction with $68 \%$ ee albeit at a mere conversion of $23 \%$ after $72 \mathrm{~h}$.

Nordlander explored the analogous phosphine-rhenium clusters of the Josiphos and Walphos-families and observed that, as for the ruthenium clusters, the Walphos-family ligand afforded better catalyst precursors in the asymmetric hydrogenation of 29a [86]. While the trirhenium clusters demonstrated poor conversion (15\%) and enantioselectivity (13\% ee), the corresponding dinuclear complexes afforded superior conversion (88\%) and selectivity (57\%). Moreover, the ligand discrepancy is suggested to relate to a potential wider bite angle of the Walphos.

Furthermore, Singh and Nordlander investigated the effect of a face-capping chalcogenide to provide stability of the cluster framework in a triruthenium cluster under hydrogenation of 29a [87]. Thus, employing the Walphos-ligand affords two diastereomers of the $\mathrm{Ru}_{3}$-cluster $\mathbf{3 4}$, Scheme 11a. Cluster mediated catalysis is strongly suggested based on spectroscopic analyses demonstrating an intact organometallic species in solution and neither diastereomers had interconverted after the reaction. The authors provide mechanistic insights by combining their experimental observations with DFT calculations, and rationalize a catalytic cycle invoking an initial dissociation of a CO transpositioned to the phosphine leading to 34a, Scheme 11b. Thereby an unsaturated cluster is formed, permitting the formation of a $\pi$-complex (34b), which undergoes alkene insertion (34c). Subsequent oxidative addition of $\mathrm{H}_{2}$ at the same Ru-center (34d) results in reductive elimination regenerating the cluster concurrently with formation of the hydrogenation product (30a). Moreover, the authors conclude that the face-capping chalcogenide ensures cluster integrity throughout the transformation.

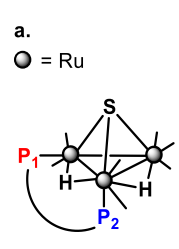

341

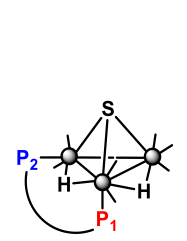

34II

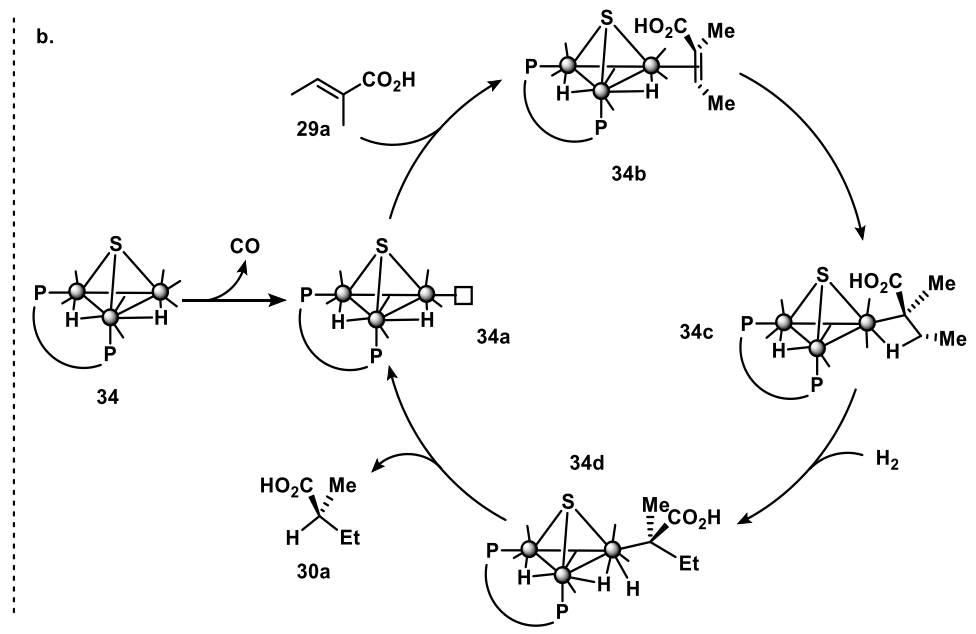

Scheme 11 a. The two Ru3-cluster diastereomers 34I and 34II. b. Catalytic scheme for the asymmetric hydrogenation of 29a to 30a as proposed by Nordlander. Terminal CO molecules have been omitted for clarity, [87]. 
A more recent study by Nordlander investigated the use of chiral binaphthyl mono-substituted phosphiranes as ligands in use with the tetraruthenium hydrido cluster for asymmetric hydrogenation of 29a [88]. While the clusters demonstrated catalytic activity, no enantioselectivity was observed. As no products associated with cluster fragmentation was found, cluster catalysis is suggested by the authors. Moreover, based on their comprehensive studies, Nordlander suggests that asymmetric induction in cluster catalyzed alkene hydrogenation reactions is, in large, determined by the properties of the ligand and that bidentate phosphine provides more beneficial properties relative to the monodentate congeners.

Ikariya investigated the asymmetric Meerwein-Ponndorf-Verley reduction of ketones $\mathbf{3 5}$ to alcohols $\mathbf{3 6}$ by mixing $\mathrm{Ru}_{3}(\mathrm{CO})_{12}$ with chiral diiminodiphosphine ligands in the presence of isopropanol, Table 5 [89]. Evidence in support of in-situ formation of a triruthenium cluster is presented by combining spectroscopical measurements, reactivity differences compared to a mononuclear ruthenium complex (the latter is inactive), as well as preparation and test of catalytic competence of a related anionic species. Additionally, kinetic studies suggest first-order rate-dependency with respect to the cluster concentration. Moreover, while the addition of base affected the conversion of the sterically encumbered ketone 35c, the enantioselectivity remained generally similar. Thus, treating $35 \mathbf{c}$ with $\mathrm{Ru}_{3}(\mathrm{CO})_{12}$ in presence of $\mathbf{L} \mathbf{2}$ and base afforded $90 \%$ ee, whereas in the absence of base $94 \%$ ee was obtained.

Table 5. Asymmetric transfer hydrogenation of $\mathbf{3 5}$ to $\mathbf{3 6}$ by in-situ formed triruthenium clusters, [89].

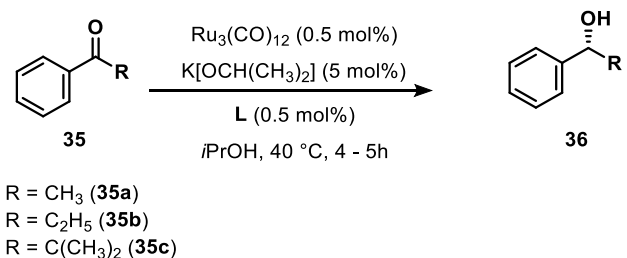

$\mathrm{R}=\mathrm{C}\left(\mathrm{CH}_{3}\right)_{2}(35 \mathrm{c})$

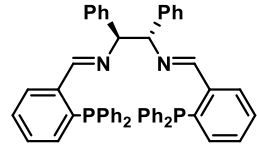

L1

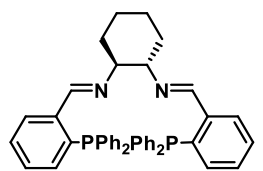

L2

\begin{tabular}{lccccc}
\hline $\mathrm{R}$ & \multirow{2}{*}{ Ligand } & $\begin{array}{c}\text { Base } \\
\text { present }\end{array}$ & $\begin{array}{c}\text { Time } \\
{[\mathrm{h}]}\end{array}$ & $\begin{array}{c}\text { Yield } \\
{[\%]}\end{array}$ & $\begin{array}{c}e e \\
{[\%]}\end{array}$ \\
\hline \multirow{3}{*}{$\mathrm{CH}_{\left(\mathrm{CH}_{3}\right)_{2}}$} & \multirow{2}{*}{$\mathbf{L 1}$} & No & 5 & 48 & $>99$ \\
& & Yes & 4 & 79 & $>99$ \\
& \multirow{2}{*}{$\mathbf{L 2}$} & No & 5 & 30 & 94 \\
& & Yes & 4 & 66 & 90 \\
$\mathrm{C}_{2} \mathrm{H}_{5}$ & \multirow{2}{*}{$\mathbf{L 2}$} & No & 5 & 72 & 92 \\
& & Yes & 4 & 93 & 92 \\
$\mathrm{CH}_{3}$ & \multirow{2}{*}{$\mathbf{L 1}$} & No & 5 & 91 & 81 \\
& & Yes & 4 & 96 & 82 \\
\hline
\end{tabular}

Rio and Gossage investigated the asymmetric hydrogenation of acetophenone 35a, as well as the asymmetric DielsAlder reaction of cyclopentadiene $\mathbf{3 7}$ and acrolein 38a, employing catalytic amounts of each of the compounds 39-40 $(0.5 \mathrm{~mol} \%)$ acquired from treating $\mathrm{Ru}_{3}(\mathrm{CO})_{12}$ with three different chiral aminooxazolines, Figure 4 [90]. Singlecrystal X-ray diffraction revealed that two of the three clusters possess a triangular face-capped $\mathrm{Ru}_{3}$-core $(39 \mathrm{a}$ and 39b), where the amido unit binds two Ru-centers and the oxazoline nitrogen atom coordinates to the remaining Rucenter. In the third complex (40), the amido and hydrido spans the same Ru-Ru edge. The authors tested the mentioned reactions using $\mathrm{Ru}_{3}(\mathrm{CO})_{12}$ as precatalyst mixed with the respective ligands. They observed conversions lower than 5\% in the hydrogenation reaction, whereas the Diels-Alder reaction showed up to $20 \%$ conversion. Contrary, when using either of the preformed precatalysts 39-40, excellent conversion is seen (99\%) with TOF(10h) values of $144-200 \mathrm{~h}^{-1}$ 
albeit with poor enantioselectivities ranging between $18-20 \%$ ee in the hydrogenation. The authors suggest that the prepared clusters form catalytically active hydrido compounds in-situ. They rationalize their conclusion based on the observation that addition of $\mathrm{KOH}$ increases the TOF(10h) from 65 to $200 \mathrm{~h}^{-1}$ and elevates the conversion from 51 to $99 \%$. In the absence of catalyst precursors, the [4+2]-cycloaddition achieved approximately $20 \%$ conversion within 2 hours, whereas the use of the precursors afforded $80 \%$ conversion in the same timespan, with a TOF(10 min) of $25 \mathrm{~h}^{-1}$.
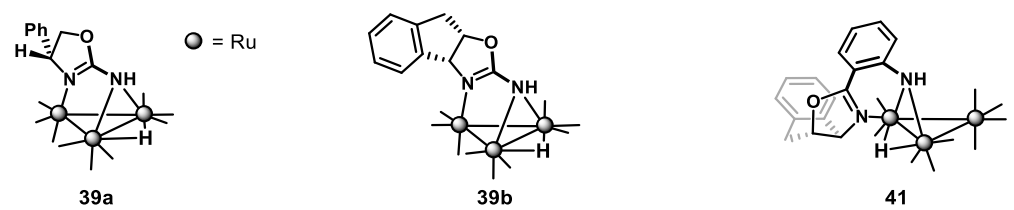

Figure 4. Three triruthenium clusters 39-40 derived from chiral aminooxazolines. Terminal CO molecules have been omitted for clarity, [90].

Llusar and Beller employed the incomplete cubane-type $\mathrm{Mo}_{3} \mathrm{~S}_{4}$-cluster, $\left[\mathrm{Mo}_{3} \mathrm{~S}_{4} \mathrm{X}_{3}\left(\mathrm{Y}_{2}\right)_{3}\right]^{+}(\mathbf{1 5})$, Scheme 7, in several settings with variation of the terminal ligands, $\mathrm{X}$ and $\mathrm{Y}$. The hydrido dmpe ligated [Mo $\left.\mathrm{M}_{4}\right]$ cluster, $\left[\mathrm{Mo}_{3} \mathrm{~S}_{4} \mathrm{H}_{3}(\mathrm{dmpe})_{3}\right] \mathrm{BPh}_{4}(\mathbf{1 5 c})$, was found to catalytically reduce functionalized nitroarenes $\mathbf{4 1}$ to aminoarenes $\mathbf{4 2}$, and the extent of conversion was affected by the source of reductant [91]. While $\mathrm{H}_{2}$ provided merely 5\% yield, a mixture of $\mathrm{HCO}_{2} \mathrm{H} / \mathrm{Et}_{3} \mathrm{~N}=5: 2$, afforded up to $>99 \%$ conversion with yields up to $>99 \%$ of the corresponding 42 for an array of compounds as shown in Scheme 12. In a later study, they reported chemoselective reduction of $\mathbf{4 1}$ and azoarenes 43 in the presence of other reduction-susceptible functional groups, such as ketones and esters, using the trihydridocluster $\left[\mathrm{Mo}_{3} \mathrm{~S}_{4} \mathrm{Cl}_{3}(\mathrm{dmen})_{3}\right]\left[\mathrm{BF}_{4}\right] \mathbf{1 5} \mathbf{d}$, dmen $=N, N^{\prime}$-dimethylethylenediamine [92]. Later, the scope was expanded to include additional functional groups, Table 6 [93]. Of the screened catalyst precursors, the cluster having a $N, N$-bidentate ligand, $\left[\mathrm{Mo}_{3} \mathrm{~S}_{4} \mathrm{Cl}_{3}(\mathrm{dnbpy})_{3}\right]\left[\mathrm{PF}_{6}\right] \mathbf{1 5 e}$, was found to provide the optimal conditions. When using a 5 mol\% catalyst loading, quantitative yields were obtained under 20 bar of $\mathrm{H}_{2}$ and $70{ }^{\circ} \mathrm{C}$ in $\mathrm{MeOH}$. To account for cluster integrity during the transformation, the reaction mixture was analyzed after four hours by ESI-MS, and no other ions corresponding to species of lower-nuclearity were observed. Further, the catalyst was recovered and reused, which afforded a modest yield of $52 \%$.

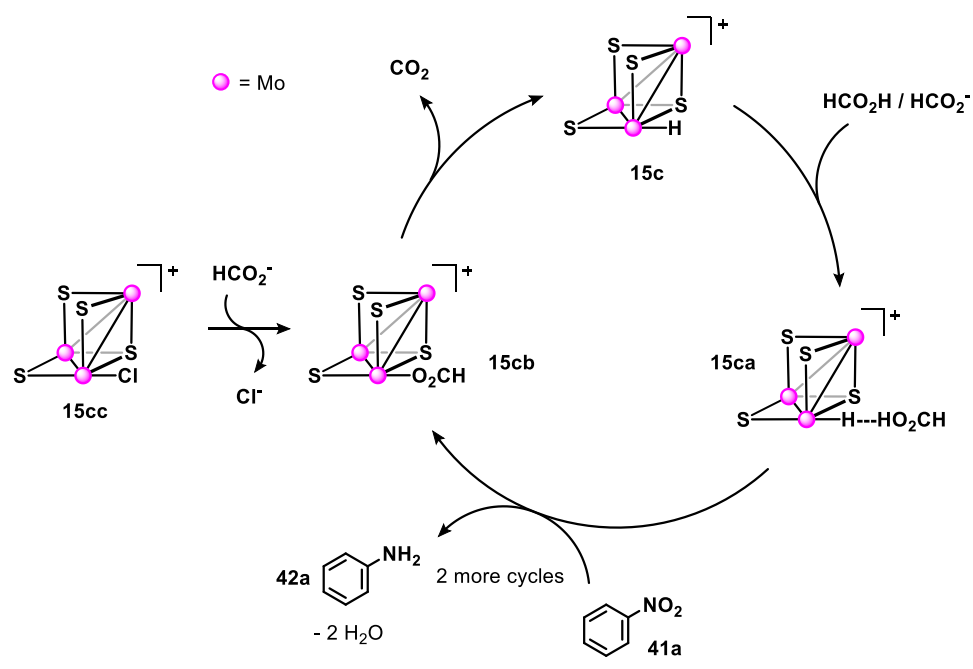

Scheme 12. Catalytic scheme proposed by Llusar and Beller for the cubane-type cluster $\mathbf{1 5}$ catalyzing the reduction of 41a to 42a. Terminal, chelating phosphines, and hydrides/chlorides have been omitted for clarity, [91]. 
Table 6. Chemoselective reduction of functionalized 41 to $\mathbf{4 2}$ catalyzed by 15e, [93].
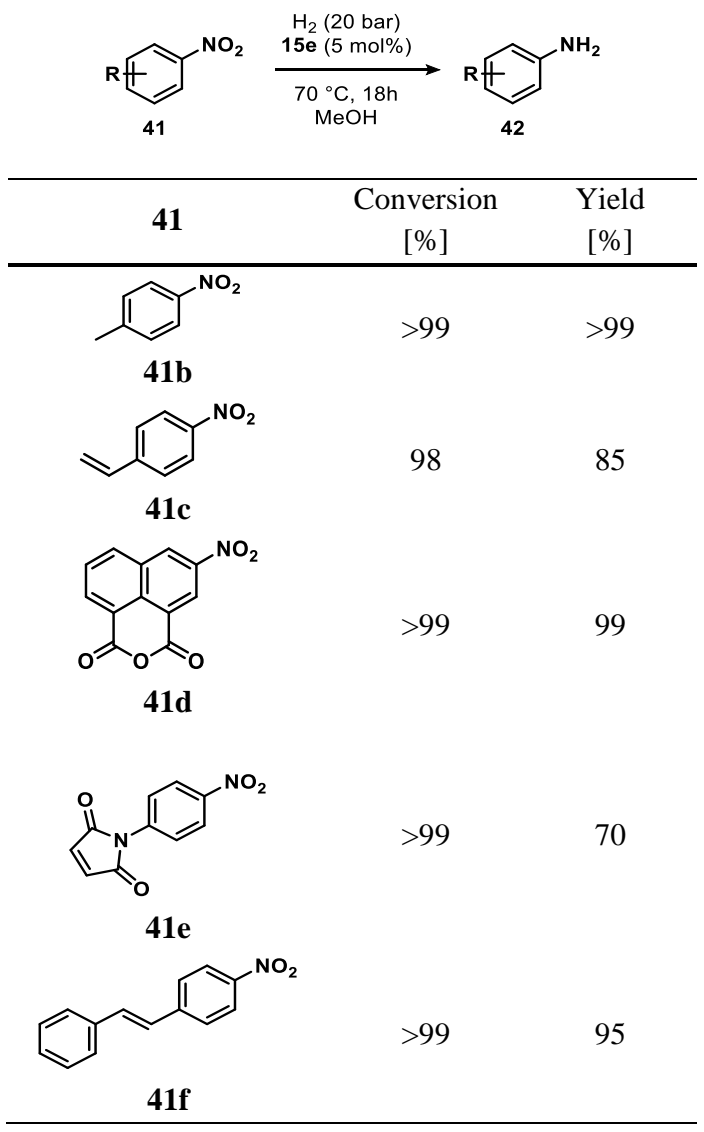

The incomplete cubane-type cluster 15d was also found by Llusar and Beller to afford catalytic reductive amination of 41a with benzaldehyde 44 using $6 \mathrm{~mol} \%$ catalyst loading under approximately 20 bar of $\mathrm{H}_{2}$ at $70{ }^{\circ} \mathrm{C}$ in $\mathrm{THF}$ on a $4 \mathrm{mmol}$ scale to form $N$-benzylaniline $\mathbf{4 2 g}$, Scheme 13 [94]. The authors account for cluster integrity throughout the transformation based on ESI-MS showing no ions of lower-nuclearity as well as ${ }^{1} \mathrm{H}$ NMR of the reaction mixture revealing intact cluster. Moreover, the cluster was recovered and used in a recycling experiment, which afforded full conversion with $90 \%$ yield of $\mathbf{4 2 g}$.

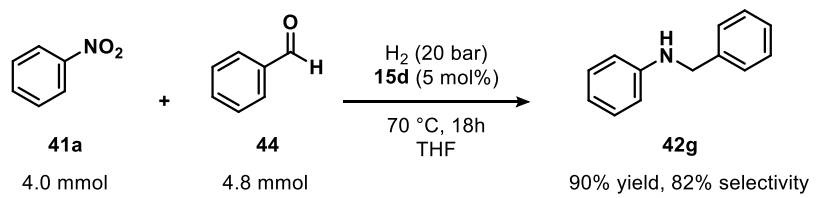

Scheme 13. Reductive amination using incomplete cubane 15d as catalyst precursor, [94].

Suzuki and Takao studied the neutral polyhydrido triruthenium cluster, $\left\{(\mathrm{Cp} * \mathrm{Ru}(\mu-\mathrm{H})\}_{3}\left(\mu_{3}-\mathrm{H}\right)_{2}, \mathbf{4 5}\right.$ in Scheme 14, for the hydrogenation of diazenes $\mathbf{4 3}$ and hydrazines 46, Table 7 [95]. As such, $\mathbf{4 5}$ activated the $N-N$ bond of $\mathbf{4 6}$ to afford asymmetric capped bis- and mono-( $\mu_{3}$-imido) clusters, $\mathbf{4 5 a}$ and $\mathbf{4 5} \mathbf{b}$, respectively (left hand side of Scheme 14). Only the latter reacted with $\mathrm{H}_{2}$ to provide $42 \mathrm{a}$ and regenerate 45 . Under catalytic amounts of $\mathbf{4 5}(0.12 \mathrm{~mol} \%), \mathrm{H}_{2}$ (approximately $100 \mathrm{bar}$ ), at $100{ }^{\circ} \mathrm{C}$ in $\mathrm{EtOH}, 46$ was converted to 42a in $31 \%$. Despite the high pressure of $\mathrm{H}_{2}$ suppressing the formation of the inactive complex $\mathbf{4 5 a}$, most of $\mathbf{4 5}$ was converted into this inactive species over time. 
Table 7. Hydrogenation of $\mathbf{4 3}$ and $\mathbf{4 6}$ using $\mathbf{4 5}$ as catalyst, [95].

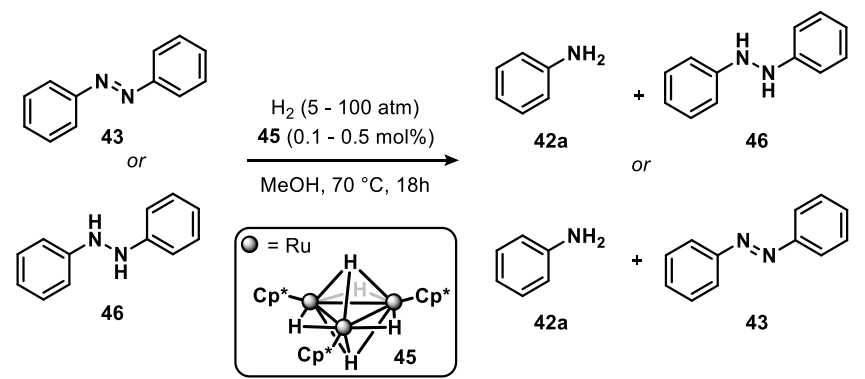

\begin{tabular}{ccccc}
\hline $\begin{array}{c}\text { Loading of 45 } \\
{[\mathrm{mol} \%]}\end{array}$ & $\begin{array}{c}\text { Pressure } \mathrm{H}_{2} \\
{[\mathrm{~atm}]}\end{array}$ & Substrate & $\begin{array}{c}\text { Conversion } \\
{[\%]}\end{array}$ & $\begin{array}{c}\text { Selectivity } \\
(\mathbf{4 2 a} / \mathbf{4 6}) \text { or }(\mathbf{4 2 a} / \mathbf{4 3})\end{array}$ \\
\hline 0.50 & 5 & $\mathbf{4 3}$ & 13 & $3.5: 1$ \\
0.40 & 100 & & 68 & $9.1: 1$ \\
0.10 & 5 & $\mathbf{4 6}$ & 72 & $1.7: 1$ \\
0.10 & 100 & & 31 & $14.9: 1$ \\
\hline
\end{tabular}

Cluster 45 was also reported by Takao as an active catalyst for the hydrogenation of benzonitrile 47a, as shown on the right hand side of Scheme 14 [96]. At approximately 10 bar of $\mathrm{H}_{2}$ and $110^{\circ} \mathrm{C}$ in $\mathrm{MeOH}, 93 \%$ conversion of 47a was achieved with $82 \%$ selectivity towards benzylamine 48a. Further increase in temperature to $130{ }^{\circ} \mathrm{C}$ achieved $98 \%$ conversion albeit at a lower product selectivity of $48 \%$. Introducing a bridging carbonyl to $\mathbf{4 5}$, thus affording cluster 49, resulted in a higher catalytic performance, allowing the transformation to occur at lower temperatures as well as providing a higher selectivity. The authors speculate that the $\mathrm{CO}$ withdraws sufficient electron density from the $\mathrm{Ru}_{3}$ core to prevent a simultaneous coordination of two $47 \mathbf{a}$ substrates. Thus, at approximately 10 bar of $\mathrm{H}_{2}$ and $120{ }^{\circ} \mathrm{C}$ in THF, 98\% conversion was observed with a 93\% selectivity towards $\mathbf{4 8 a}$. Based on extensive analyses, including crystal-structures, (decomposition) products obtained from stoichiometric reactions, the authors rationalize a catalytic cycle shown on the right hand side in Scheme 14.
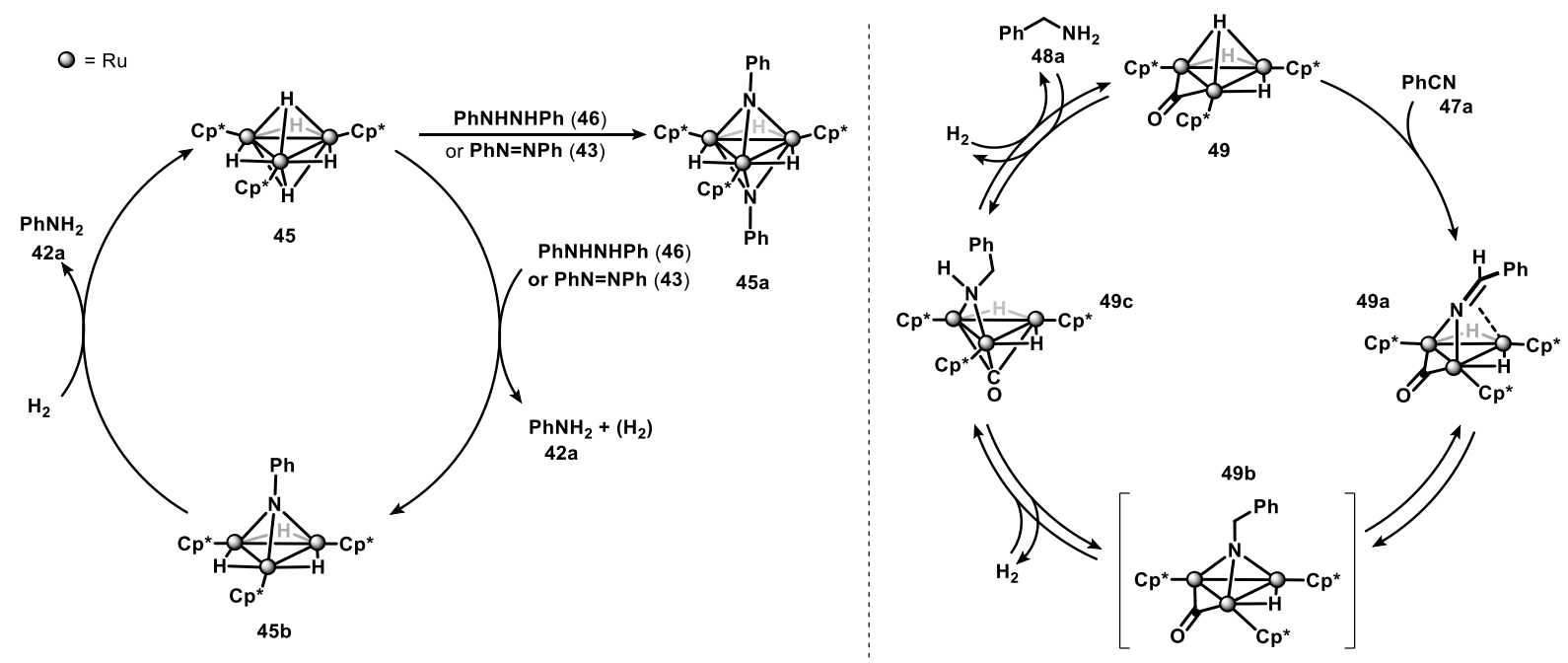

Scheme 14. Catalytic schemes for the hydrogenation of hydrazine as proposed by Suzuki [95], and of benzonitrile as proposed by Takao, [96]. Structural modification via a bridging carbonyl resulted in a compound with better catalytic behavior.

Research into efficient $\mathrm{CO}_{2}$ hydrogenation catalysis is an active area of research, and while typical examples comprise mononuclear complexes based on, for example, iron [97], cobalt [98], ruthenium [99], and iridium [100], Inagaki recently reported a trinuclear iridum cluster $\mathbf{5 0}$ working as a photocatalytic $\mathrm{CO}_{2}$ hydrogenation catalyst [101]. Whereas 
conventional catalysis invoke high pressure and temperature for this reaction, $\mathbf{5 0}$ provided approximately $60 \%$ yield under 10 bars of pressure $\left(\mathrm{H}_{2} / \mathrm{CO}_{2}=1: 1\right)$ at room temperature. The authors suggest a catalytic cycle as shown Scheme $\mathbf{1 5}$, invoking initial coordination of $\mathrm{CO}_{2}$ leading to $\mathbf{5 0 a}$, which is followed by insertion into the $\mathrm{Ir}-\mathrm{H}$ bond leading to 50b. Reductive elimination leads to 50c while concomitantly forming an acid-basic adduct. Finally, subsequent oxidative addition of $\mathrm{H}_{2}$ regenerates $\mathbf{5 0}$. While both irradiation and base are necessary for the reaction to proceed, the effect of irradiation remains unclear. The authors suggests that its involvement is to facilitate hydride dissociation forming a vacant coordination-site for $\mathrm{CO}_{2}$. However, evidence is presented that suggests further involvement by enhancing the reaction with $\mathrm{CO}_{2}$.
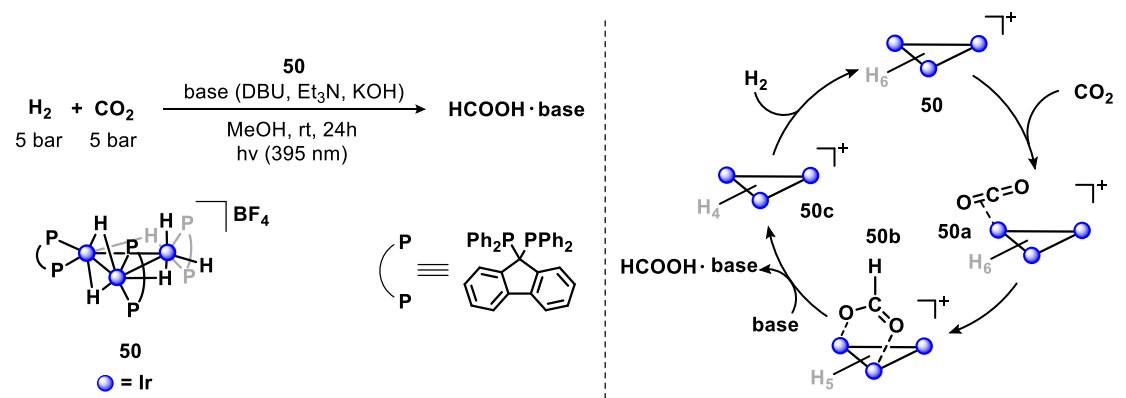

Scheme 15. Catalytic hydrogenation of $\mathrm{CO}_{2}$ using trinuclear complex $\mathbf{5 0}$ as proposed by Inagaki. The diphosphine ligands are omitted for clarity, [101].

\subsection{Carbonylation}

Whitmire studied the homologous series of chalcogenide capped triironclusters, $\left[\mathrm{Et}_{4} \mathrm{~N}\right]_{2}\left[\mathrm{Fe}_{3}(\mathrm{CO})_{9} \mathrm{E}\right], \mathrm{E}=\mathrm{S}(\mathbf{5 1 S}), \mathrm{Se}$ $(\mathbf{5 1 S})$, and Te $(\mathbf{5 1 T e})$, for the carbonylation of methanol to methyl formate 52, while concurrently providing insight into the effect of main-group chalcogenides on cluster stability, as well as on the reactivity pattern [102]. Kinetic studies established a first-order rate dependence with respect to cluster concentration, that in conjunction with a lack of activity of the related mononuclear iron complexes, $\mathrm{Fe}(\mathrm{CO})_{5}$ and $\left[\mathrm{HFe}(\mathrm{CO})_{4}\right]^{-}$, worked to support cluster catalyzed transformation. Despite the almost identical rates in formation of $\mathbf{5 2}$ between the various chalcogenide clusters, the authors find substantial differences in activation energy (43, 76 and $72 \mathrm{~kJ}$ for $\mathbf{5 1 S}, \mathbf{5 1 S e}$ and $\mathbf{5 1 T e}$, respectively). This discrepancy between formation rates and activation energies are explained by the deduced preexponential factors, where $\mathrm{E}=\mathrm{S}$ contains a less favorable value $\left(3.5 \times 10^{3}\right.$ for $\mathbf{5 1 S}$, vs. approximately $2.0 \times 10^{7}$ for $\mathbf{5 1 S e}$ and $\mathbf{5 1 T e}$, respectively). From these values, and in addition to a readily isolation of the open Te complex $\left[\mathrm{Te}\left\{\mathrm{Fe}(\mathrm{CO})_{4}\right\}_{3}\right]^{2-}[103]$ not observed for $\mathbf{5 1 S}$, the authors conclude a variation in the rate-determining step, despite a similar rate-law. The proposed catalytic scheme shown in Scheme 16, invoke a catalytically active species that undergoes $\mathrm{Fe}-\mathrm{Fe}$ bond breakage, which $\mathbf{5 1 S}$ strongly disfavor. While a tentative mechanism involving rupture of a Fe-Fe bond, the authors limit the discussion to on M-M bond opening of a dianionic species in presence of $\mathrm{CO}$.

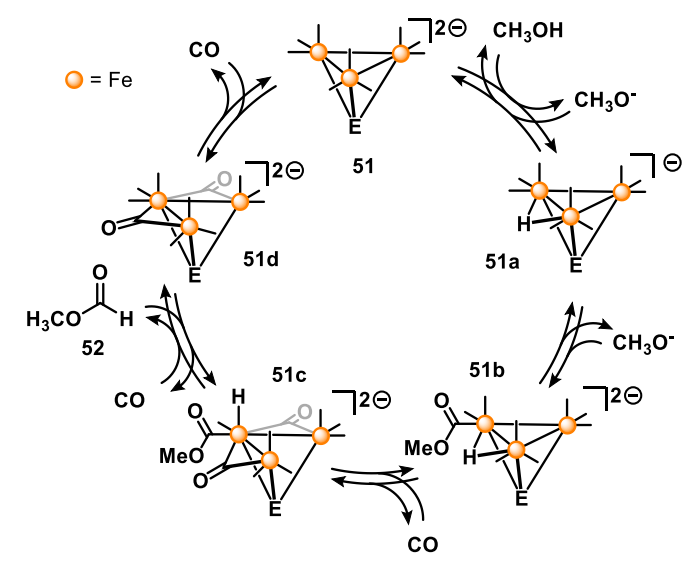

P. 19 of 52 
Scheme 16. The catalytic cycle in carbonylation of $\mathrm{MeOH}$ using the triiron chalcogenide cluster $\mathbf{5 1}$ homologue series $(\mathrm{E}=\mathrm{S}, \mathrm{Se}$ or Te$)$ as proposed by Whitmire. Terminal CO molecules have been omitted for clarity, [102].

By using $\mathrm{Ru}_{3}(\mathrm{CO})_{12}$ as catalyst precursor in junction with $\mathrm{N}$-methylpiperidine, Mitsudo was able to afford cross carbonylation affording hydroquinones $\mathbf{5 4}$ from alkynes $\mathbf{1 1}$ and 2-norbonenes $\mathbf{5 3}$ [104]. While catalyst (precursor) screening demonstrated a distinct catalyst activity between triruthenium (up to $85 \%$ yield) and the mononuclear complex (trace), thus satisfying Laine's second criterion, diruthenium complexes afforded only a slightly lower yield (up to 76\%) compared to the polynuclear precursor, Table 8. Moreover, no studies into the concrete structure of the active catalyst were provided.

Table 8. Cross carbonylation of $\mathbf{5 3}$ with 11b, [104].

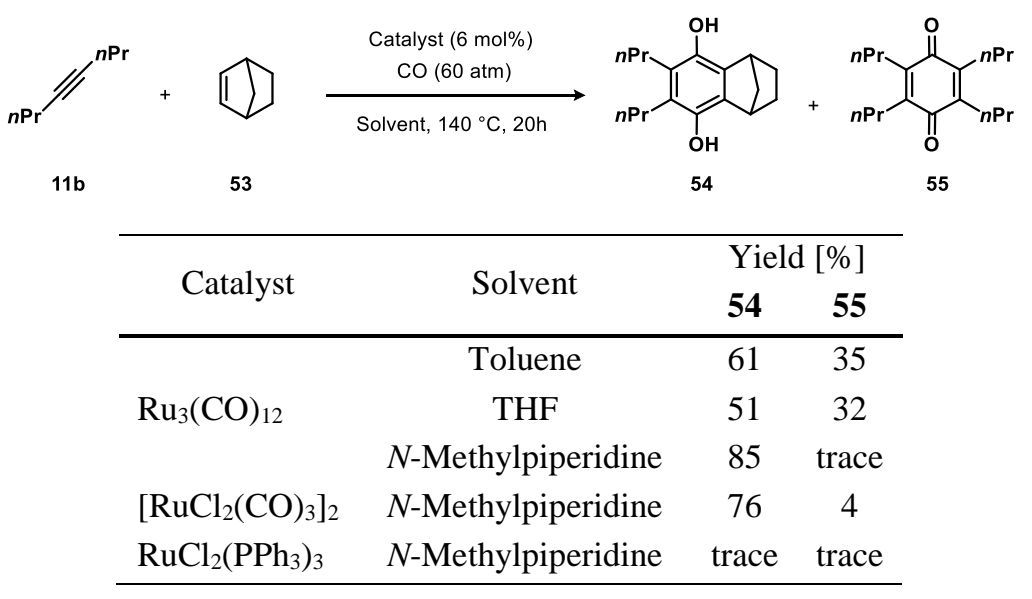

\section{Hydroformylation}

Süss-Fink found indirect evidence that the anionic cluster $\left[\mathrm{Ru}_{3}(\mu-\mathrm{H})(\mathrm{CO})_{11}\right]^{-56}$ remained intact while catalyzing hydroformylation of ethylene to yield aldehyde 57a, as shown in Scheme 17 [105]. The authors were able to ascertain the sequence of elementary steps in the catalytic cycle using an isotopic labeling method. Thus, by mixing $\mathbf{5 6}$ with $\mathrm{CF}_{3} \mathrm{CO}_{2} \mathrm{D}$ and ethylene in THF, they were successful in trapping the deuterated intermediate, $\left[\mathrm{Ru}_{3}(\mu-\mathrm{D})\left(\mu-\eta^{2}-\right.\right.$ $\left.\left.\mathrm{OCCH}_{2} \mathrm{CH}_{3}\right)(\mathrm{CO})_{10}\right]$, which enabled them to locate the position of the bridging hydride by ${ }^{1} \mathrm{H}$ and ${ }^{2} \mathrm{H}$ NMR. In addition, they were able to establish that the hydride transfer to ethylene precedes hydrogen incorporation.

Further studies, using propylene (1c) as substrate probed the selectivity as a function of temperature, pressure and solvent [106]. Generally, the cluster was found to provide chemoselective formation of aldehydes rather than alcohols independent of the conditions. On the contrary, control of regioselectivity ( $n$ over iso) was feasible, and under 10 bar of total pressure $\left(\mathrm{CO} / \mathrm{H}_{2}=2: 1\right)$ at $75{ }^{\circ} \mathrm{C}$ in diglyme, $n$-butanal $(\mathbf{5 7 b})$ was produced in practically quantitative yield $(n / i s o=73)$. Importantly, the authors provided spectroscopically evidence that no fragmentation occurs during the reaction. 


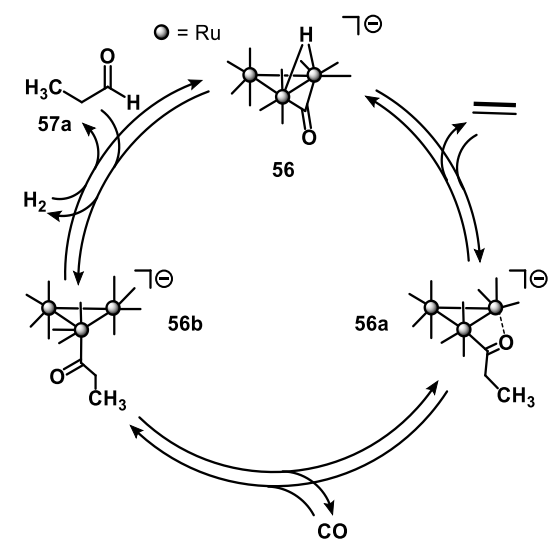

Scheme 17. Mechanism of the hydroformylation of ethylene to 57a catalyzed by $\mathbf{5 6}$ as proposed by Süss-Fink. Terminal CO molecules have been omitted for clarity, [105].

Süss-Fink further investigated the hydroformylation of olefins (1), and changes resulting from substituting CO in $\mathrm{Ru}_{3}(\mathrm{CO})_{12}$ with sterically demanding diphosphines [107]. Single-crystal X-ray diffraction unambiguously established four structures, one of which was found having an unusual $\mu_{1}-\eta^{2}$ coordination (chelating) 58, opposed to $\mu_{2}-\eta^{2}$ (bridging) 59-61, Figure 5. In DMF at $80{ }^{\circ} \mathrm{C}$, both cluster-types demonstrated catalytic activity towards hydroformylation. Moreover, the clusters were largely recovered unaltered. The maximum TON value in the hydroformylation of ethylene was observed for $\mathrm{Ru}_{3}(\mathrm{CO})_{10}(\mathrm{~F}$-dppe), $\mathrm{F}$-dppe $=$ bis(perfluoro-diphenylphosphino)ethane 60, obtaining 429 cycles, compared to merely 157 cycles for $\mathrm{Ru}_{3}(\mathrm{CO})_{12}$.
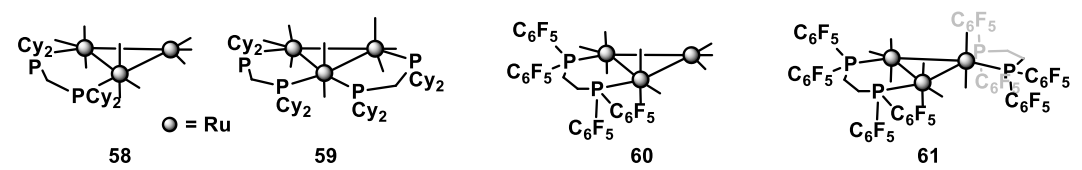

Figure 5. Various ligated triruthenium clusters as catalysts for the hydroformylation of $\mathbf{1}$. Terminal CO molecules have been omitted for clarity, [107].

Pittman reported the use of two different cobalt clusters, $\mathbf{6 2}$, and $\mathbf{6 3}$, catalysts for achieving hydroformylation of 1and 2-pentene with a predominantly linear selectivity, Table $9[108,109]$. A high yield of the intact cluster, as well as a different reactivity compared to $\mathrm{Co}_{2}(\mathrm{CO})_{8}$, work to support cluster mediated catalysis. The authors suggest that the $\mu_{3}-\mathrm{C}$ ligand of cluster $\mathbf{6 2}$, and the bridging $\mathrm{PC}_{6} \mathrm{H}_{5}$ ligands of cluster $\mathbf{6 3}$, discourages fragmentation into lower nuclearity species. A small selectivity difference (n/iso) was observed between 62 and $\mathbf{6 3}, 5.4$ vs. 2.6 in favour of the $n$-isomer $\boldsymbol{n - 5 7 b}$, respectively. Further, the authors note that whereas an elevated temperature reduced selectivity, a pressure increase enhanced the selectivity. For cluster 62 , at $90^{\circ} \mathrm{C}$ a selectivity of 5.4 was achieved, which was more than halved to 2.2 at $130^{\circ} \mathrm{C}$, despite reaching almost full conversion at roughly a fifth of the time. The authors further investigated cluster $\mathbf{6 3}$, and the catalytic properties of a phosphine-substituted homologue $\mathbf{6 4}$ for hydroformylation of 1- and 2-pentene [110]. The high yield of recovered cluster $\mathbf{6 3}$ (95\%), the lack of other organometallic species, as well as a reactivity difference compared to $\mathrm{Co}_{2}(\mathrm{CO})_{8}$, works to support cluster-mediated catalysis. Moreover, single-crystal $\mathrm{X}$-ray diffraction was used to establish the structural configuration of cluster 64 . Interestingly, only cluster 63 was recovered from the reaction mixture were $\mathbf{6 4}$ was used originally. 
Table 9. Hydroformylation of 1-pentene by tri- and tetracobalt clusters, $\mathbf{6 2}$ and $\mathbf{6 3}$, [108-110].

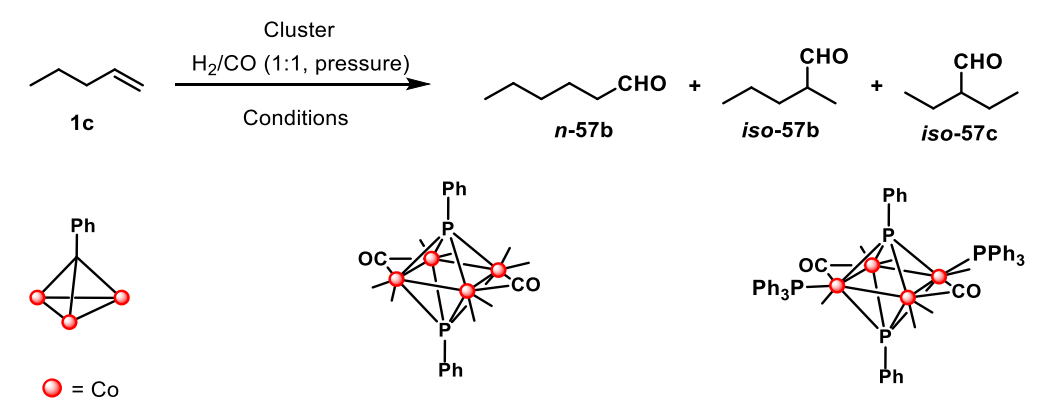

$62\left(\mathrm{Co}_{3}(\mathrm{CO})_{9}\right) \quad 63\left(\mathrm{Co}_{4}(\mu-\mathrm{CO})_{2}(\mathrm{CO})_{8}\right) \quad 64\left(\mathrm{Co}_{4}(\mu-\mathrm{CO})_{2}(\mathrm{CO})_{6}\left(\mathrm{PPh}_{3}\right)_{2}\right)$

\begin{tabular}{lllcccccc}
\hline Cluster & $\begin{array}{c}\text { Loading } \\
{[\mathrm{mol} \%]}\end{array}$ & Substrate & $\begin{array}{c}\text { Temp } \\
{\left[{ }^{\circ} \mathrm{C}\right]}\end{array}$ & $\begin{array}{c}\text { Pressure } \\
{[\mathrm{bar}]}\end{array}$ & Solvent & $\begin{array}{c}\text { Time } \\
{[\mathrm{h}]}\end{array}$ & $\begin{array}{c}\text { Yield aldehyde } \\
{[\%]}\end{array}$ & $\begin{array}{c}\text { Selectivity } \\
\mathbf{n - 5 7 b} / \\
\text { (iso-57c+iso-57c) }\end{array}$ \\
\hline $\mathbf{6 2}$ & 0.36 & $\mathbf{1 c}$ & 90 & $61-56$ & $\mathrm{C}_{6} \mathrm{H}_{6}$ & 104 & 57.5 & 5.4 \\
& & & 130 & $63-54$ & & 22 & 99.7 & 2.2 \\
$\mathbf{6 3}$ & 0.36 & $\mathbf{1 c}$ & 130 & $48-44$ & $\mathrm{C}_{6} \mathrm{H}_{6}$ & 88 & 62.5 & 2.6 \\
& & & 150 & $50-44$ & & 23.5 & 84.2 & 1.9 \\
\hline
\end{tabular}

Lavigne observed $\mathbf{6 5}$ in Scheme 18c, as a catalyst for the hydroformylation of tolan (11a), forming $\alpha$-phenylcinnamaldehyde $\mathbf{3 8 b}$ [111, 112]. Ligand substitution demonstrated two distinct reactivities, of which one was important in the catalytic cycle. Whereas $\mathrm{PPh}_{3}$ resulted in migratory insertion of $\mathrm{CO}$ to 11a leading to 65a, coordination of $\mathrm{CO}$ afforded the vinyl group to undergo migratory insertion leading to $\mathbf{6 5 b}$. This step is described to occur by an $\sigma-\pi$ motion. As such, under sufficient $\mathrm{CO}$ pressure the migration of the vinylic group is argued to constitute an important intermediate in the catalytic cycle. Oxidative addition of $\mathrm{H}_{2}$ then enables reductive elimination, forming 38b and hydride compound $65 \mathrm{c}$ that can react with 11a and conclude the cycle. Moreover, the cluster was active for up to six catalytic cycles.
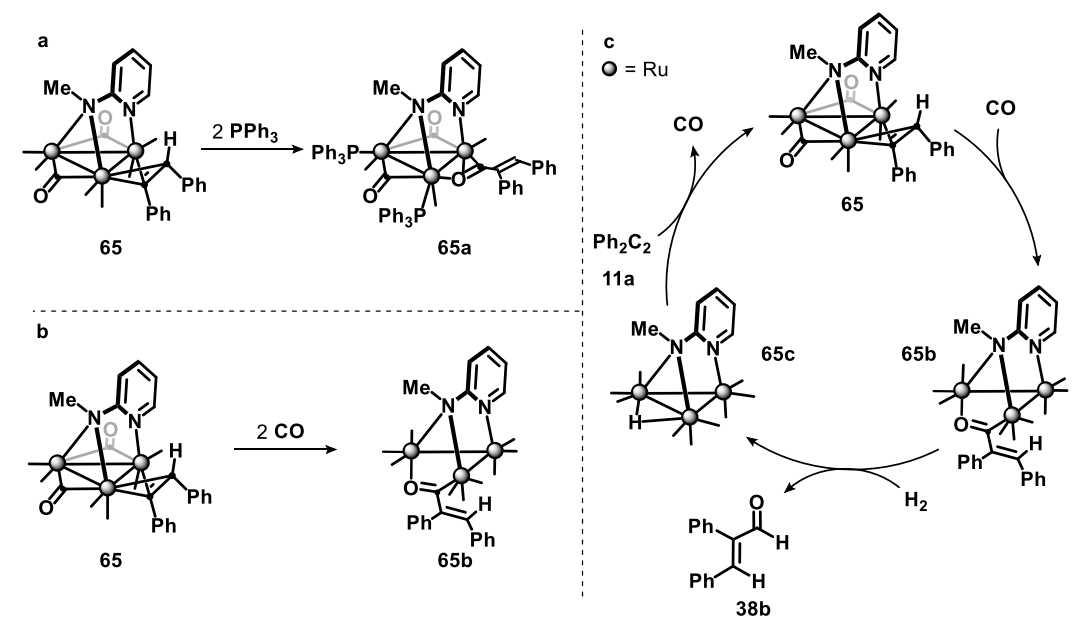

Scheme 18. Hydroformylation of 11a using face-capped triruthenium cluster 65 as catalyst as proposed by Lavigne. Terminal CO molecules have been omitted for clarity, [111, 112].

\section{Hydrocarbonylation}

Jun reported a chelation-assisted hydroesterification of 66 using sodium formate 67 as the $\mathrm{C}_{1}$-source and 2phenylethanol 68 as alcohol to provide ester 32b, Table 10 [113]. ${ }^{13} \mathrm{C}$-labeling experiments established the carbonylic carbon in 69 originated from 67 . Thermal decomposition of 67 was further substantiated by $\mathrm{pH}$ measurements showing 
an increase from 6.9 to 9.1 after an hour of heating at $170{ }^{\circ} \mathrm{C}$, as well as trapping of $\mathrm{CO}$ in a $\mathrm{Rh}(\mathrm{I})$ complex. The role of 2-pyridinemethanol is explained in terms of a five-membered metallacycle, concluding the mechanism to consists of a chelation-assisted hydroesterification, and transesterification. While the nuclearity of the catalyst(s) was not addressed directly, considering the various precatalysts employed, the difference in product distributions satisfy Laine's second criterion, thus suggesting cluster catalysis.

Table 10. Hydroesterification of $\mathbf{6 6}$ catalyzed by an in situ mixture of $\mathrm{Ru}_{3}(\mathrm{CO})_{12}$ and 2-pyridinemethanol, [113].

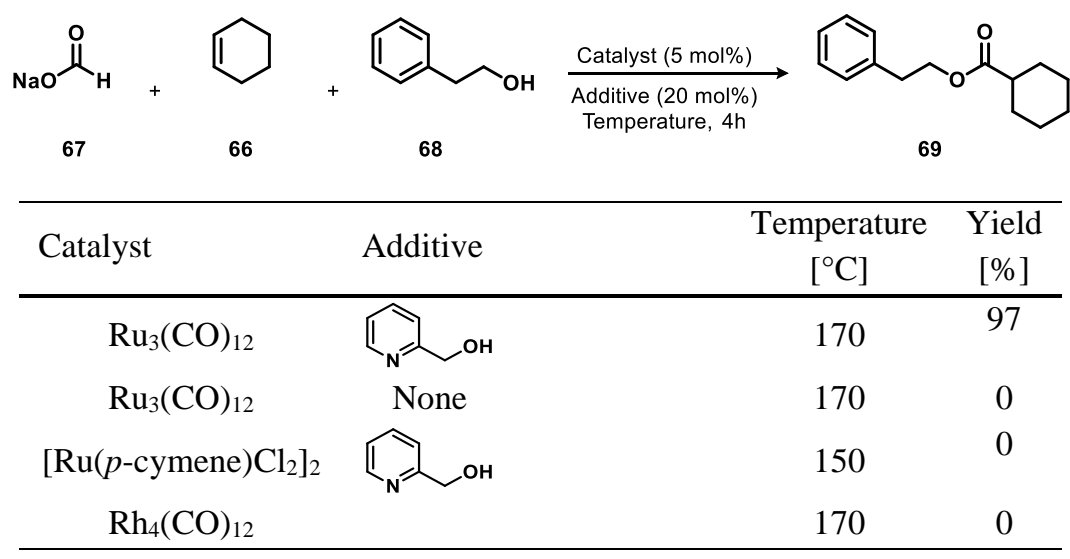

Chang demonstrated the hydroesterification of various alkenes $(\mathbf{1})$ employing catalytic amounts of $\mathrm{Ru}_{3}(\mathrm{CO})_{12}$ to afford products $\boldsymbol{n - 3 2 c}$ or iso-32c with predominantly linear selectivity (up to >99:1), Table 11 [114]. Comparing of a number of catalyst precursors resulted in a significant product variation between the triruthenium species relative to di- and monoruthenium compounds, with the two latter severely lacking activity. No further studies to ascertain the nature of the catalyst were provided.

Table 11. Hydroesterification of $1 \mathrm{a}$ using $\mathrm{Ru}_{3}(\mathrm{CO})_{12}$ as catalyst precursor, [114].

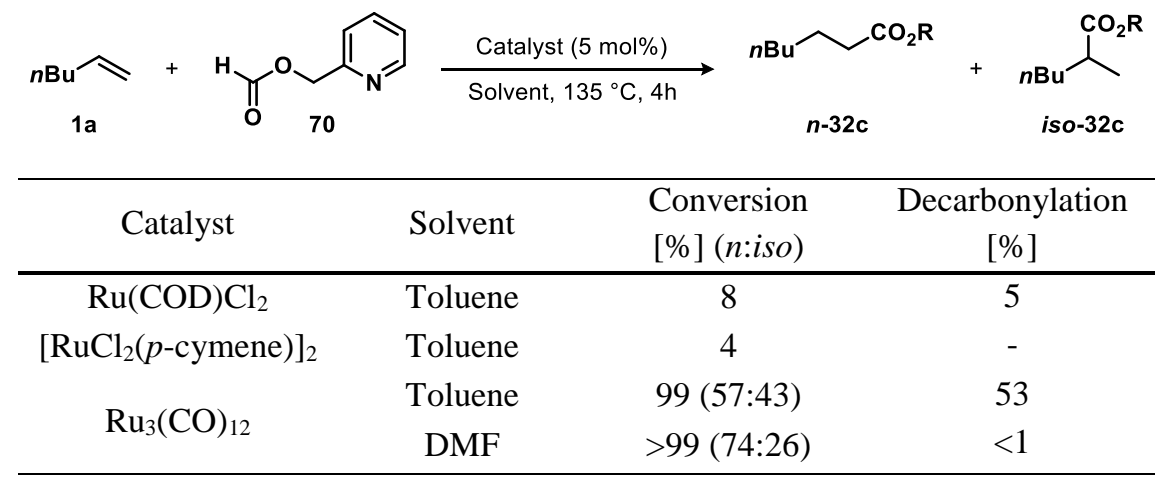

A later study by Chang found that using $\mathrm{Ru}_{3}(\mathrm{CO})_{12}$ in $\mathrm{DMSO}$ worked to provide conditions for regioselective catalytic hydroesterification of alkynes, whereas DMF provided beneficial conditions for dienes [115]. No experiments were done to address the structure of the catalyst, nor was ruthenium-sources of varying nuclearities investigated. However, a triruthenium species 71, shown in Scheme 19, was isolated from another study on cooperative coupling using Ru and Pd, thus suggesting a polynuclear nature of the catalyst [116]. A later study found that, whereas DMF suppressed decarbonylation for hydroesterification, the opposite was true in hydroamidation [117]. Utilizing $\mathrm{CH}_{3} \mathrm{CN}$ as solvent provided conditions affording varying yields $(53-76 \%)$ of predominantly linear selectivity. 


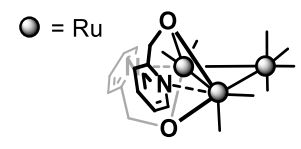

71

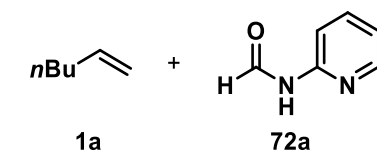

$1 \mathrm{a}$

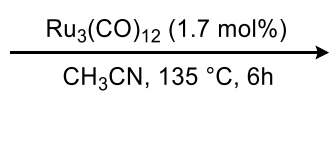

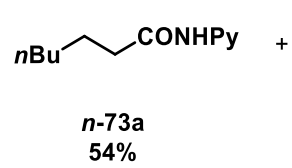

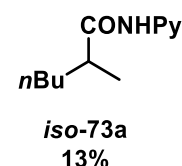

Scheme 19. Stoichimetric reaction of pyridylmethylalcohol with $\mathrm{Ru}_{3}(\mathrm{CO})_{12}$ resulting in a $N, O$-chelated cluster. Hydroamidation 1a with 72a leading to mixtures of $\boldsymbol{n - 7 3 a}$ and iso-73a, respectively, using $\mathrm{Ru}_{3}(\mathrm{CO})_{12}$ as precatalyst. Terminal CO molecules have been omitted for clarity, [117].

Following these results, Chang demonstrated that co-catalytic amounts of halide salts worked to enhance the ruthenium-catalyzed hydroesterification of olefins 1 and alkynes such as ${ }^{n} \operatorname{Pr}-\mathrm{CC}-{ }^{n} \operatorname{Pr} 11 \mathbf{b}$ [118]. While the presence of halide has been reported to promote cluster fragmentation (vide supra), the authors invoke that this equilibrium is relevant only at high pressures of $\mathrm{CO}$, as opposed to their conditions (absence of $\mathrm{CO}$, and a maximum of $110{ }^{\circ} \mathrm{C}$ in DMSO). Rather, based on spectroscopic data, the role of halide was argued to promote dissociation of CO ligand. As such, using $\mathrm{Bu}_{4} \mathrm{NI}$ as additive afforded excellent yields (up to 99\%) with predominantly linear selectivity (up to >98:2) in the hydroesterification of $\mathbf{1}$.

Formyl addition of $\mathbf{7 2 b}$ to $\mathbf{5 3}$ leading to $\mathbf{7 4}$ was successfully achieved by Kondo and Mitsudo using a catalyst precursor system comprising the anionic triruthenium hydrido cluster 75, $[\mathrm{PPN}]\left[\mathrm{Ru}_{3} \mathrm{H}(\mathrm{CO})_{11}\right], \quad \mathrm{PPN}=$ bis(triphenylphosphine)iminium, and $\mathrm{PCy}_{3}$, Table 12 [119]. From screening a range of catalyst precursors, the mononuclear compound $\mathrm{Ru}(\mathrm{COD})(\mathrm{COT})$ demonstrated good conversion and similar regioselectivity (exo:endo) to that of $\mathbf{7 5}$, albeit at a significantly reduced yield of $16 \%$ compared to $97 \%$. The more simple $\operatorname{Ru}_{3}(\mathrm{CO})_{12}$ also showed a exo:endo regioselectivity in the same range (84/16), but with significantly lower conversion of merely $26 \%$. While these differences in conversions and product distributions satisfies Laine's second criterion, further studies could potentially shed more light on the nature of the catalytically active species.

Table 12. Alkene insertion into formyl bond using anionic triruthenium cluster, [119].

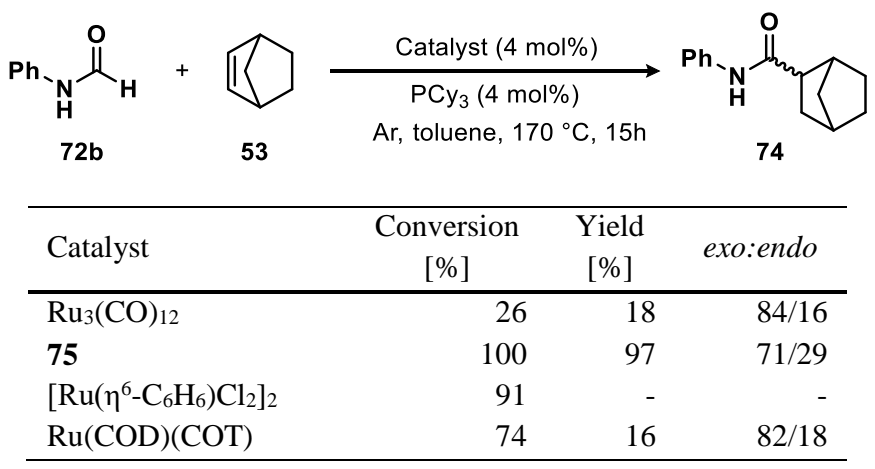

\section{Cyclocarbonylation}

Takahashi demonstrated that $\mathrm{Ru}_{3}(\mathrm{CO})_{12}$ is an efficient catalyst (precursor) for cyclocarbonylation to selectively afford $\gamma$ - and $\delta$-lactones, such as 77a, from allenylic alcohols, such as 76a (91-99\% yield), Scheme 20 [120]. When substituting to mononuclear ruthenium complexes, such as $\mathrm{RuCl}_{3} \cdot x \mathrm{H}_{2} \mathrm{O}$ and $\mathrm{RuCl}_{2}\left(\mathrm{PPh}_{3}\right)_{3}$, catalytic activity was observed albeit with lower yields of $82 \%$ and $41 \%$, respectively. Additionally, related metalcarbonyls demonstrated no activity. Investigation of the reaction conditions found that absence of additive $\mathrm{Et}_{3} \mathrm{~N}$ reduced the yield to approximately $60 \%$. Moreover, while the nuclearity of the actual catalyst was not addressed, the catalyst precursor nuclearity was shown to affect the yield of product formation. 


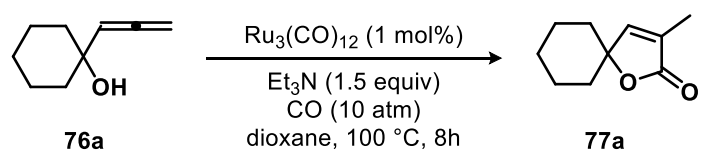

Scheme 20. Triruthenium $\mathrm{Ru}_{3}(\mathrm{CO})_{12}$ of $\mathbf{7 6}$ affording $\gamma$ - and $\delta$-lactones, [120].

A subsequent study on the same reaction demonstrated a linear correlation of TOF with respect to the $\mathrm{Ru}_{3}(\mathrm{CO})_{12}$, in accordance with Laine's first criterion [121]. Labelling studies revealed the formation of two furanone-based products, of which tautomerisation to 77 occurs at elevated temperature in presence of $\mathrm{Et}_{3} \mathrm{~N}$ and ruthenium. To conclude their findings to a catalytic cycle, Scheme 21, the authors argue for an initial formation of a $\pi$-allyl complex. This suggestion is based on two observations, (i) excess addition of $\mathrm{MeOH}$ did not increase the rate of carbonylation, and (ii) the isolation of $\pi$-allyl adducts of both $\mathrm{Fe}_{2}(\mathrm{CO})_{9}$ and $\mathrm{Os}_{3}(\mathrm{CO})_{12}$.

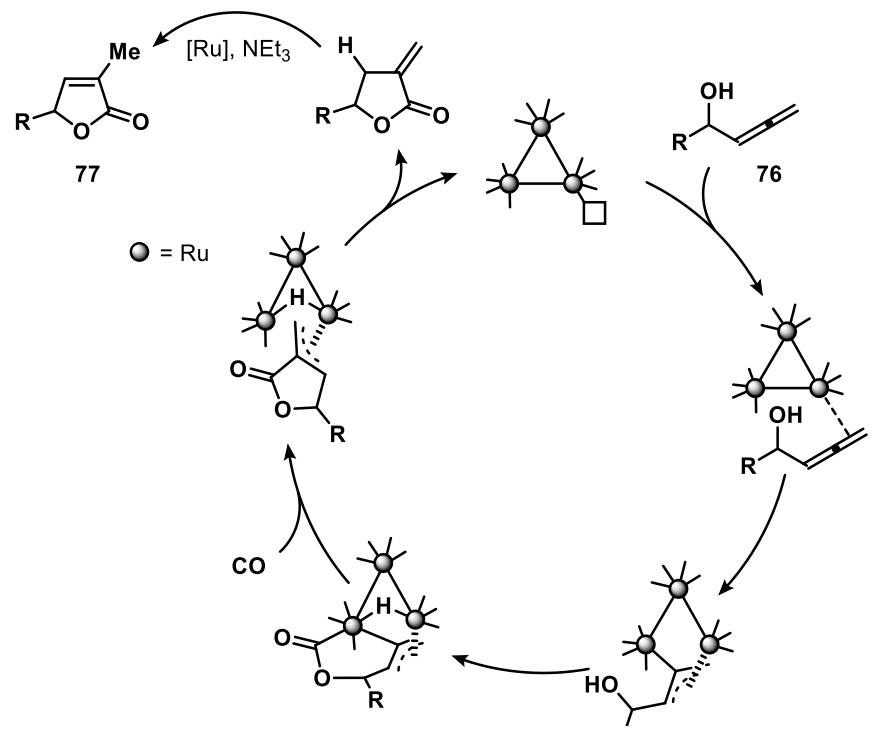

Scheme 21. The catalytic cycle for cyclocarbonylation of $\mathbf{7 6}$ to yield $\mathbf{7 7}$ using $\mathrm{Ru}_{3}(\mathrm{CO})_{12}$ as catalyst, as proposed by Takahashi. Terminal CO molecules have been omitted for clarity, [121].

With reference to the work by Takahashi, Tsubuki and Honda reported that the use of $\mathrm{Ru}_{3}(\mathrm{CO})_{12}$ in catalytic amounts under atmospheric pressure of $\mathrm{CO}$ selectively affords cyclocarbonylation of homoallenylic alcohols $\mathbf{7 8}$ to either fiveor six-membered lactones, such as 76, Scheme 22 [122]. The nature of the solvent was found to affect the formation of endo vs. exo product. Whereas acyclic tertiary amines resulted in complex mixtures, using cyclic tertiary amines resulted in a predominantly endo selectivity in varying yields $58-76 \%$. Of the various solvents, 2,4,6-collidine resulted in a endo-exo distribution of 3.0:1. Additionally, the solvent affected the necessary pressure for cyclocarbonylation. Using $\mathrm{Et}_{3} \mathrm{~N}$, pressures below five atmospheres resulted in approximately $10 \%$ yield, while 2,4,6collidine afforded up to $79 \%$ yield under atmospheric pressure of CO. The catalyst nuclearity was not addressed, nor was any other ruthenium sources investigated as potential catalysts.

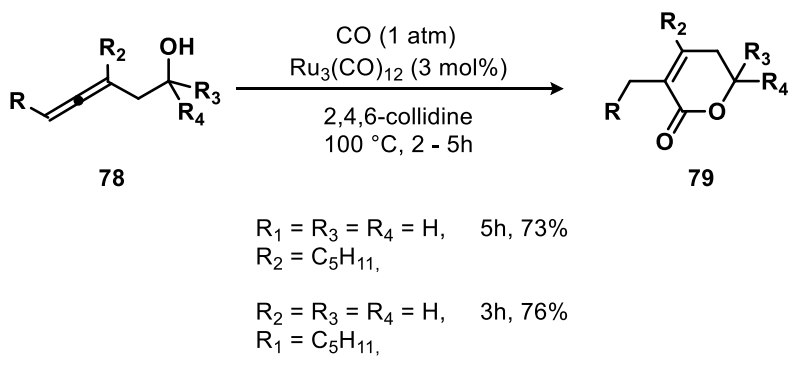

P. 25 of 52 
Scheme 22. Cyclocarbonylation of $\mathbf{7 8}$ to $\mathbf{7 9}$ under atmospheric pressure of $\mathrm{CO}$ using $\mathrm{Ru}_{3}(\mathrm{CO})_{12}$ as (pre)catalyst, [122].

\subsection{Miscellaneous \\ Hydrosilylation}

Nagashima reported that the acenaphthylene face-capped triruthenium cluster, 80 [6], undergoes a distinct hydrogenation of the arene-moiety, affording hydrogenation of the C-C double bond within the six membered ring of the ligand to provide 81, shown in Scheme 23 [7]. A later study revealed the resultant oxidative addition adduct of silanes to $\mathbf{7 5}$ provided clusters with retained integrity, 82 [123].
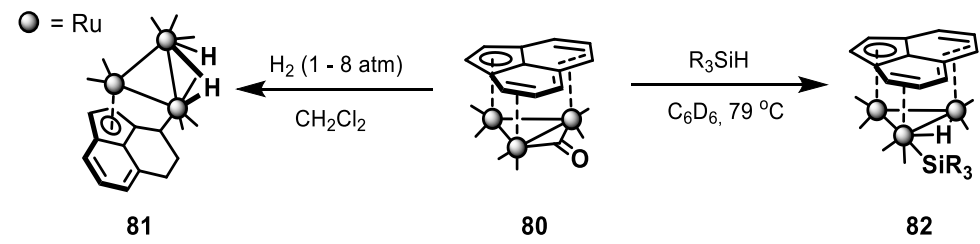

Scheme 23. Treatment of triruthenium-acenaphthylene cluster $\mathbf{8 0}$ with molecular hydrogen affording a distinct hydrogenation of the ligand $\mathbf{8 1}$, or provides an oxidative addition adduct with silanes $\mathbf{8 2}$. Terminal CO molecules have been omitted for clarity. $[6,7,123]$

The same study disclosed $\mathbf{8 0}$ as an efficient catalyst precursor for the hydride addition to $\alpha, \beta$-unsaturated carbonyls 83 to afford either $\mathbf{8 4}$ or $\mathbf{8 5}$, as well as for ring-opening polymerization of THF to polymeric ether $\mathbf{8 6}$, Table 13. Up to full selectivity of the hydride addition was achieved by pairing $\mathbf{8 3}$ with the appropriate silane. As such, employing diphenylsilane resulted in 1,2-addition to yield $\mathbf{8 4}$, whereas dihydrosilanes resulted in 1,4-addition providing $\mathbf{8 5}$. Interestingly, ring-opening polymerization of THF provided a selective $\mathrm{M}_{\mathrm{n}}$ in the range of $10^{3}-10^{5}$, a process commonly initiated in strongly acidic media. The authors suggest a transient species, structurally resembling $\mathbf{8 2}$, based on an induction period, as well as ${ }^{1} \mathrm{H}$ NMR studies of the reaction mixture showing similar resonances. Moreover, 82 was preparatively synthesized albeit under thermally different conditions than those in the catalytic cycle $\left(79{ }^{\circ} \mathrm{C} v s\right.$. $\left.40^{\circ} \mathrm{C}\right)$. These observations thus suggests cluster catalysis.

Table 13. Initial discovery using $\mathbf{8 0}$ as precatalyst. Terminal CO molecules have been omitted for clarity, [123].

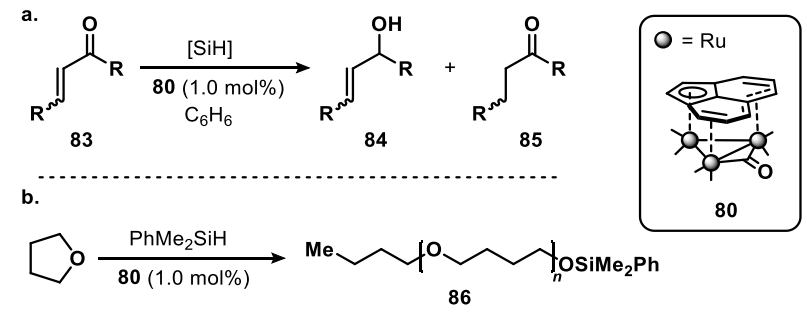

\begin{tabular}{|c|c|c|c|c|c|c|c|c|c|c|c|}
\hline a. & Substrate & $\begin{array}{c}{[\mathrm{SiH}]} \\
\text { (1 equiv.) }\end{array}$ & $\begin{array}{c}\text { Time } \\
{[\mathrm{h}]}\end{array}$ & $\begin{array}{c}\text { Yield } \\
{[\%]}\end{array}$ & $84: 85$ & b. $\mathrm{THF} / \mathrm{SiH}$ & $\begin{array}{c}\text { Temperature } \\
{\left[{ }^{\circ} \mathrm{C}\right]}\end{array}$ & $\begin{array}{c}\text { Time } \\
{[\mathrm{h}]}\end{array}$ & $\begin{array}{c}\text { Yield } \\
{[\%]}\end{array}$ & $\mathrm{M}_{\mathrm{n}}$ & $\frac{M_{w}}{M_{n}}$ \\
\hline & & $\left(\mathrm{HSiMe}_{2}\right)_{2}\left(\mathrm{CH}_{2}\right)_{2}$ & 1 & 80 & $12: 88$ & \multirow{2}{*}{20} & \multirow{2}{*}{40} & \multirow{2}{*}{20} & \multirow{2}{*}{40} & \multirow{2}{*}{5500} & \multirow{2}{*}{1.4} \\
\hline & & $\mathrm{Ph}_{2} \mathrm{SiH}_{2}$ & 4 & 93 & $91: 9$ & & & & & & \\
\hline & & $\left(\mathrm{HSiMe}_{2}\right)_{2}\left(\mathrm{CH}_{2}\right)_{2}$ & 1 & 94 & $94: 6$ & \multirow[t]{2}{*}{100} & \multirow[t]{2}{*}{40} & \multirow[t]{2}{*}{20} & \multirow[t]{2}{*}{44} & \multirow[t]{2}{*}{16000} & \multirow[t]{2}{*}{1.5} \\
\hline & $\mathrm{Me}^{\text {ل }} \mathrm{Me}$ & $\mathrm{Ph}_{2} \mathrm{SiH}_{2}$ & 2.5 & 74 & 100:0 & & & & & & \\
\hline
\end{tabular}

Nagashima provided further reports on selective reduction of functional groups using $\mathbf{8 0}$ as catalyst precursor. For example, addition of tertiary amines, such as $\mathrm{Et}_{3} \mathrm{~N}$, as additive afforded selective reduction of the amide unit in ketoamide compounds [124]. In another example, the presence of $\mathrm{Me}_{2} \mathrm{~S}$ in mixtures of aldehydes and ketones selectively suppressed reduction of the ketones [125]. Furthermore, under neutral conditions $\mathbf{8 0}$ catalyzes the cleavage 
of the $\mathrm{C}-\mathrm{O}$ bond in a range of functionalities containing the $\mathrm{C}-\mathrm{O}{ }^{t} \mathrm{Bu}$ unit, including $N$ - and $O$-Boc as well as ${ }^{t} \mathrm{Bu}$-esters and ${ }^{t} \mathrm{Bu}$-ethers [126]. Further substrate selectivity was demonstrated by varying the source of silane. To this end, reduction of carboxylic acids using monofunctional silanes afforded the corresponding silylether, whereas bifunctional silanes provided the aldehyde [127]. Finally, bifunctional silanes were further employed in dehydration of amides $[128]$.

Variation of the substituents changes the reactivity from vinyl ether polymerization to a [1,3] $\mathrm{O}$ to $\mathrm{C}$ rearrangement. A stereo-electronic-activity relationship of the substituents in the substrate $\mathbf{8 7}$ concluded that, H as $\alpha$-substituent (R') generally results in polymerization, shown in Scheme 24 [129][130] On the other hand, when R' is different from H, in addition to a vinyl substituent that form a stabile cation, such as furfuryl vinyl ether or $p$-methoxybenzyl vinyl ether, rearrangement was observed, Table 14. Moreover, the addition of excess hydrosilane resulted in a step-wise formation of the corresponding silylether going through an initial $[1,3] \mathrm{O}$ to $\mathrm{C}$ rearrangement to the corresponding carbonylic moiety, followed by reduction, finally forming the silylether. While using $10 \mathrm{~mol} \% \mathrm{PhMe} 2 \mathrm{SiH}$ selectively provide $\mathbf{8 8}$, a complete reversal in selectivity was achieved using $130 \%$ of the silane and using 1 mol\% $\mathbf{8 0}$ providing 89.

Table 14. Alkoxysubstituent promoting rearrangement over polymerization, [130].

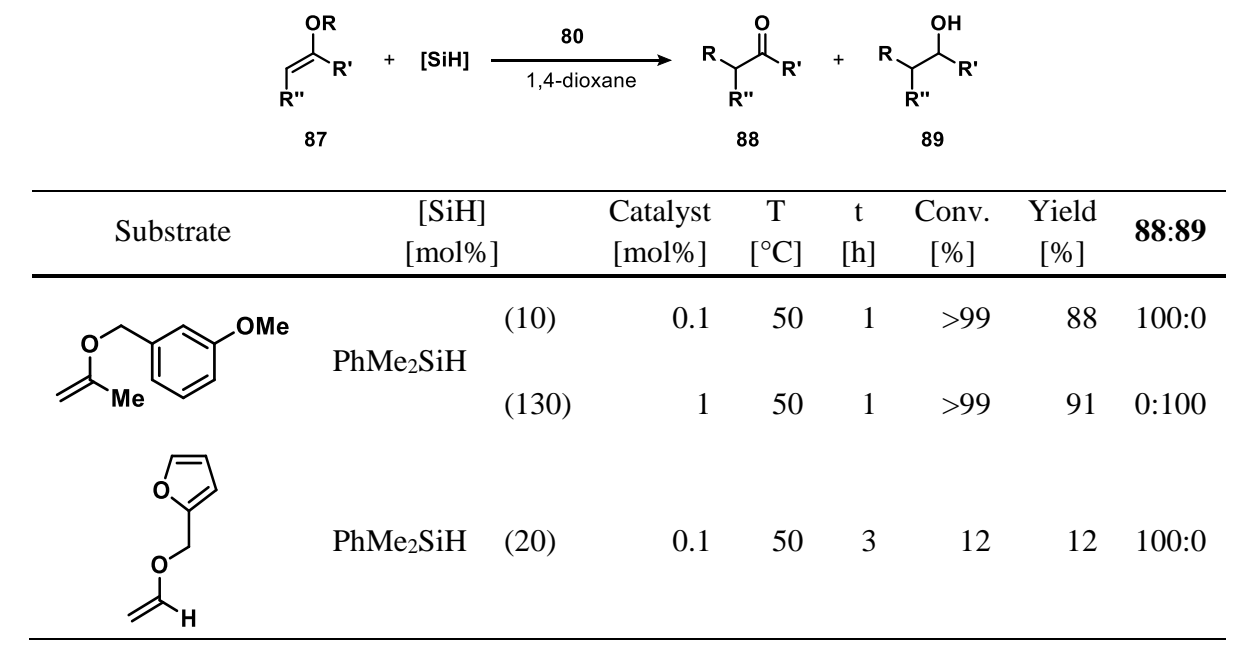

The polymerization is described by a cationic mechanism initiated by a heterolytic cleavage of the $\mathrm{H}-\mathrm{SiR} \mathrm{R}_{3}$ bond, resulting in an ion pair consisting of $\mathrm{R}_{3} \mathrm{Si}^{+}-\left[\mathrm{H}-\mathrm{Ru}_{3}\right]^{-}(\mathbf{9 0 d})$. The siliconium ion then adds to the terminal carbon of $\mathbf{8 3}$ leading to $90 \mathrm{a}$, which is followed by propagation of the monomer $(\mathbf{9 0 b}$ and $90 \mathbf{c})$ and terminated by hydride transfer providing the polymerization product 91, as shown in Scheme 24. The Lewis acidity of the siliconium species is proposed to be insufficient for activating compounds bearing electron withdrawing substituents. End group analysis using deuterium corroborates the authors' suggested mechanism and observations regarding insertion of alkene between the $\mathrm{Si}$ and $\mathrm{H}$ bond in $\mathrm{R}_{3} \mathrm{Si}-\mathrm{H}$. 


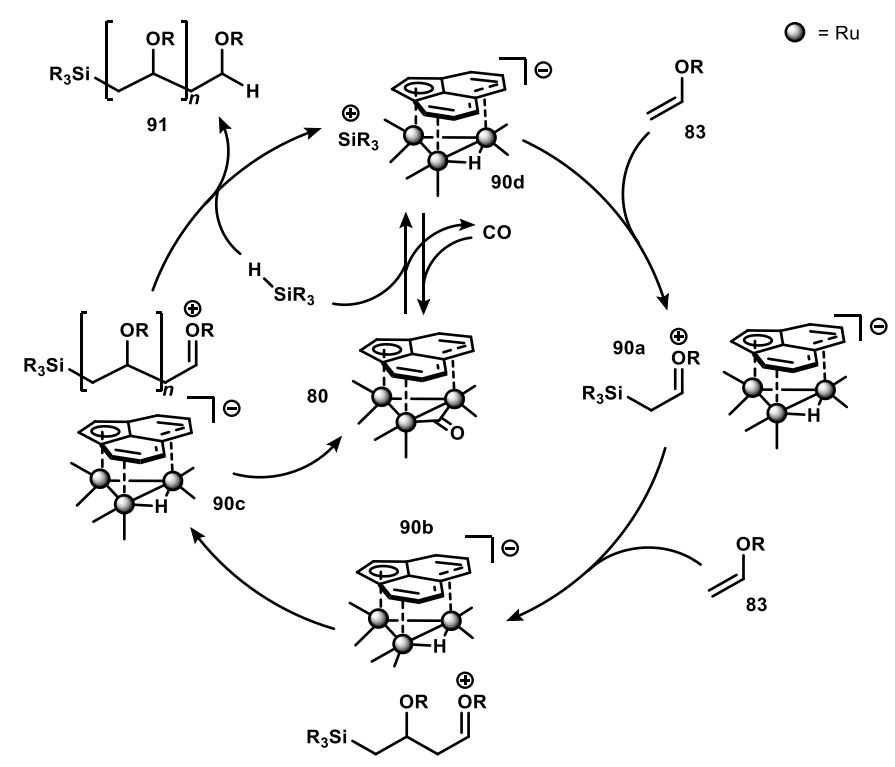

Scheme 24. Catalytic scheme for the polymerization of ethers to 91 , exemplified by polymerization of vinyl ether $\mathbf{8 3}$, as proposed by Nagashima [129]. Terminal CO molecules have been omitted for clarity.

\section{Hydrodefluorination}

Catalytic hydrodefluorination of perfluoropyridine 91 to tetrafluoropyridine 92 was achieved using the incomplete cubane-type cluster, $\left[\mathrm{M}_{3} \mathrm{~S}_{4} \mathrm{H}_{3}(\mathrm{dmpe})_{3}\right]^{+} \mathrm{M}=\mathrm{Mo}$ (15c), W (93a), of which 93a was reported by Llusar to afford a superior TON value of 90 [131]. Using $1 \mathrm{~mol} \%$ catalyst loading and $\mathrm{Me}_{2} \mathrm{PhSiH}$ as silane source afforded $90 \%$ yield under microwave conditions. Under the applied conditions, no cluster degradation was observed, and any reaction was only observed in the presence of the cluster. Mechanistic accounts were rationalized from DFT studies suggesting an initial phosphine dissociation from the cluster permitting M-H/C-F $\sigma$-bond metathesis. This compound, in turn, undergoes $\mathrm{M}-\mathrm{F} / \mathrm{Si}-\mathrm{H} \sigma$-bond metathesis that is concluded by re-coordination of the phosphine ligand as shown in Scheme 25. To assess the influence of the phosphine ligands on catalytic activity, Llusar reported in a later study the activity of the dppe congeners, $\left[\mathrm{M}_{3} \mathrm{~S}_{4} \mathrm{H}_{3}(\mathrm{dppe})_{3}\right]^{+}, \mathrm{M}=\mathrm{Mo}$ (15f), W (93b) [132]. Approximately $90 \%$ yield was achieved at a significantly lower temperature $\left(115 \mathrm{vs} .180^{\circ} \mathrm{C}\right)$ and catalyst loading ( $0.7 \mathrm{vs.} 1.0 \mathrm{~mol} \%$, respectively). Thus, substitution for less basic chelating phosphine was found to afford higher catalytic activity.

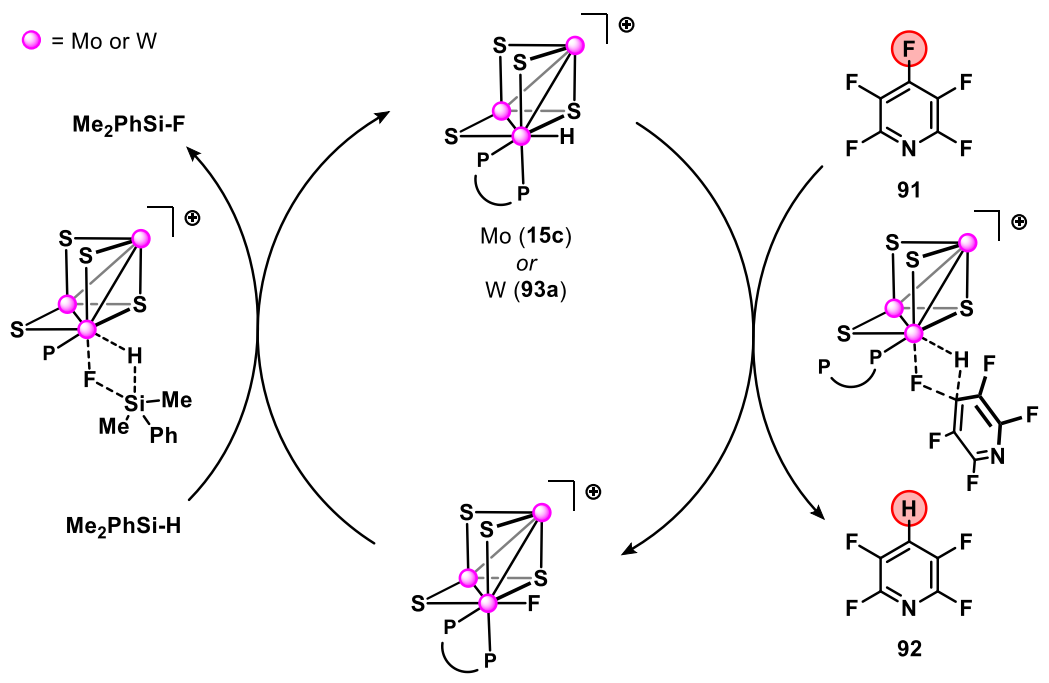

Scheme 25. Catalytic regioselective hydrodefluorination of 91 to 92 using the high valent clusters 15c or 93a, as proposed by Llusar. For clarity, ligands have been omitted on residual metal centers, [131]. 


\section{Dehydrogenation reactions}

Yi demonstrated that the tetraruthenium complex, $\left\{[(\mathrm{PCy} 3)(\mathrm{CO}) \mathrm{RuH}]_{4}\left(\mu_{4}-\mathrm{O}\right)\left(\mu_{3}-\mathrm{OH}\right)\left(\mu_{2}-\mathrm{OH}\right)\right\}$, 94, is a highly effective catalyst for the Oppenauer oxidation of primary $(62-85 \%)$ and secondary alcohols $(79-98 \%)$, Table 15 [133]. The authors were able to recover 94 after the reaction, which by ${ }^{1} \mathrm{H}$ NMR spectra showed no changes. Further, the activity was found to remain the same throughout five cycles. In addition, the activity of $\mathbf{9 4}$ was greater than either of the parent compounds, $\mathrm{RuHCl}(\mathrm{CO})\left(\mathrm{PCy}_{3}\right)_{2}$ and $\left[\left(\mathrm{PCy}_{3}\right)_{2}(\mathrm{CO}) \mathrm{RuH}\right](\mu-\mathrm{H})(\mu-\mathrm{OH})\left[\mathrm{RuH}(\mathrm{CO}) \mathrm{PCy}_{3}\right]$, which afforded merely 30\% and trace conversions, respectively. Additional two mononuclear ruthenium complexes were tested, of which neither afforded any oxidation. This drastic difference suggests cluster catalysis according to Laine's second criterion. Moreover, the transformation was concluded to proceed by cooperative interaction, as Hammett studies demonstrate an outer-sphere mechanism, as well as a sigmoidal curve-shape for the initial reaction rates. As such, the substrate seemingly binds to multiple ruthenium centers. Finally, a $\mathrm{Hg}(0)$ poisoning test indicates homogeneous-phase catalysis.

Table 15. Dehydrogenation of $\mathbf{6 8}$ to 88 using a tetraruthenium cluster 94 as catalyst. Terminal CO molecules have been omitted for clarity [133].

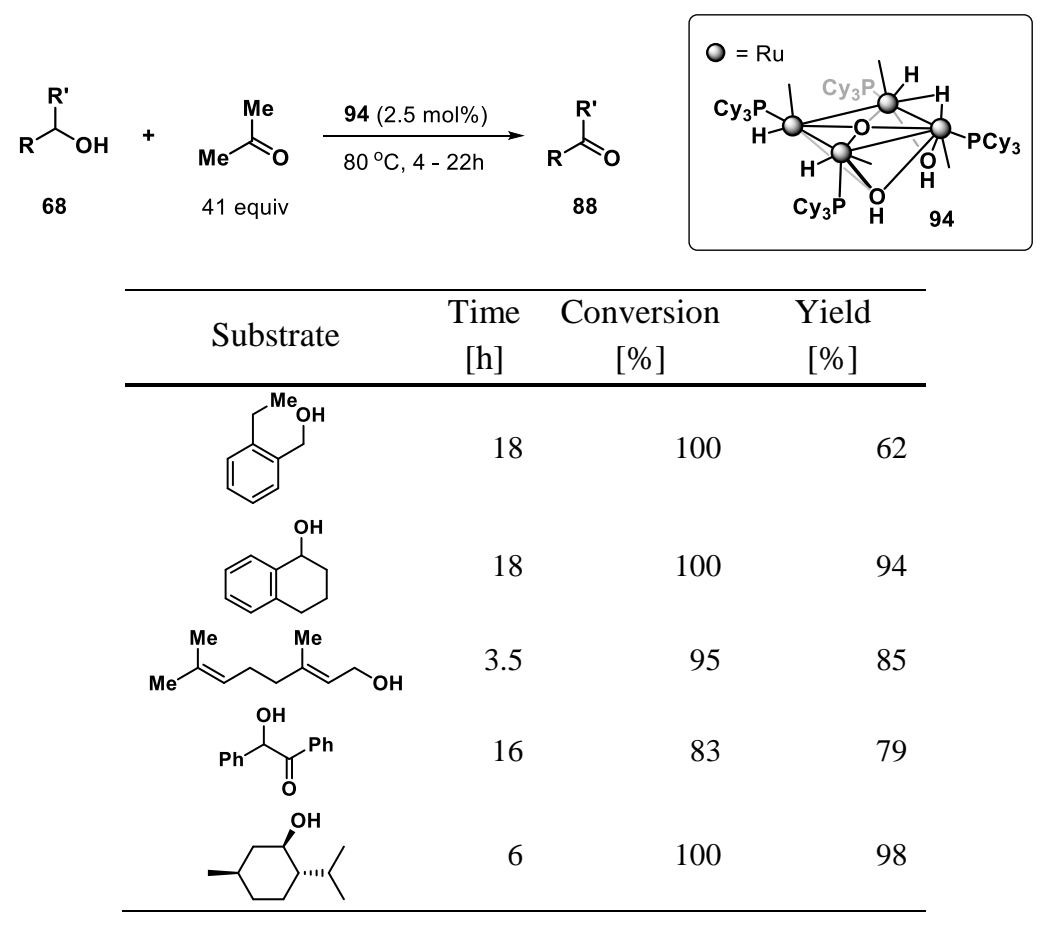

Using the same ruthenium cluster, 94, Yi demonstrated its ability as an efficient catalyst for the dehydrogenation of unreactive $\mathrm{C}-\mathrm{H}$ bonds in amines and carbonyls, resulting in TON values up to 20,000 within $2 \mathrm{~h}$ at $200{ }^{\circ} \mathrm{C}$ [134]. Additional mechanistic insights were obtained by phosphine inhibition and labeling studies, demonstrating that the cluster undergoes dissociative activation, as a significant reduction in TON was observed following increasing equivalents of phosphine. Further, the transformation was established to occur via a reversible $\mathrm{C}-\mathrm{H}$ activation at the vinylic position of tert-butylethylene (TBE). From these findings, Yi later reported a tandem one-pot setup for dehydrogenation-alkylation of hydrocarbons to provide a variety of aromatic compound, using a combination of tetraruthenium cluster 94 and the cationic monoruthenium species $\left[\left(\eta^{6}-\mathrm{C}_{6} \mathrm{H}_{6}\right) \mathrm{RuH}(\mathrm{CO})\left(\mathrm{PCy}_{3}\right)\right] \mathrm{BF}_{4}$ [135]. This method worked to afford a highly regio- and stereoselective protocol for the one-pot dehydrogenation-alkylation and insertion of $\mathbf{1}$ to ketones, such as 88a, Table 16. 
Table 16. Tandem one-pot dehydrogenation-alkene insertion using two ruthenium catalysts, [135].

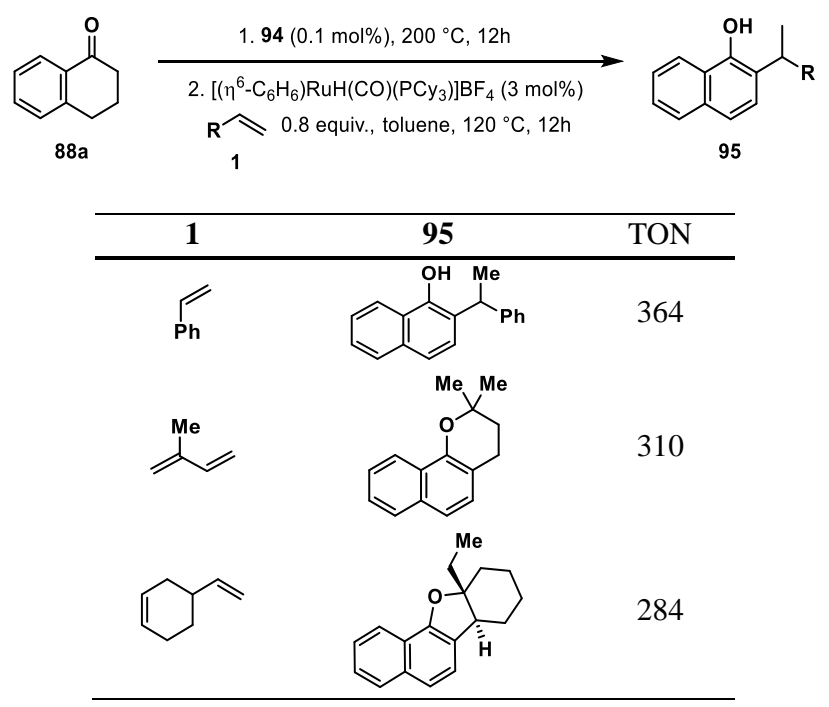

Suzuki reported that cluster $\mathbf{4 5}$ is active for the catalytic dehydrogenative coupling of electron-donating 4-substitued pyridine compounds 96 to yield 4,4'-dimethyl-bipyridine 97, Scheme 27 [136]. Cluster 45 treated with excess pyridine reacted via a C-H bond cleavage at the $\alpha$-position resulting initially in the formation of an edge-bridge pyridyl species 45d, which for electron-withdrawing functional groups transformed into the thermodynamically favored face-capped $\mu_{3}$-pyridyl complex, 45e, Scheme 26.

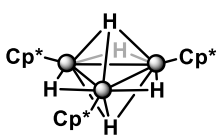

45

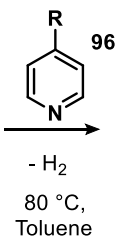

Toluene

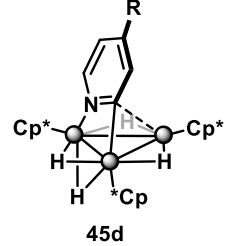

$\mathrm{R}=\mathrm{H}, \mathrm{CO}_{2} \mathrm{Me}, \mathrm{CO}_{2} \mathrm{Et}, \mathrm{Me}$

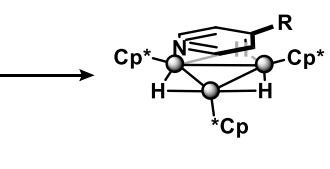

45e

Scheme 26. Transformation of the pentahydrido triruthenium cluster $\mathbf{4 5}$ with pyridines, [136].

Using $0.2 \mathrm{~mol} \%$ of 45 at $180{ }^{\circ} \mathrm{C}$, dehydrogenative coupling forming 97 was achieved in turn-over number of 80 after 120 hours. The reaction in general provided moderate yields of the coupling products. However, it constitutes a rare example of reactions that utilize $\mathrm{C}-\mathrm{H}$ bond activation for $\mathrm{C}-\mathrm{C}$ bond formation, Table 17. The authors noted strongly coordinating solvent suppressed the reaction, as demonstrated by the difference in yields by one order magnitude between DME (2\%) and mesitylene (20\%). Moreover, the lack of products observed for electron-withdrawing substituents is suggested to relate to formation of $\mathbf{4 5 e}$. 
Table 17. Dehydrogenative coupling of 96 leading to 97 using 45 as catalyst precursor, [136].

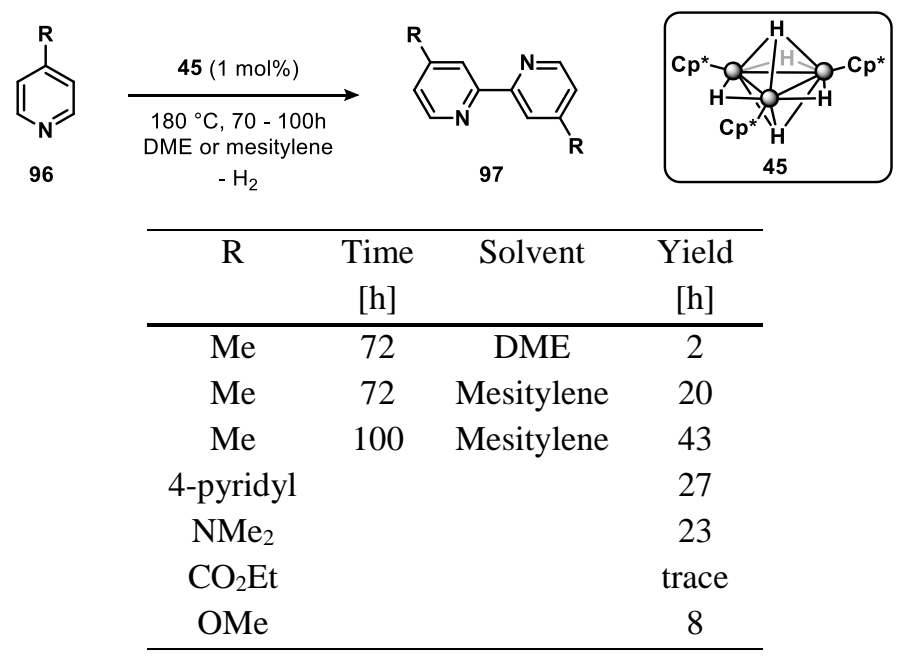

While a full mechanistic account remained unclear, the authors provide a tentative mechanism based on an initial oxidative addition of a C-H bond at the $\alpha$-position to give $\mathbf{4 5 f}$, Scheme 27. This is followed by the coordination of a second pyridine compound giving $\mathbf{4 5}$, which promotes loss of hydrido ligands as $\mathrm{H}_{2}$. The second pyridine compound undergo $\mathrm{C}-\mathrm{H}$ bond scission to provide $\mathbf{4 5 h}$, which via a rupture of a $\mathrm{Ru}-\mathrm{Ru}$ bond permits for reductive elimination (45i). Finally, regenerating the Ru-Ru bond, releasing 97, and allowing oxidative addition of a new pyridine compound closes the catalytic cycle by reforming $\mathbf{4 5}$.

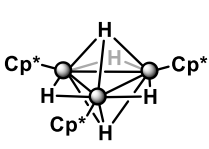

45
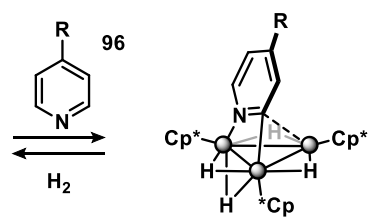

45d
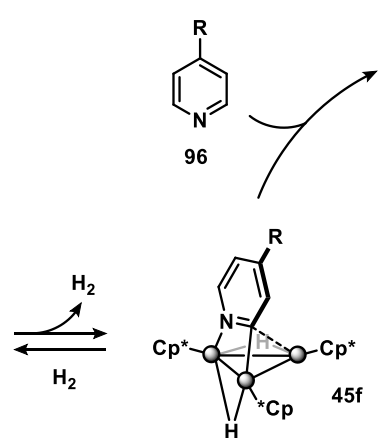

(1)

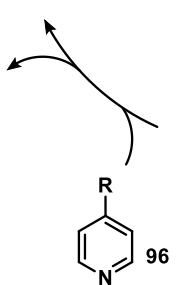

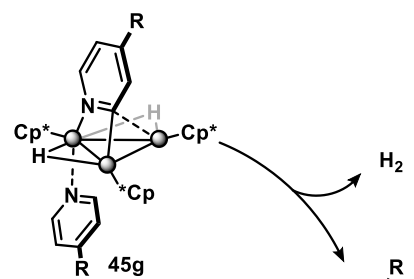
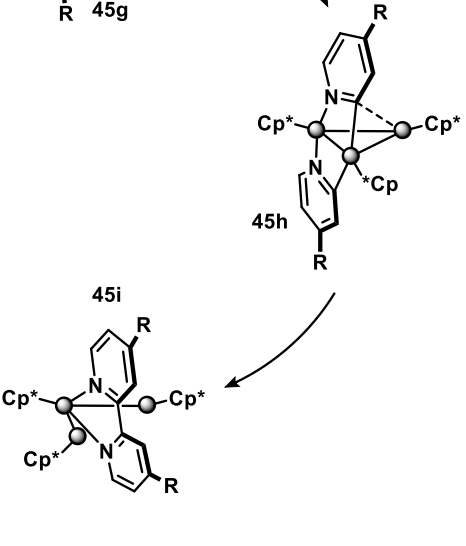

Scheme 27. Tentative mechanism involved in dehydrogenative coupling of 96 leading to 97 using 45 as catalyst precursor, as proposed by Suzuki, [136]. 


\section{Hydration}

Subsequent studies disclosed insights into the nature of the cooperative catalytic interactions by employing cluster $\mathbf{9 4}$ in the hydration of nitriles 47 to amides (either $47 \mathrm{c}$ or $\mathbf{4 7 d}$ ), Scheme 28 [8]. By comparing the binding differences between benzonitrile $\mathbf{4 7 a}$ and methacrylonitrile $\mathbf{4 7 b}$ to $\mathbf{9 4}$, and based on a Hill coefficient of approximately three, it was found that likely only $\mathbf{4 7 a}$ demonstrated multiple binding interactions. Thus, three sites are able to bind 47a, whereas $47 \mathrm{~b}$ was found to have a lower binding affinity. Consequently, 94 does only demonstrate cooperativity when reacting with 47a. Single-crystal X-ray structure of a tetraruthenium-MeCN adduct 94a revealed insight into the nature of the cluster, which upon $\mathrm{MeCN}$ coordination undergoes transformation of three structural features: (i) $\mu_{3}-\mathrm{OH}$ to $\mu-\mathrm{OH}$, (ii) rearrangement of hydrides from terminal to bridging, and (iii) increased bond length between the ruthenium centers opposite to the nitrile. Moreover, the same adduct was found to provide four times the catalytic activity compared to 94. From kinetic studies, it was demonstrated that only electron-poor arenes undergo cooperative transformation to a significant extent. This observation is suggested by the authors to relate to Ru-Ru bond rupture leading to cluster fragmentation from electron-rich arenes. Furthermore, DOSY NMR studies demonstrated that the active species is mononuclear under transformations of electron-rich arenes, corroborating the postulate. Finally, a $\mathrm{Hg}(0)$ poisoning test concluded homogenous phase catalysis.

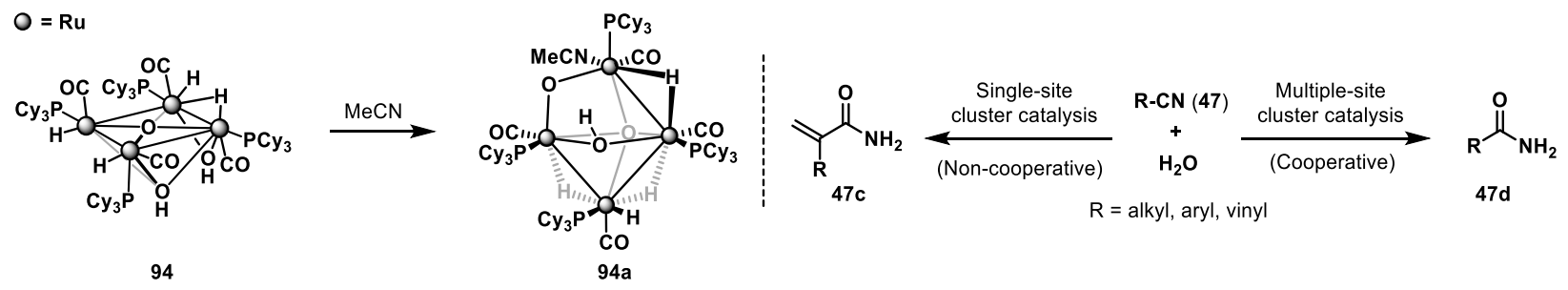

Scheme 28. MeCN adduct of tetraruthenium cluster (94) demonstrating retention of nuclearity. Electronic properties of the nitrile affects the interaction with the cluster, electron-poor resulting in multiple-site catalysis, [8].

\section{Cycloaddition}

Kleij investigated the octanuclear zinc clusters 100, resulting from a conglomeration of four symmetrical $\mathrm{Zn}_{2}-\mathrm{Schiff}_{-}$ bases, as potential catalyst precursors for the cycloaddition of $\mathrm{CO}_{2}$ to oxiranes $\mathbf{9 8}$ leading to carbonates $\mathbf{9 9}$, Scheme 29 [137]. Single-crystal X-ray diffraction demonstrated two distinct zinc sites, of which the coordination environment and geometry of the "inner" site, was argued to be a consequence of the nature of the "outer" site. Moreover, the former has a single water molecule associated, whereas the latter is exclusively coordinated by the phenoxo ligands. Spectroscopic and chromatographic analyses established an intact spherical cluster-entity. In methylethylketone, after 68h of reaction time, $0.63 \mathrm{~mol} \%$ of $\mathbf{1 0 0}$ afforded $87 \%$ yield of $\mathbf{9 9}$, Scheme $\mathbf{2 9}$.

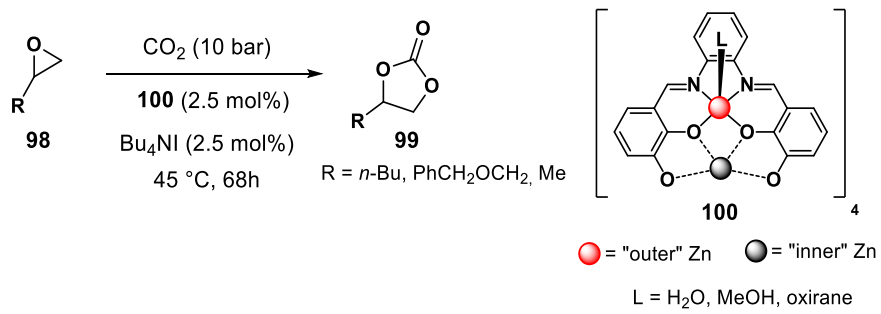

Scheme 29. Using an octazinc cluster 100 for the cycloaddition of $\mathrm{CO}_{2}$ to oxiranes 99, [137].

A later study by Kleij assessed the catalytic activity of $\mathbf{1 0 0}$ by introducing functional groups varying in electronic properties, as well as using asymmetric Schiff bases as building blocks, Table 18 [138]. Higher TON values were observed when employing electron-donating groups, which was accounted for in terms of a lower Lewis acidity of the zinc metals. On the contrary, employing electron-poor ligand backbone substituents resulted in a facile ligand dissociation and thus lower substrate turnover. Comparing the turnover number reveal a difference by a factor of approximately 1.5 between the methoxy and nitro-substituted cluster, at 417 vs 271, respectively. Notably, mononuclear $\mathrm{Zn}$-salen complexes showed similar activities as $\mathbf{1 0 0}$ did. 
Table 18. Cycloaddition of 98a with $\mathrm{CO}_{2}$ leading to 99a using 100 as catalyst, [138].

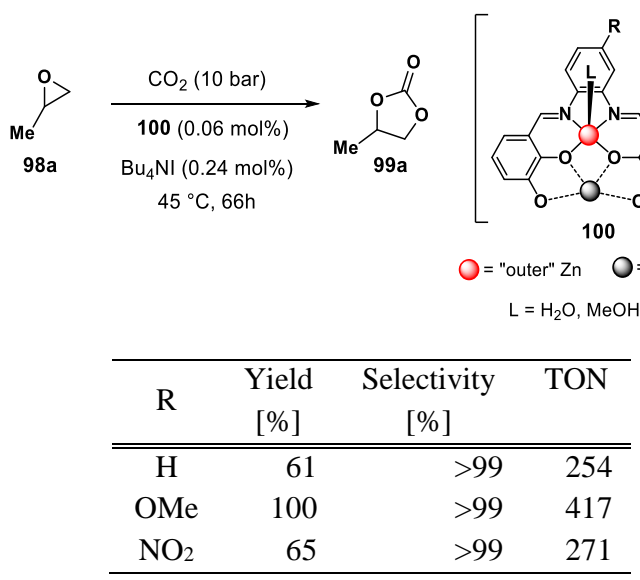

Using iodide as additive, Chang reported reaction conditions that selectively afford either 5-exo-, or 6-endo-cyclization of formamides 101 using catalytic amounts of $\mathrm{Ru}_{3}(\mathrm{CO})_{12}$, Scheme $\mathbf{3 0}$ [139]. Based on their prior results combined with those of Geoffroy and Dombek [41], the authors suggest the halide bridged triruthenium species 102, $\left[\mathrm{Ru}_{3}(\mathrm{CO})_{10}(\mu-\mathrm{I})\right]^{-}$, as the catalytically active species for producing the 5-exo-cyclization 101b. The lack of either product using other catalyst precursors, such as $\mathrm{Os}_{3}(\mathrm{CO})_{12}$, and $\mathrm{Ru}\left(\mathrm{PPh}_{3}\right)_{4} \mathrm{H}_{2}$, combined with their prior findings, supports cluster mediated catalysis.
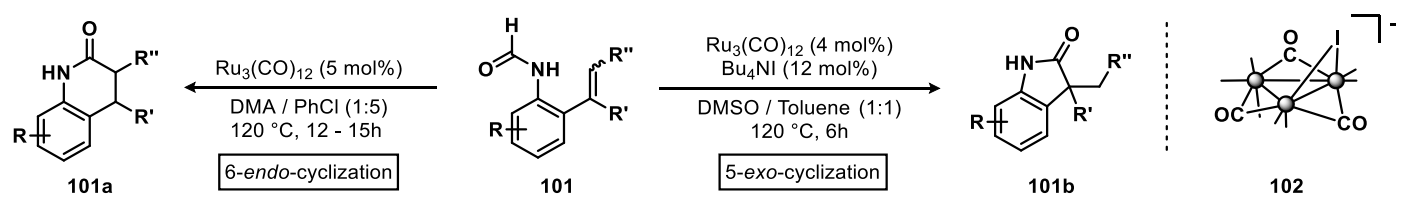

Scheme 30. Regioselective cyclocarbonylation of 101 to yield either 101a or 101b. Terminally bound CO ligands have been omitted for clarity, [139].

Exploring the chemistry of alkyne ligands for polynuclear architectures, Wangelin prepared the first examples of a heteroleptic alkynyl-Mn cubane structure 103, shown in Scheme 31 [140]. Based on their previous studies on $\mathrm{Fe}\left(\mathrm{N}\left(\mathrm{SiMe}_{3}\right)_{2}\right)$ complexes in cyclotrimerization of phenylacetylene 104a to provide either $105 \mathrm{a}$ or $105 \mathbf{b}$, cluster 103 was employed as catalyst. Both the cluster and the parent compound, $\mathrm{Mn}(\mathrm{hmds})_{2}$ was found to be moderately active in the same reaction. While $\mathrm{Mn}(\mathrm{hmds})_{2}$ achieved $37 \%$ yield with a distribution of $\mathbf{1 0 5 a} / \mathbf{1 0 5} \mathbf{b}$ of $1.5: 1$, cluster $\mathbf{1 0 3}$ afforded $41 \%$ yield with the same product distribution.
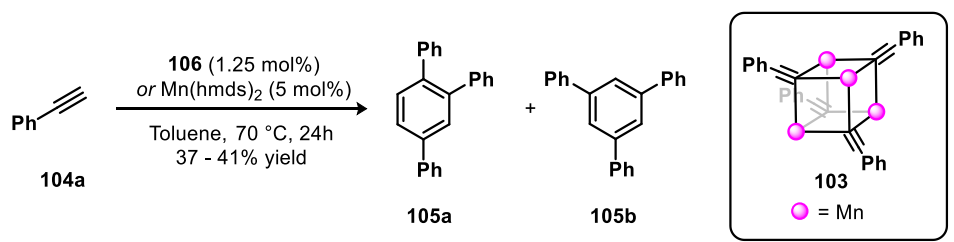

Scheme 31. Cyclotrimerization of 104a to either $105 \mathrm{a}$ or $105 \mathrm{~b}$ using cubane $\mathrm{Mn}_{4}$-Alkynyl cluster 103 as catalyst. Hmds ligands have been omitted for clarity, [140].

Further catalytic studies on $\mathbf{1 0 3}$ found that the cluster is active in the hydrogenation of alkenes, such as $\alpha$-methylstyrene 1b. Using $1.3 \mathrm{~mol} \%$ cluster in toluene at $70{ }^{\circ} \mathrm{C}$ under 5 bars pressure of $\mathrm{H}_{2}$ for 20 hours resulted in full hydrogenation. Interestingly, a significant difference between 103 and $\mathrm{Mn}(\mathrm{hmds})_{2}$ in the hydrogenation of 11a was observed. Whereas $\mathrm{Mn}(\mathrm{hmds})_{2}$ afforded full conversion, 103 afforded merely $30 \%$. 


\section{HETERONUCLEAR CLUSTERS IN CATALYSIS}

\subsection{Hydrogenation}

For the selective hydrogenation of COD (20), low valent heterometallic clusters were studied by Pittman and Braunstein, Table 19 [141]. All of the clusters 106 were moderately active as hydrogenation catalysts, however considerable amount of isomerization products were observed as well. To assess whether the ligand $\left(\mathrm{PEt}_{3} v s . \mathrm{PPh}_{3}\right)$ or the combination of metals was more influential on the activity, the clusters' activities were compared at $100{ }^{\circ} \mathrm{C}$. Of the group six metals, the Mo-PEt 3 clusters favored monohydrogenation over the $\mathrm{PPh}_{3}$ congeners. While the choice of group ten metal had a much less pronounce effect, the Pd-PEt $t_{3}$ clusters were in general more active. As such, the nature of phosphine ligand significantly affected the activity. At $100{ }^{\circ} \mathrm{C}$ and under approximately 14 bar of $\mathrm{H}_{2}$ in THF with a $0.12 \mathrm{~mol} \%$ catalyst loading, approximately $70 \%$ selectivity of the mono hydrogenated product was achieved using the $\left(\eta^{5}-\mathrm{Cp}\right)_{2} \mathrm{Pd}_{2}\left(\mu_{3}-\mathrm{CO}\right)_{2}(\mu-\mathrm{CO})_{4} \mathrm{Mo}_{2}\left(\mathrm{PEt}_{3}\right)_{2}$ cluster.

Table 19. Planar triangulated low valent heterometallic cluster used as selective hydrogenation catalyst of 20 using 106 as catalyst (precursor), [141].

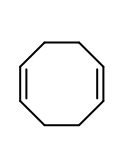

20

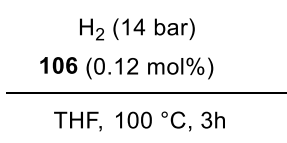

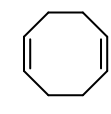

20

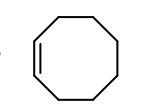

21

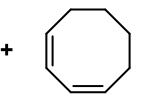

22a

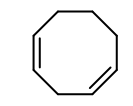

22b

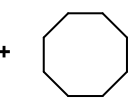

23

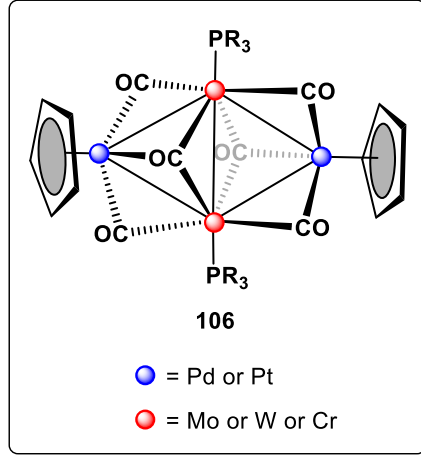

\begin{tabular}{cccccccc}
\hline \multirow{2}{*}{$\mathrm{M}$} & \multirow{2}{*}{ M' } & \multirow{2}{*}{ R } & \multicolumn{5}{c}{ Selectivity $[\%]$} \\
& & & $\mathbf{2 1}$ & $\mathbf{2 2}$ & $\mathbf{2 3 a}$ & $\mathbf{2 3 b}$ & $\mathbf{2 4}$ \\
\hline \multirow{2}{*}{$\mathrm{Pd}$} & \multirow{2}{*}{$\mathrm{W}$} & $\mathrm{Et}$ & 7.0 & 24.5 & 61.3 & 7.2 & trace \\
& & $\mathrm{Ph}$ & 7.7 & 4.4 & 79.0 & 7.9 & 1.0 \\
\hline \multirow{2}{*}{$\mathrm{Pd}$} & \multirow{2}{*}{$\mathrm{Mo}$} & $\mathrm{Et}$ & 2.6 & 70.4 & 23.7 & 3.0 & 0.4 \\
& & $\mathrm{Ph}$ & 12.9 & 22.2 & 51.1 & 13.0 & 0.7 \\
\hline \multirow{2}{*}{$\mathrm{Pt}$} & \multirow{2}{*}{$\mathrm{W}$} & $\mathrm{Et}$ & - & 18.7 & 77.7 & trace & 3.6 \\
& & $\mathrm{Ph}$ & - & 0.6 & 95.6 & trace & 3.8 \\
\hline \multirow{2}{*}{$\mathrm{Pt}$} & \multirow{2}{*}{$\mathrm{Mo}$} & $\mathrm{Et}$ & trace & 61.1 & 32.1 & - & 6.8 \\
& & $\mathrm{Ph}$ & 0.3 & 19.3 & 79.5 & trace & 0.9 \\
\hline $\mathrm{Pd}$ & $\mathrm{Cr}$ & $\mathrm{Et}$ & - & 15.7 & 83.8 & trace & 0.5 \\
\hline
\end{tabular}

Cluster mediated hydrogenation and isomerization of diolefins 107 were established by Sappa and Tiripicchio, using tetrahedral heterometallic clusters $\mathbf{1 0 8}$ comprising a triangular array of the group eight metals capped by a Ni-Cp unit, Table 20 [142, 143]. From the well-defined tetrahedral bimetallic osmium cluster, $\mathrm{CpNiOs}_{3}(\mu-\mathrm{H})_{3}(\mathrm{CO})_{9} \mathbf{1 0 8 O}_{\mathbf{s a}}$, the authors hypothesise a similar structure of the ruthenium congener, $\mathrm{CpNiRu}_{3}(\mu-\mathrm{H})_{3}(\mathrm{CO})_{9}$ 108Rua. While both 108Osa and 108Rua were found catalytically active, spectroscopic analysis established a poor stability of 108Rua, as decomposition was observed within 40 minutes. Fragmentation is further supported by comparing the amount of 1c found using 108Osa and 108Rua. While 108Osa provide up to $22 \%$ after 240 minutes, only $2 \%$ is found for the 108Rua within the first 30 minutes. The authors suggests the role of the capping group to provide a "trans-effect" that promotes the dissociation of $\mathrm{CO}$, as isomerization predominantly was observed as it was lost. Comparing the reactivity of $\mathrm{HRu}_{3}(\mathrm{CO})_{7}\left(\mu-\mathrm{PPh}_{3}\right)_{3}$ to $(\mathrm{Cp}) \mathrm{NiRu}_{3}(\mu-\mathrm{H})_{3}(\mathrm{CO})_{7}\left(\mathrm{PPh}_{3}\right)_{2} \mathbf{1 0 8 R} u \mathbf{d}$ a similar selectivity for isomerization is seen. 
Further insights were disclosed on changes in catalytic activity induced by various phosphine ligands, by substituting the tetrahedral bimetallic 108Ru and 108Os clusters [144]. The ruthenium clusters were again observed to decompose within the first 40 minutes. While monosubstituted $\mathrm{PPh}_{3}$ clusters, $(\mathrm{Cp}) \mathrm{NiRu}_{3}(\boldsymbol{\mu}-\mathrm{H})_{3}(\mathrm{CO})_{8}\left(\mathrm{PPh}_{3}\right) \mathbf{1 0 8} \boldsymbol{R} \boldsymbol{u b}$, were less active than $108 R u$ a, the doubly substituted clusters, such as $108 R \boldsymbol{u d}$, clusters generally demonstrate a higher turnover than the respective parent clusters. This observation led the authors to conclude that isomerization precedes hydrogenation. The lack of recovered degradation $\mathrm{Ru}_{3}(\mathrm{CO})_{12-\mathrm{n}} \mathrm{L}_{\mathrm{n}}$ products from the reaction mixture supports catalysis by an intact $\left[\mathrm{Ru}_{3}\right]$-cluster framework. Moreover, the phosphine is suggested to lower hydride acidity rather than promoting the dissociation of $\mathrm{CO}$ ligands.

Table 20. Hydrogenation of pent-1,4-diene using Ni-Cp faced-capped clusters. Terminal CO molecules have been omitted for clarity, [142-144].

\begin{tabular}{|c|c|c|c|c|c|c|c|c|c|}
\hline $107 a$ & 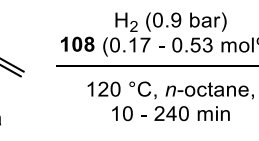 & $\nearrow$ & C & $\overbrace{1 \mathrm{c}}^{+}$ & $\begin{array}{c}\text { 2-pente } \\
1\end{array}$ & & O7b & & \\
\hline & 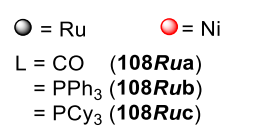 & $\begin{aligned} \mathrm{O} & =\mathrm{Os} \\
\mathrm{L} & =\mathrm{CO} \\
& =\mathrm{PPh}_{3}(1 \\
& =\mathrm{PCy}_{3}(\end{aligned}$ & $\begin{array}{l}\text { 8Osa) } \\
80 s b) \\
80 s c)\end{array}$ & & & & & & \\
\hline \multirow{2}{*}{ Cluster } & \multirow{2}{*}{\multicolumn{2}{|c|}{$\begin{array}{c}\text { Catalyst loading } \\
{[\mathrm{mol} \%]}\end{array}$}} & \multirow{2}{*}{$\begin{array}{l}\text { Time } \\
{[\mathrm{min}]}\end{array}$} & \multicolumn{5}{|c|}{ Composition [\%] } & \multirow{2}{*}{ TON } \\
\hline & & & & Unreacted & $17 b$ & $1 c$ & 1 & $107 b$ & \\
\hline \multirow{3}{*}{$\mathrm{HRu}_{3}(\mathrm{CO})_{7}\left(\mu-\mathrm{PPh}_{3}\right)_{3}$} & & & 10 & 93 & - & 3 & - & 4 & 39 \\
\hline & & 0.20 & 20 & 82 & trace & 4 & - & 15 & 95 \\
\hline & & & 40 & 53 & 1 & 14 & - & 32 & 240 \\
\hline \multirow{3}{*}{ 108Rua } & & & 10 & 98 & - & 0 & - & 2 & 12 \\
\hline & & 0.37 & 20 & 95 & 1 & 1 & - & 3 & 27 \\
\hline & & & 30 & 91 & 1 & 2 & - & 5 & 42 \\
\hline \multirow{4}{*}{$108 R u b$} & & \multirow{4}{*}{0.22} & 10 & 100 & - & trace & - & - & 1 \\
\hline & & & 20 & 98 & - & trace & - & 2 & 9 \\
\hline & & & 30 & 91 & - & 2 & - & 6 & 39 \\
\hline & & & 40 & 90 & - & 4 & - & 8 & 54 \\
\hline \multirow{4}{*}{ 108Rud } & & \multirow{4}{*}{0.18} & 10 & 91 & trace & 1 & - & 8 & 52 \\
\hline & & & 20 & 62 & 0 & 4 & - & 35 & 215 \\
\hline & & & 30 & 40 & 0 & 6 & - & 54 & 337 \\
\hline & & & 40 & 36 & 0 & 8 & - & 55 & 356 \\
\hline \multirow{3}{*}{ 108Ruc } & & & 10 & 64 & 0 & 3 & - & 32 & 130 \\
\hline & & 0.28 & 20 & 54 & 0 & 9 & - & 37 & 167 \\
\hline & & & 40 & 49 & 0 & 11 & - & 40 & 184 \\
\hline \multirow{3}{*}{$1080 s a$} & & & 60 & 79 & 0 & 6 & 15 & - & 79 \\
\hline & & 0.53 & 120 & 68 & 5 & 21 & 7 & - & 68 \\
\hline & & & 240 & 71 & 3 & 22 & 3 & - & 71 \\
\hline \multirow{3}{*}{$1080 \mathrm{sb}$} & & & 60 & 94 & trace & 1 & - & 6 & 36 \\
\hline & & 0.17 & 120 & 92 & trace & 1 & - & 7 & 45 \\
\hline & & & 240 & 87 & 1 & 5 & - & 7 & 74 \\
\hline \multirow{3}{*}{$1080 \mathrm{sb}$} & & & 60 & 94 & 0 & 1 & - & 5 & 33 \\
\hline & & 0.17 & 120 & 86 & 1 & 2 & - & 11 & 79 \\
\hline & & & 240 & 68 & 2 & 4 & - & 26 & 186 \\
\hline
\end{tabular}


Concluding their studies on hydrogenation and isomerization of (cyclic) dienes, the combined findings are summarized by the authors who suggest a catalytic cycle shown in Scheme 32. Either [ $\left.\mathrm{NiRu}_{3}\right]$ or $\left[\mathrm{NiOs}_{3}\right]$ act in the cycle that initially work by ligand substitution of a terminally bound ligand $\mathbf{L}$ from 108 with $107 \mathrm{c}$ leading to $\mathbf{1 0 8 d}$. Substitution is followed by either of two pathways. Loss of the CpNi unit results in cluster degradation forming $\mathbf{1 0 8 e}$ and cluster-mediated isomerization products, whereas hydride insertion results in a vacant site (108f), which permit for oxidation addition of $\mathrm{H}_{2}$, followed by reductive elimination. This step generates product $\mathbf{1}$ and cluster $\mathbf{1 0 8 g}$, which undergoes ligand association by either $\mathbf{L}$ or $\mathbf{1 0 7}$, thus closing the cycle.

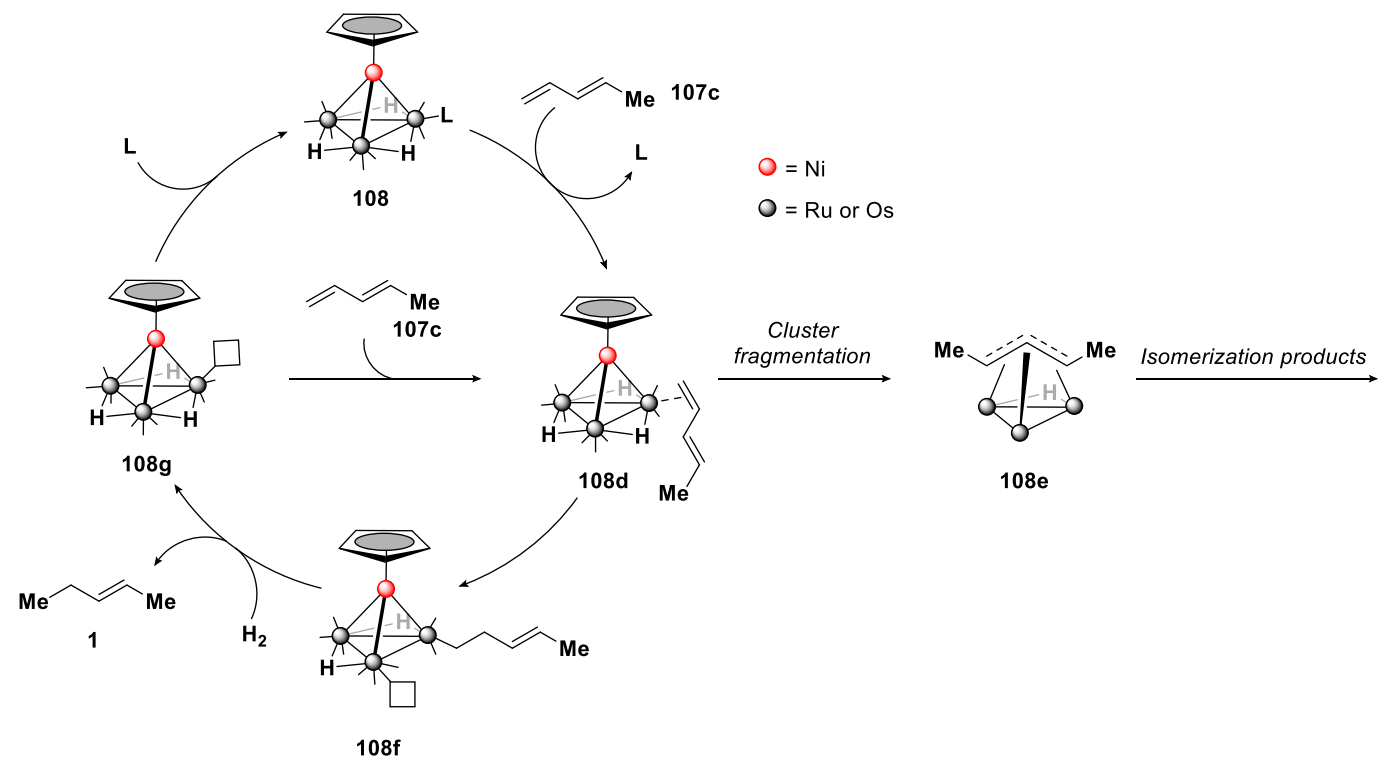

Scheme 32. Catalytic scheme for the selective hydrogenation of $\mathbf{1 0 7}$ in presence of $\mathbf{1 0 8}$ as proposed by Sappa and Tiripicchio. Fragmentation of the cluster results in isomerization products. Terminal CO molecules have been omitted for clarity, [142-144].

Hydrogenation of 103a was demonstrated by Pittman and Braunstein by employing the same triangulated planar clusters 106 as in Table 19 to selectively afford partial hydrogenation of 103a to styrene 1d [141]. Of the various combinations, the use of $\left(\eta^{5}-\mathrm{Cp}\right)_{2} \mathrm{Pt}_{2}\left(\mu_{3}-\mathrm{CO}\right)_{2}(\mu-\mathrm{CO})_{4} \mathrm{Mo}_{2}\left(\mathrm{PEt}_{3}\right)_{2}$ achieved $99 \%$ selectivity at $60{ }^{\circ} \mathrm{C}$ under approximately 14 bar of $\mathrm{H}_{2}$. Hydrogenation of $n$-hexyne 103b demonstrated that terminal alkyl alkynes readily hydrogenated to the corresponding alkene as well.

A mixed-metal Ru-Pt cluster $109, \mathrm{Pt}_{3} \mathrm{Ru}_{6}(\mathrm{CO})_{20}\left(\mu_{3}-\mathrm{PhC}{ }_{2} \mathrm{Ph}\right)\left(\mu_{3}-\mathrm{H}\right)(\mu-\mathrm{H})$, was prepared by Adams as a catalyst precursor for the selective partial hydrogenation of 11a [145]. To assess ligand exchange, and to provide evidence in support of cluster catalysis, 109 as well as the ditolylacetylene homologue 110, $\mathrm{Pt}_{3} \mathrm{Ru}_{6}(\mathrm{CO})_{20}\left(\mu_{3}-\mathrm{TolC}_{2} \mathrm{Tol}\right)\left(\mu_{3}-\mathrm{H}\right)(\mu$ $\mathrm{H}$ ), were used in labelling studies, that demonstrated incorporation of reagents [146]. Additionally, kinetic studies revealed first order rate-dependence with respect to cluster concentration, whereas $\mathrm{CO}$ had an inverse first order dependence. Further kinetic studies of appropriate (fragmentation) species afforded TOF values of insufficient magnitude (up to $3 \mathrm{~h}^{-1}$ vs up to $82.4 \mathrm{~h}^{-1}$ for 109). Thus, the empirically derived activation parameters suggest cluster catalysis. Similar results with respect to rate order dependency, as well as labelling studies, were observed when using 109 as catalyst precursor for the hydrosilylation of 11a [147].

To ascertain the active site for the transformation, and to account for the interplay between Ru-Pt, a homologue of 109 containing the labile ligand $\mathrm{Me}_{2} \mathrm{~S}$ was used for the partial hydrogenation of 11a [148]. The initial reaction rate (20 min) was three times as large using this homologue, which the authors argue is a result of more facile ligand dissociation. In spite of the high catalytic activity, the cluster interconverts back to 109 under the reaction conditions, which precluded a detailed kinetic account. The authors conclude that the transformation of both $\mathrm{H}_{2}$ and 11a necessarily must take place at the $\mathrm{Ru}_{3}$-triangle, with a tentative explanation that the $\mathrm{Ru}$-Pt interaction originates in an electron donation from the latter transition metal. Thus, a catalytic transformation of 11a is proposed to follow the 
mechanism shown in Scheme 33. The initial step proceeds via ligand (CO) dissociation resulting in an electronically unsaturated species with a vacant coordination site (109a), which then undergoes oxidative addition of $\mathrm{H}_{2}$ to provide 109b. A $\mu_{3}$-bridging $\mathrm{H}$ is argued based on structures of related fragments, and the subsequent interaction to 11a at the free ruthenium triangle promotes the formation of a C-H bond from the hydride and the originally coordinated alkyne. The resulting vinyl ligand, with cis-positioned phenyl groups, then becomes triply coordinated to the cluster (109c), that further promote a hydride transfer to form the cis-12a. Moreover, steric encumbering was found to favor product dissociation. The authors note that at a high substrate loading and after several catalytic cycles, fragmentation and alkene adducts play a significant role in the loss of catalytic activity.
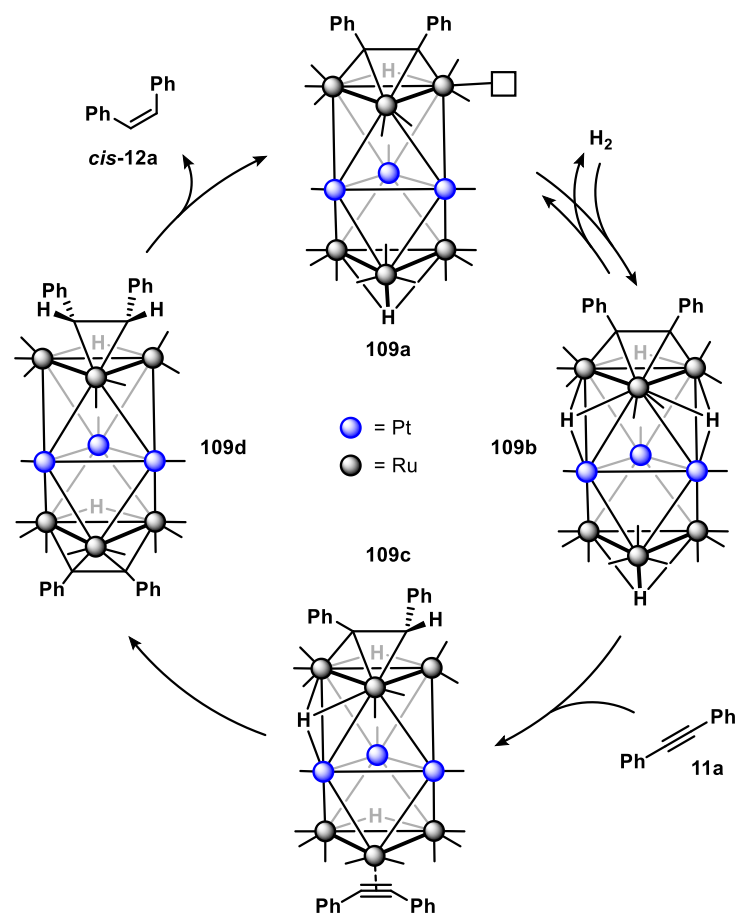

Scheme 33. Catalytic scheme for hydrogenation of 11a by a formation of a vacant coordination site, followed by formation of two triply bridging hydrides as proposed by Adams. Coordination of 11a to the unencumbered ruthenium triangle promotes insertion of one hydride to the originally coordinated alkyne. Terminal $\mathrm{CO}$ molecules have been omitted for clarity, [148].

Further insight on the Ru-Pt interaction was provided using the mixed-metal hexanuclear cluster 111, $\mathrm{Ru}_{5}(\mathrm{CO})_{14}(\mu-\mathrm{H})_{2}\left(\mu_{6}-\mathrm{C}\right)\left[\mathrm{Pt}\left(\mathrm{P}^{t} \mathrm{Bu}_{3}\right)\right]$, demonstrating that the $\mathrm{Pt}$ was involved in activation of hydrogen and 103a [14]. The hexanuclear $\left[\mathrm{Ru}_{5} \mathrm{Pt}\right]$ was found in an equilibrium with the open structure 111a, Scheme 34. Treatment of 111 with 103a at $40{ }^{\circ} \mathrm{C}$ resulted in a platinum-capped square-pyramidal pentaruthenium cluster, with the alkyne bridging a $\mathrm{PtRu}_{2}$ triangle 111b. Subsequent treatment with $\mathrm{H}_{2}$ at elevated temperature $\left(80^{\circ} \mathrm{C}\right)$ regenerated 111 along with the production of $\mathbf{1 d}$. Overall, the TOF was $20 \mathrm{~h}^{-1}$. 


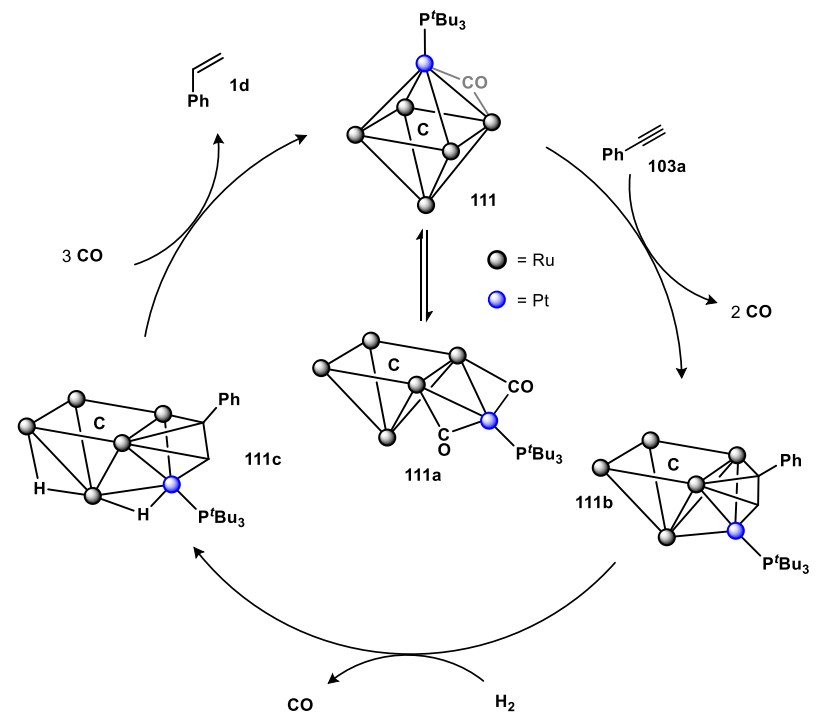

Scheme 34. Probing the role Pt plays in transformation of alkynes in the related layer segregated Ru-Pt cluster, Adams prepared a hexanuclear Ru-Pt compound, in which Pt is connected to substrate activation rather than an extended ligand. Terminal CO molecules have been omitted for clarity, [14].

\subsection{Carbonylation}

Echavarren studied a series of polynuclear gold clusters, of which the pentabimetallic $\mathrm{Au}_{4}{ }^{\mathrm{I}} \mathrm{Ag}^{\mathrm{I}}$ cluster 112 was found to catalyze carbonylation of various primary amines $\mathbf{4 2}$ to ureas $\mathbf{1 1 3}$ with up to $99 \%$ yield [149]. In support of cluster catalysis, $\mathbf{1 1 2}$ was recovered and reused, which afforded a yield of 73\%. In addition, the lack of an induction period suggests that catalysis is taking place in the homogeneous phase. Conducting a $\mathrm{Hg}(0)$ poisoning test was precluded as the mercury reacted with 112. From the optimized reaction conditions, a broad scope of $\mathbf{4 2}$, including sterically demanding examples, were carbonylated to the corresponding urea compounds 113, Table 21.

Table 21. Catalytic carbonylation of primary amines using $\mathrm{Au}_{4}{ }^{\mathrm{I}} \mathrm{Ag}^{\mathrm{I}}$ cluster, [149].

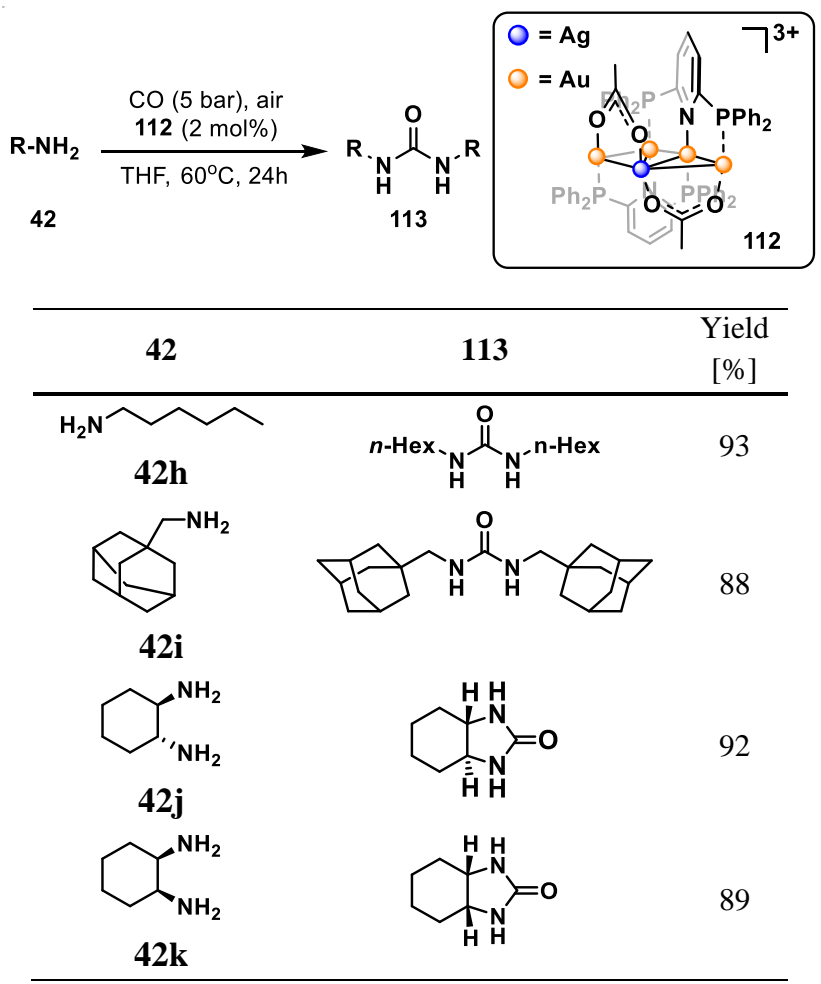

P. $\mathbf{3 8}$ of $\mathbf{5 2}$ 


\section{Hydroformylation}

Pittmann and Braunstein found that two different clusters containing Co and Pt, a triangular (114) and a butterfly cluster (115), respectively, Table 22, was active in hydroformylation of $n$-pentene (1c) to mixture of $\boldsymbol{n - 5 7 b}$ and iso-57b [141]. The chemical nature of the coordinating atoms in the chelating ligand was found to significantly influence the activity of 114. Comparing the reactivities between complexes of dppe, $\mathrm{Ph}_{2} \mathrm{P}\left(\mathrm{CH}_{2}\right)_{2} \mathrm{PPh}_{2}(\mathbf{1 1 4 P})$, and dpae, $\mathrm{Ph}_{2} \mathrm{As}\left(\mathrm{CH}_{2}\right)_{2} \mathrm{AsPh}_{2}(\mathbf{1 1 4 A s})$, ligated clusters respectively, showed that whereas 114As was inactive, 114P afforded a yield of approximately $39 \%$ at $80{ }^{\circ} \mathrm{C}(n / i s o=3.7: 1)$. The authors suggest the reactivity difference to origin from retention of cluster integrity, of which only dppe aids towards this, based on the amount of recovered compound. Using $0.11 \mathrm{~mol} \%$ catalyst loading of $\mathbf{1 1 5}$ provided 85\% conversion with a predominantly linear selectivity $(n / i s o=$ $4: 1)$ at $100{ }^{\circ} \mathrm{C}$.

Table 22. Triangular (114) and butterfly (115) PtCo mixed-metal complexes as catalysts for the hydroformylation of 1c to mixtures of $\boldsymbol{n - 5 7 b}$ and $\boldsymbol{i s o - 5 7 b}$. Terminal CO molecules have been omitted for clarity, [141].

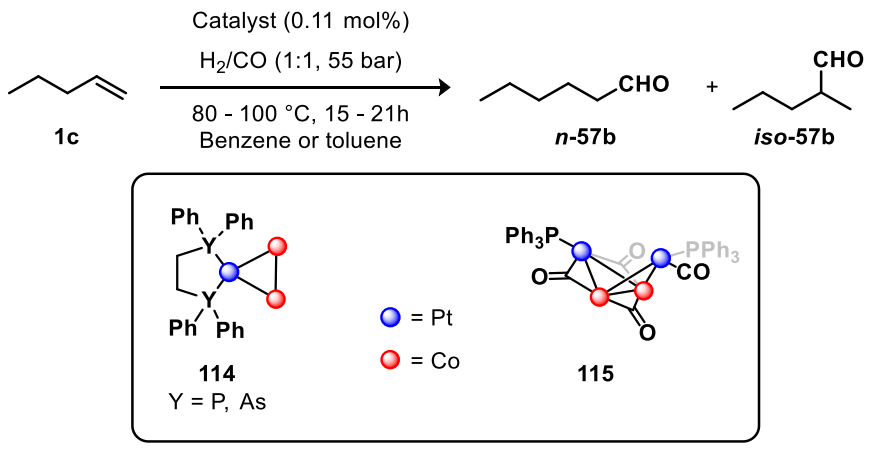

\begin{tabular}{cccccc}
\hline Catalyst & $\begin{array}{c}\text { Temperature } \\
{\left[{ }^{\circ} \mathrm{C}\right]}\end{array}$ & $\begin{array}{c}\text { Time } \\
{[\mathrm{h}]}\end{array}$ & $\begin{array}{c}\text { Conversion } \\
{[\%]}\end{array}$ & $\begin{array}{c}\text { Yield }[\%] \\
\mathbf{n - 5 7 b}\end{array}$ & iso-57b \\
\hline $\mathbf{1 1 4 P}$ & 80 & 21 & 39 & 3.7 & 8.2 \\
$\mathbf{1 1 4 A s}$ & 80 & 22 & 0 & - & \\
$\mathbf{1 1 5}$ & 62 & 17 & trace & trace & trace \\
& 75 & 18 & 16.5 & 14 & 2.5 \\
& 100 & 17 & 85.4 & 63.5 & 14.6 \\
& & & & $(+7.3 \% 1-$-hexanol $)$ & \\
\hline
\end{tabular}

To investigate the postulate that polydentate $\mu_{3}$-ligands suppress cluster fragmentation, whilst accommodating M-M bond rupture to facilitate (catalytic) transformations, a series of face-capped triangular mixed-metal clusters 116-121, Table 23, were prepared by Pittman for the catalytic hydroformylation of $\mathbf{1 c}$ to mixtures of $\boldsymbol{n - 5 7 b}$ and iso-57b [150]. Under the conditions for transformation of 1c, isomerization competition was observed. Most notably for the clusters 116, 119, and 121. While cluster 116 initially (7h) catalyze the hydroformylation of $1 \mathrm{c}$, extending the reaction time (24h) significantly lowers the selectivity, due to hydroformylation of the 2-pentenes (1). Fragmentation was suspected for $\mathbf{1 2 1}$ and, as such, its activity was compared to that of $\mathrm{Co}_{2}(\mathrm{CO})_{10}$. Interestingly, they showed nearly identical activities, thereby indeed indicating a fragmentation of $\mathbf{1 2 1}$ to a lower nuclearity complex. Moreover, the authors conclude cluster mediated catalysis for clusters $\mathbf{1 1 6}$ through $\mathbf{1 2 0}$ based on a lack of evidence supporting the presence of lower nuclearity species, as well as the amount of recovered cluster (>90\% yield). Finally, the transformation is suggested to proceed via a metal-metal bond cleavage, and the $\mu_{3}$-ligand likely works to retain cluster integrity throughout the catalytic cycle. 
Table 23. Tetrahedral clusters with $\mu_{3}$-briding ligands 116-121, investigated by Pittman as catalyst (precursors) for the hydroformylation of $\mathbf{1 c}$ to mixtures of $\boldsymbol{n - 5 7 b}$ and $\boldsymbol{i s} \mathbf{o - 5 7} \mathbf{5}$. Terminal CO molecules have been omitted for clarity, [150].

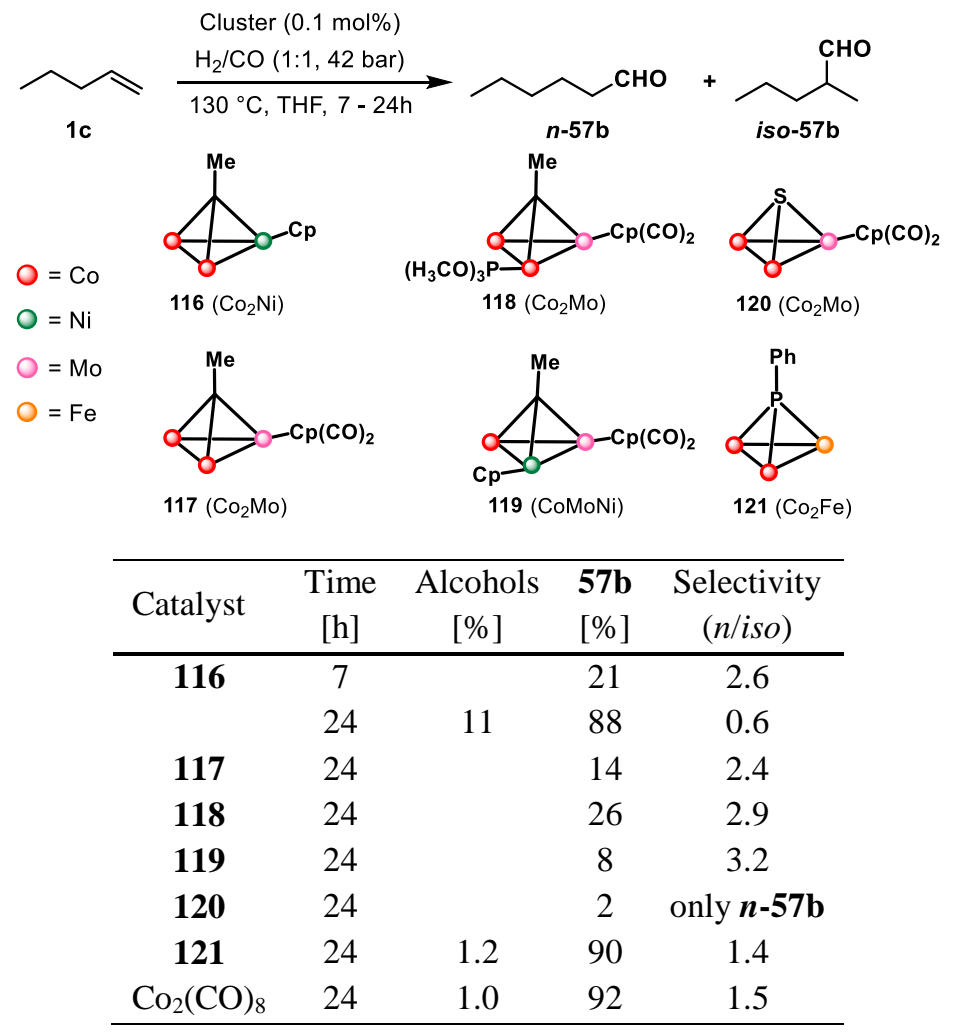

Gervais and Kalck observed that the heterometallic $d^{0}-d^{8}\left[\mathrm{ZrRh}_{2}\right]$ cluster $122\left(\eta^{5}-\mathrm{Cp}\right)_{2} \mathrm{Zr}\left(\mathrm{CH}_{2} \mathrm{PPh}_{2}\right)_{2} \mathrm{Rh}_{2}(\mu$ $\left.\mathrm{S}^{\prime} \mathrm{Bu}\right)_{2}(\mathrm{CO})_{2}$ afforded catalytic hydroformylation of 1a, under mild reaction conditions $[151,152]$. Approximately

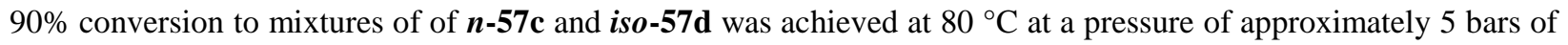
$\mathrm{H}_{2} / \mathrm{CO}(1: 1)$, with predominantly linear selectivity $(n / i s o=2: 1)$, Table 24. The authors speculate that the role of $\mathrm{Zr}$ is to act as an electron reservoir. Choukroun provided further insight on the role of $\mathrm{Zr}$ by introducing sterically encumbered zirconocene substituents at the cyclopentadienyl group [153,154]. Single-crystal X-ray diffraction of the ${ }^{t} \mathrm{Bu}$ homologue of $\mathbf{1 2 2}$ revealed a disruption of the $\mathrm{Zr}-\mathrm{S}$ interactions, consequently changing the coordination environment of $\mathrm{Zr}$ from a pentacoordinate to that of pseudo-tetrahedron. However, the role of $\mathrm{Zr}$ is in large suggested to ensure that the Rh-centres remain vicinal thereby warranting a cooperativity between the two Rh-centers. 
Table 24. Hydroformylation of $1 \mathrm{a}$ to mixtures of $\boldsymbol{n - 5 7 c}$ and iso-57d using the trinuclear bimetallic cluster 122 as catalyst (precursor), $[153,154]$.

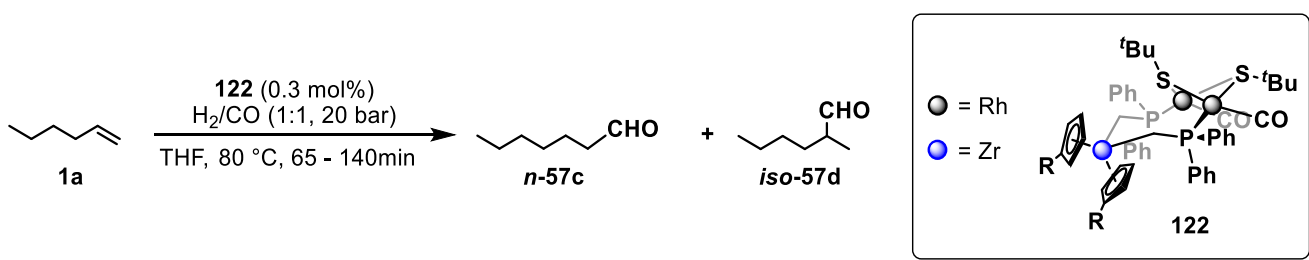

\begin{tabular}{cccc}
\hline $\mathrm{R}$ & $\begin{array}{c}\text { Time } \\
{[\mathrm{min}]}\end{array}$ & $\begin{array}{c}\text { Conversion } \\
{[\%]}\end{array}$ & $\begin{array}{c}\text { Selectivity } \\
(\text { n/iso })\end{array}$ \\
\hline $\mathrm{H}$ & 65 & 56 & 2.1 \\
& 115 & 96 & 2.0 \\
${ }^{t} \mathrm{Bu}$ & 70 & 38 & 2.2 \\
& 140 & 97 & 1.8 \\
\hline
\end{tabular}

Similarly, Ciriano, Oro and Claver provided insight on cluster compounds 123 comprising the early transition metal titanium and late transition metal rhodium, [TiRh 3 , in the hydroformylation of $\mathbf{1 a}$ and $\mathbf{1 d ~ [ 1 5 5 ] . ~ P r o b i n g ~} \mathbf{1 2 3}$ with monodentate phosphine and phosphites, the authors were able to ascertain the active catalyst to exist in an equilibrium between a bis- (123a) and a tris ligated (123b and 123c) compound type, as shown in Scheme 35. A previous study by Ciriano and Oro on the iridium homologue further corroborated this equilibrium [156]. Thus, using $0.5 \mathrm{~mol} \%$ of precatalyst $\mathbf{1 2 3}$ at $80{ }^{\circ} \mathrm{C}$ under approximately 5 bar of $\mathrm{H}_{2} / \mathrm{CO}(1: 1)$ in toluene with $\mathrm{PPh}_{3}$ in a $\mathrm{P} / \mathrm{Rh}$ ratio of four, 1a was converted in $96 \%$ to $\mathbf{5 7 c}$ with a predominantly linear selectivity of $78 \%$. On the contrary, $88 \%$ conversion of $\mathbf{1 d}$ to 57d was achieved, at a slightly higher pressure of approximately 30 bar in THF, with an interestingly iso-selectivity of $89 \%$.

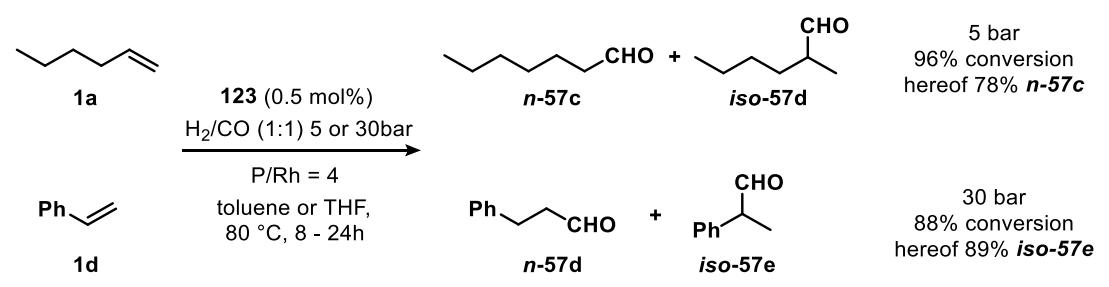

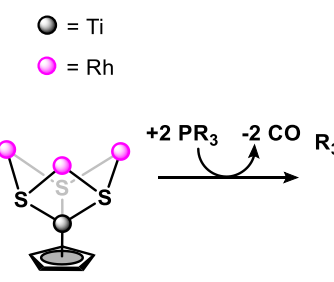

123

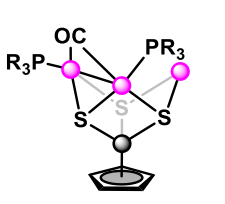

123a

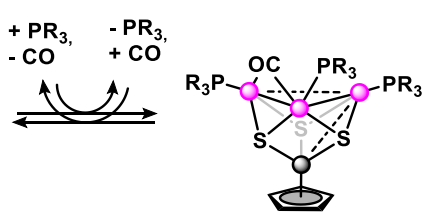

$123 b$

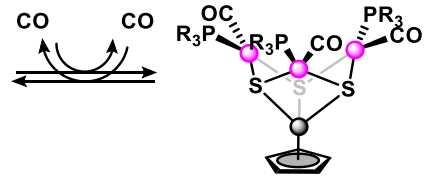

$123 c$

Scheme 35. Hydroformylation of $1 \mathrm{a}$ to mixtures of $\boldsymbol{n - 5 7 \mathrm { c }}$ and iso-57d as well as of $1 \mathrm{~d}$ to mixtures of $\boldsymbol{n - 5 7 d}$ and iso57e using 123 as catalyst precursor. Terminal CO molecules have been omitted for clarity, [156].

Haupt investigated the synergism between $\mathrm{Rh}$ and $\mathrm{Mn}$ as well as between $\mathrm{Rh}$ and $\mathrm{Re},\left[\mathrm{M}_{2} \mathrm{Rh}(\mu-\mathrm{PCy})-(\mu-\mathrm{CO})_{2}(\mathrm{CO})_{8}\right.$, $\mathrm{M}=\operatorname{Re}(124 R e), M n(124 M n)]$, Table 25, for the hydroformylation of 1a [157]. The Rh-Mn cluster 124Mn was found to catalyze isomerization to $\mathbf{1 e}$ and $\mathbf{1 f}$ with predominantly trans-selectivity with TOF values of up to $473 \mathrm{~h}^{-1}$. 
On the contrary, the Rh-Re complex $124 R e$ achieved hydroformylation to 57c with TOF values of up to $246 \mathrm{~h}^{-1}$ with predominantly linear selectivity $(n / i s o=3.4)$.

Table 25. Triangular mixed-metal $\mathrm{RhM}_{2}, \mathrm{M}=\mathrm{Mn}(\mathbf{1 2 4 M n})$ and $\mathrm{Re}(\mathbf{1 2 4 R e})$ as catalysts for the hydroformylation of 1a to mixtures of $\boldsymbol{n - 5 7 c}$, iso-57d, 1e, and 1f. Terminal CO molecules have been omitted for clarity, [157].

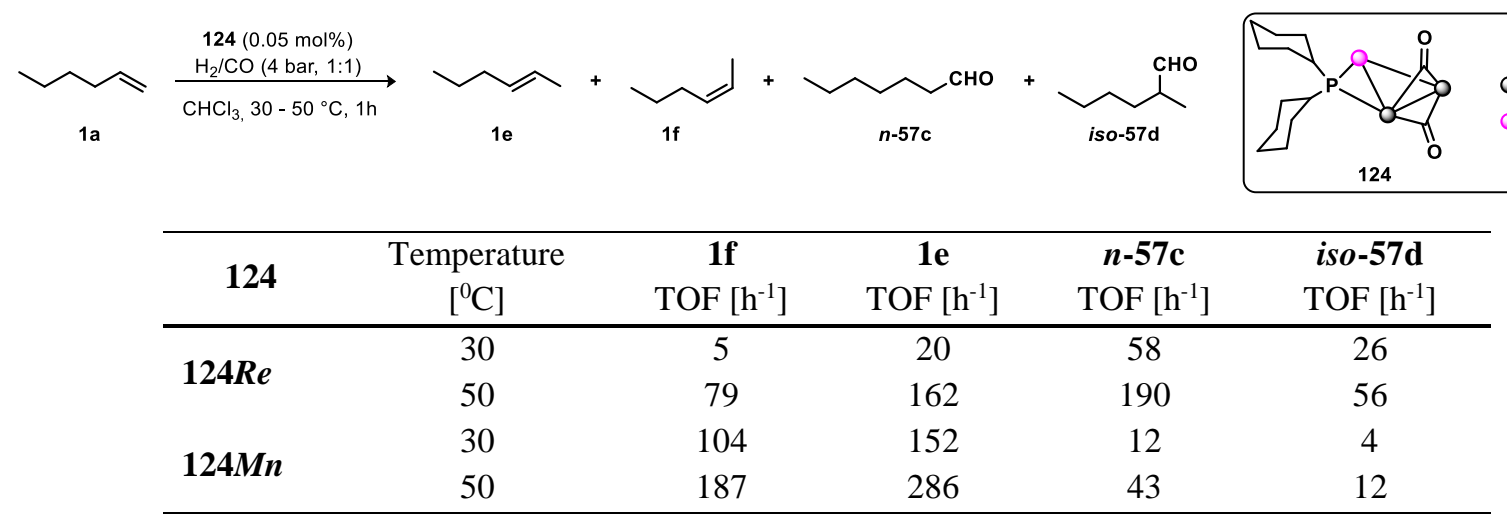

\subsection{Miscellaneous}

\section{Hydrosilylation}

As previously discussed by Pittman, the use of non-fluxional ligands in metal-carbonyl clusters, such as the face capping $\mu_{3}$-ligands used in Table 23, serve to inhibit cluster fragmentation under thermal catalysis. Pittman and Vahrenkamp present evidence to support this proposal by using such $\mu_{3}$-ligated clusters as catalyst precursors in the photoinitiated reaction between $\mathrm{Et}_{3} \mathrm{SiH}$ and acetophenone (35a) leading to either hydrosilylation (125) or Mukaiyama silyl enol ether formation (126) [158]. In the absence of both 121 and irradiation ( $\lambda=254$ or 355 nm) no reaction was observed, and the amount of recovered 121 after photolysis was up to $98 \%$. A higher quantum yield was observed using irradiation at $254 \mathrm{~nm}$, which is discussed in relation to a possible mechanism invoking loss of a CO ligand. Whereas high-energy irradiation results in a metal-ligand charge transfer that consequently destabilizes the M-CO bonds, low energy light merely results in M-M bond cleavage that readily reform, Scheme 36.

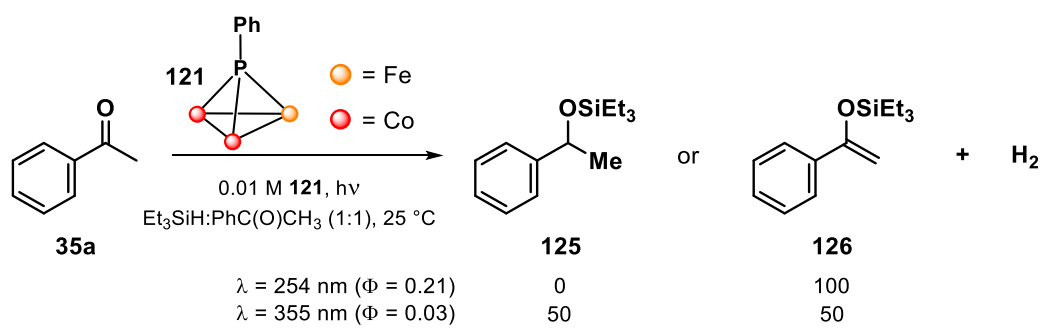

Scheme 36. Photoinitiated catalytic (dehydrogenative) silylation of 35a leading to 125 or 126 using 121 as catalyst. Terminal CO molecules have been omitted for clarity, [158].

\section{Dehydrogenation reactions}

Shapley investigated the activity of a trinuclear bimetallic cluster 127 complex comprising Ru and the group ten metals, (dppe)M $\left(\mu_{3}-\mathrm{S}\right)_{2}\left\{\mathrm{Ru}(\mathrm{N}) \mathrm{Me}_{2}\right\}_{2}, \mathrm{M}=\mathrm{Ni}(\mathbf{1 2 7 N i}), \mathrm{Pd}(\mathbf{1 2 7 P d})$, and Pt (127Pt), for the dehydrogenation of $65 \mathrm{f}$ to 44, Table 26 [19]. A bond length variance of approximately $0.2 \AA$ between $\mathrm{Ni}$ and Ru centers was observed in $\mathbf{1 2 7 N i}$, of which the shorter distance ( $2.9 \AA)$ was suggested by the authors to stem from a two-electron interaction from Ru to $\mathrm{Ni}$. This is rationalized based on the relative small HOMO-LUMO gap between Ni and Ru. On the contrary, the Pt-Ru bonds were both found to be equidistant (3.16 $\AA$ ) in 127Pt [159]. Comparing the activity of 127Pt cluster at 18.8 and 44 bars pressures of $\mathrm{O}_{2}$, respectively, the authors established that an increase in $\mathrm{O}_{2}$ pressure does not increase the oxidation rate. This observation is suggested to be due to that $\mathrm{O}_{2}$ and $\mathbf{6 5 f}$ likely compete between the same binding sites at the cluster. Additionally, an increase in the concentration of $\mathrm{O}_{2}$ lowers the $\mathrm{CO}_{2}$ and thus the cluster solubility. 
While 127Ni demonstrates a direct metal-metal interaction, its effect on catalytic activity is not addressed. The conversion difference of approximately $20 \%$ (in toluene) is also not addressed in detail, [19].

Table 26. Catalytic dehydrogenation of $65 \mathrm{f}$ leading to 44 employing hetero-trinuclear cluster 127 as catalyst. $\mathrm{scCO}_{2}$ denote supercritical $\mathrm{CO}_{2}[19]$.

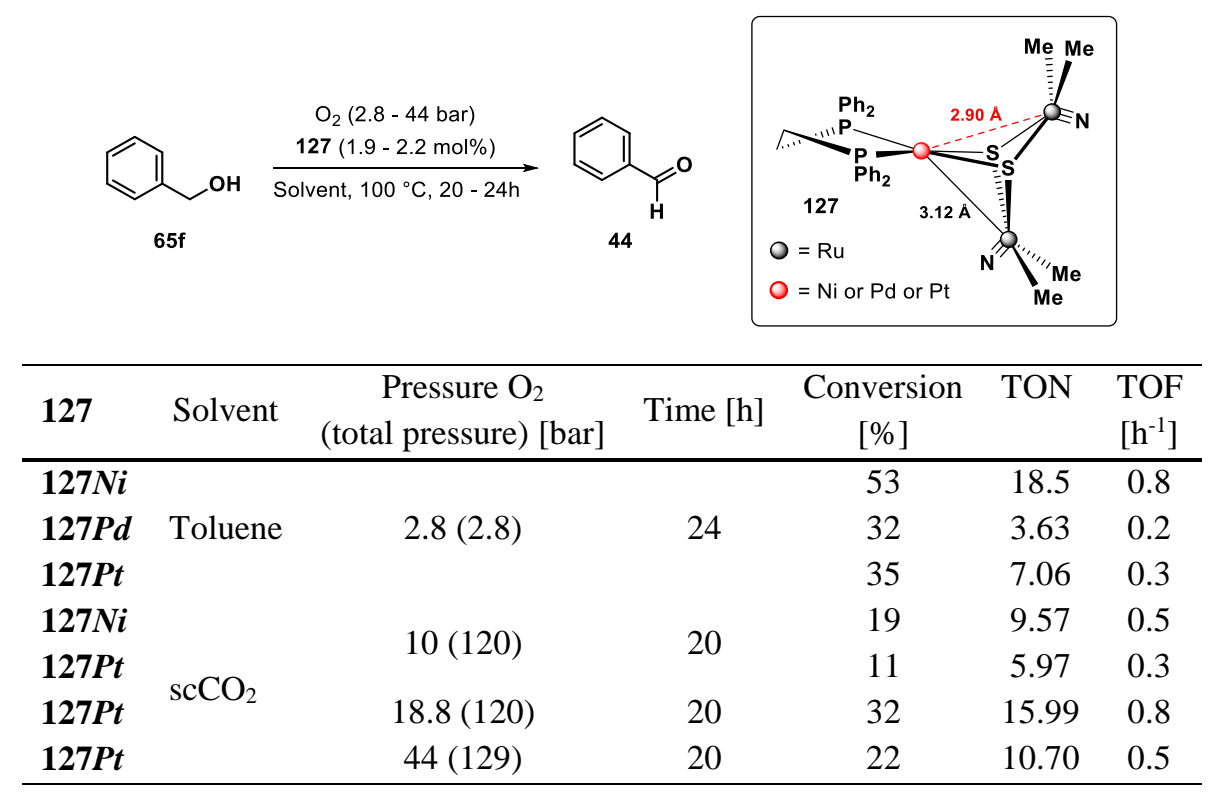

Takao studied the homologue series of triangular trimetallic clusters comprising the group nine metals and $\mathrm{Ru}$, $\mathrm{Ru}_{2} \mathrm{M}(\mu-\mathrm{H})_{3}\left(\mu_{3}-\mathrm{H}\right)\left(\eta^{5}-\mathrm{Cp}\right)_{3}, \mathrm{M}=\mathrm{Co}(\mathbf{1 2 8 C \boldsymbol { o }}), \mathrm{Rh}(\mathbf{1 2 8 R \boldsymbol { h }})$ and Ir (128Ir), for the dehydrogenative coupling of 4substituted pyridines 96 to bipyridines 97, Table 27 [160]. Compared to the all ruthenium cluster 45, a significant increase in TOF (3h) (from $0.1 \mathrm{~h}^{-1}$ to $0.3 \mathrm{~h}^{-1}$ ) was achieved by substituting one Ru-atom for Co. Interestingly, poor to

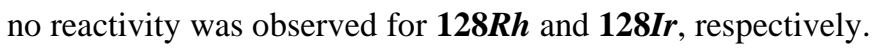

Analysis of the intermediate 128Coa was indicative of an electron transfer from the Co center to the ligand forming monoanioic dmbpy ${ }^{\bullet}$ species, which was supported by spin-density DFT calculation demonstrating a negative value residing at the ligand, and positive values at the Co-center. As such, the Co is suggested to be in oxidation state 2+, adopting a d $\mathrm{d}^{7}$ electron configuration. Evan's method was used to determine a $\mu_{\text {eff }}(297.7 \mathrm{~K})$ of $2.5 \mu_{\mathrm{B}}$, consistent with a triplet state of $128 \mathrm{Coa}$. For unsubstituted bipyridines, the lower LUMO energy level hampers the electron-transfer. Treatment of 128Coa with pyridine demonstrated a facile ligand dissociation of dmbpy, Scheme 37. Prior to dissociation of dmbpy, electron transfer from the dmbpy ${ }^{\bullet-}$ species to the $\mathrm{Co}^{2+}$ is required.

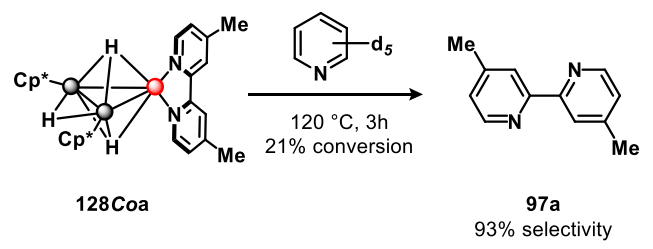

Scheme 37. Release of dmbpy ligand from 128Coa by substitution with pyridine, [160].

Using a $5 \mathrm{~mol} \%$ catalyst loading in heptane at $140-180{ }^{\circ} \mathrm{C}$ for 3 days afforded up to $87 \%$ yield. To support cluster catalysis, the authors monitored the reaction by ${ }^{1} \mathrm{H}$ NMR to analyze the reaction products. In addition, a key intermediate was structurally characterized using single-crystal X-ray diffraction, showing cobalt coordinated in a chelating-fashion by the bipyridine adduct. Moreover, 128Co was completely converted at the end of the reaction, and 
loss of catalytic activity stem from fragmentation to mononuclear species, which the authors found to be catalytically inert.

Table 27. Catalytic dehydrogenation of 96 to 97 using $128 C o$ as catalyst, [160].

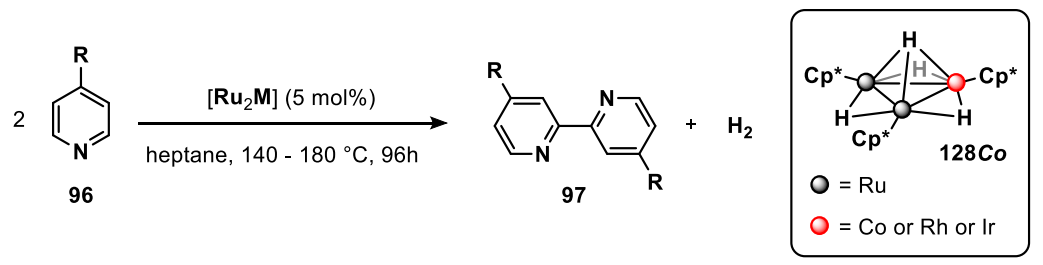

\begin{tabular}{llcc}
\hline $\mathrm{Ru}_{2} \mathrm{M}$ & \multicolumn{1}{c}{$\mathrm{R}$} & $\begin{array}{c}\text { Temperature } \\
{\left[{ }^{\circ} \mathrm{C}\right]}\end{array}$ & $\begin{array}{c}\text { Yield } \\
{[\%]}\end{array}$ \\
\hline $\mathrm{Ir}$ & $\mathrm{Me}$ & 180 & Trace \\
$\mathrm{Rh}$ & $\mathrm{Me}$ & 180 & 16 \\
$\mathrm{Co}$ & $\mathrm{Me}$ & 180 & 87 \\
& ${ }^{t} \mathrm{Bu}$ & 180 & 76 \\
& $\mathrm{NMe}_{2}$ & 140 & 58 \\
& $\mathrm{OMe}$ & 140 & trace \\
& $\mathrm{CO}_{2} \mathrm{Et}$ & 140 & 0 \\
& $\mathrm{CF}_{3}$ & 180 & 0 \\
\hline
\end{tabular}

Wong reported the pentanuclear bimetallic cluster $\mathrm{Os}_{4} \mathrm{Au}(\mu-\mathrm{H})_{3}(\mathrm{CO})_{12}\left(\mathrm{PPh}_{3}\right), \mathbf{1 2 9}$, as catalyst towards oxidative carbonylation of aniline (42a) in methanol [161]. Catalytic formation of methyl phenylcarbamate $\mathbf{1 3 0}$ was effected using 129 with $93 \%$ conversion and an $82 \%$ selectivity, compared to approximately $40 \%$ selectivity demonstrated by the two tetraosmium clusters, $\mathrm{Os}_{4}(\mu-\mathrm{H})_{4}(\mathrm{CO})_{12}$ and $\left[\mathrm{N}\left(\mathrm{PPh}_{3}\right)_{2}\right] \mathrm{Os}_{4}(\mu-\mathrm{H})_{3}(\mathrm{CO})_{12}$, Table 28. Moreover, the two latter clusters formed the byproducts $N$-methylaniline $42 \mathrm{~h}$ and formaniline $\mathbf{6 7 b}$ not observed for 129 . Lowering the concentrations of substrate and cluster in $\mathrm{MeOH}$ resulted in an increase of conversion at the expense of the selectivity towards 130. The lack of byproducts formed by $\mathbf{1 2 9}$ lead the authors to suggest two different mechanisms for $\mathbf{1 2 9}$ relative to the tetraosmium clusters.

Table 28. Carbonylation of 42a using pentanuclear bimetallic [Os $4 \mathrm{Au}$ ] cluster $\mathbf{1 2 9}$ as catalyst. Terminal $\mathrm{CO}$ molecules have been omitted for clarity, [161].
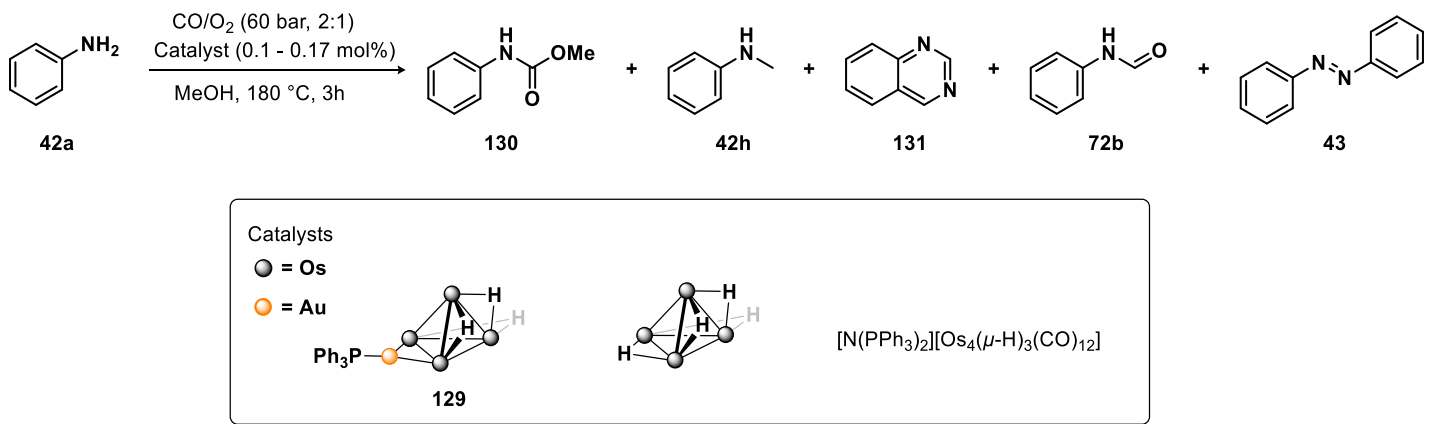

\begin{tabular}{|c|c|c|c|c|c|c|c|c|c|}
\hline \multirow[t]{2}{*}{ Cluster } & \multirow{2}{*}{$\begin{array}{c}\text { Loading } \\
{[\mathrm{mol} \%]}\end{array}$} & \multirow{2}{*}{$\begin{array}{l}\text { TOF } \\
{\left[\mathrm{h}^{-1}\right]}\end{array}$} & \multirow{2}{*}{$\begin{array}{c}\mathrm{MeOH} \\
{[\mathrm{mL}]}\end{array}$} & \multirow{2}{*}{$\begin{array}{c}\text { Conversion } \\
{[\%]} \\
\end{array}$} & \multicolumn{5}{|c|}{ Selectivity [\%] } \\
\hline & & & & & 130 & $42 \mathrm{~h}$ & 131 & $72 b$ & 43 \\
\hline \multirow[t]{2}{*}{129} & 0.13 & 248 & 3 & 93 & 82 & - & 10 & - & - \\
\hline & 0.13 & 267 & 20 & 100 & - & - & 37 & - & 39 \\
\hline \multirow{3}{*}{$\mathrm{Os}_{4}(\mu-\mathrm{H})_{4}(\mathrm{CO})_{12}$} & 0.17 & 42 & 3 & 21 & 41 & 30 & 4 & 8 & 5 \\
\hline & 0.17 & 126 & 20 & 63 & - & 12 & - & - & 28 \\
\hline & 0.10 & 33 & 3 & 10 & 43 & 37 & 8 & 7 & 5 \\
\hline
\end{tabular}




$\left[\begin{array}{llllllllll}{\left[\mathrm{N}\left(\mathrm{PPh}_{3}\right)_{2}\right] \mathrm{Os}_{4}(\mu-\mathrm{H})_{3}(\mathrm{CO})_{12}} & 0.10 & 333 & 20 & 35 & - & 22 & - & - & 78 \\ \hline\end{array}\right.$

\section{Addition reactions}

Hidai has provided several accounts on the mixed-metal sulfide cubane-type cluster $\left[\mathrm{MMo}_{3} \mathrm{~S}_{4}\right]$ as catalyst precursors for various transformation of alkynes $(\mathbf{1 0 4}, \mathbf{1 3 2}, \mathbf{1 4 2}, \mathbf{1 4 4})$, olefins $(\mathbf{1 d}, \mathbf{1 5 7})$, and hydrazines $(46)$. For example, $\left[\mathrm{PdMo}_{3} \mathrm{~S}_{4}\left(\mathrm{H}_{2} \mathrm{O}\right)_{9} \mathrm{Cl}\right] \mathrm{Cl}_{3}(\mathbf{1 3 3})$ and $\left[\mathrm{PdMo}_{3} \mathrm{~S}_{4}(\operatorname{tacn})_{3} \mathrm{Cl}\right] \mathrm{Cl}_{3}(\mathbf{1 3 4})$, tacn = 1,4,7-triazacyclononane, cubane-type clusters were found to be highly regioselective towards trans-addition of alcohols to alkynoic acid esters 132 leading to $\mathbf{1 3 5}$, Table 29 [162]. Cluster catalysis is suggested based on the combined observations that spectroscopic analyses indicate a single organometallic species in the reaction mixture, and that neither of the parent compounds $\left[\mathrm{Mo}_{3} \mathrm{~S}_{4}\left(\mathrm{H}_{2} \mathrm{O}\right)_{9}\right] \mathrm{Cl}_{4}$ nor Pd-black provide sufficient catalytic activity.

Table 29. Proposed catalytic cycle for conversion of 132 to 135 using $\mathbf{1 3 4}$ as catalyst precursor, [162].

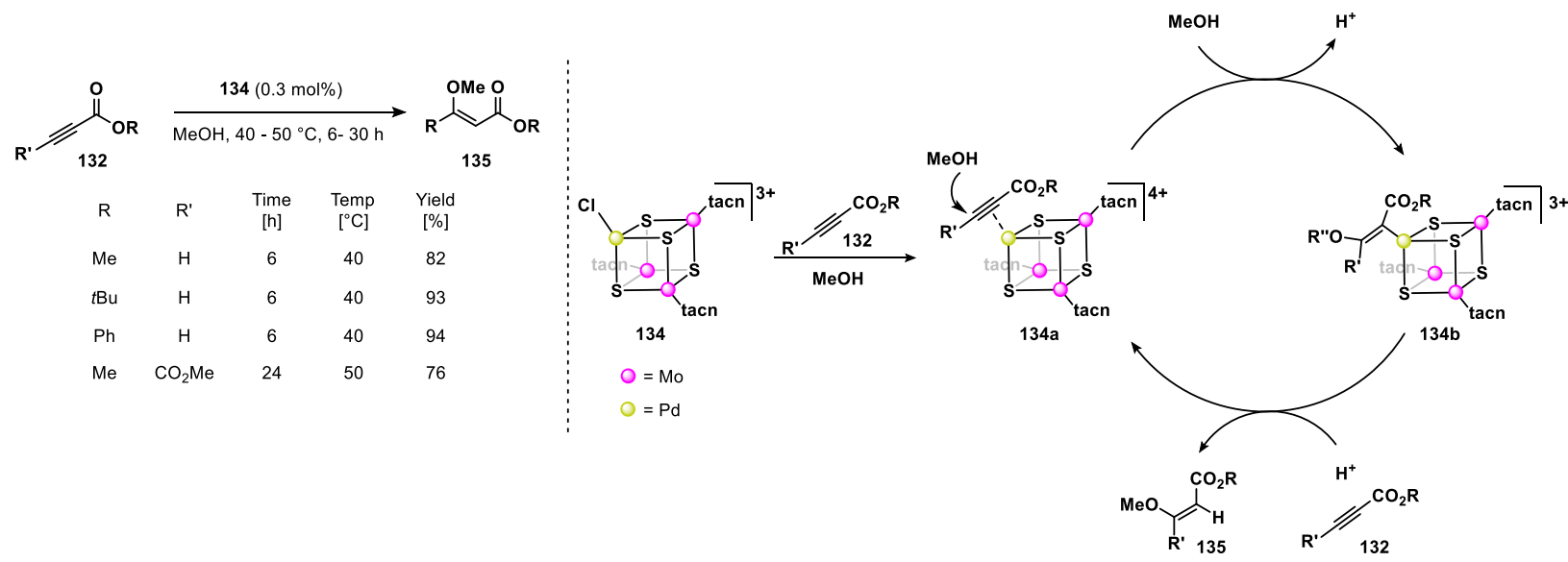

Cluster 134 was reported to catalyze the stereoselective addition of alkyl and aryl substituted hydrogen carbonates 137 to electron-deficient alkynes, such as 136a, Table 30 [163]. To support the suggestion of cluster catalysis, the reactivity of 134 was compared to that of 133, as well as to those of other appropriate mononuclear $\mathrm{Pd}, \mathrm{Ru}$, and $\mathrm{Rh}$ complexes. Whereas $\mathbf{1 3 3}$ provided transformation at a much lower rate than $\mathbf{1 3 4}$ did, neither of the mononuclear complexes resulted in any detectable transformation, which satisfies Laine's second criterion on cluster-mediated catalysis. Additionally, spectroscopic analyses substantiate a single organometallic species in the reaction mixture. Moreover, 134 demonstrated a TON(18h) of 2500. The role of the cubane-type cluster is twofold and is suggested to (i) activate the acetylenic species, and (ii) suppress side reactions. The mechanism suggested by the authors follow analogously to that in Table 29.

Table 30. Stereoselective catalytic addition of carboxylic acids to electron deficient alkynes, [163].

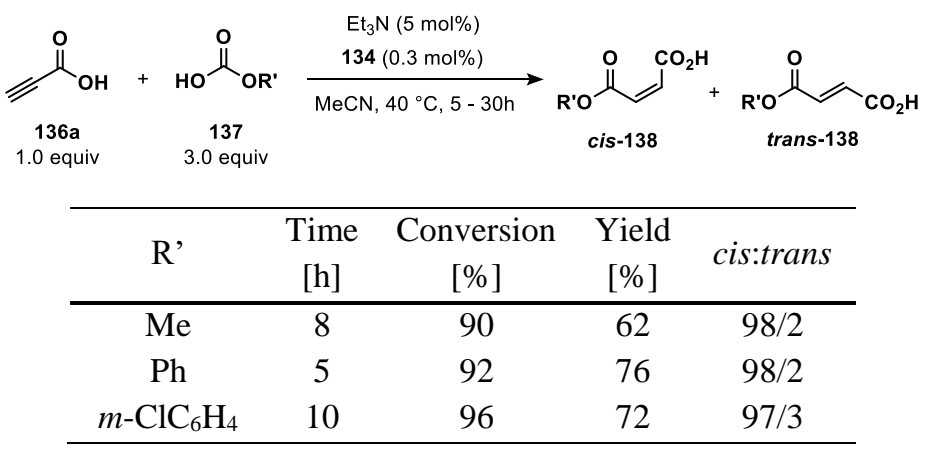

Regioselective addition of alcohols across triple bonds was catalyzed by the triangular mixed-metal sulfide cluster comprising $\operatorname{Ir}_{2} \mathrm{M}, \mathrm{M}=\mathrm{Pd}(\mathbf{1 3 9 P d})$, Pt (139Pt), Table 31 [164], where substituting Pd for Pt afforded a less selective 
cluster. Cluster catalysis is suggested based on the combination of recovered cluster, and lack of selectivity when employing lower nuclearity catalysts. A later study by Hidai provided further insights to the transformation, where it was shown that the electronic properties of the arene in $\mathbf{1 0 4}$ affected the selectivity, as electron donating groups in the $p$-position was found to decrease the regioselectivity [165]. The combined findings are concluded in the presented cycle below. The authors suggest a catalytic cycle that is initiated by ligand substitution at the palladium center of chloride for the alkyne 104, resulting in 139a. Addition of the first equivalent of alcohol and protonoloysis results in a alkoxyvinyl cluster $\mathbf{1 3 9 b}$, which further undergoes addition of alcohol to form $\mathbf{1 4 0}$.

Table 31. Regioselective alcohol addition to 104 leading to 140 or 141 using 139 as catalyst precursor, [164, 165].

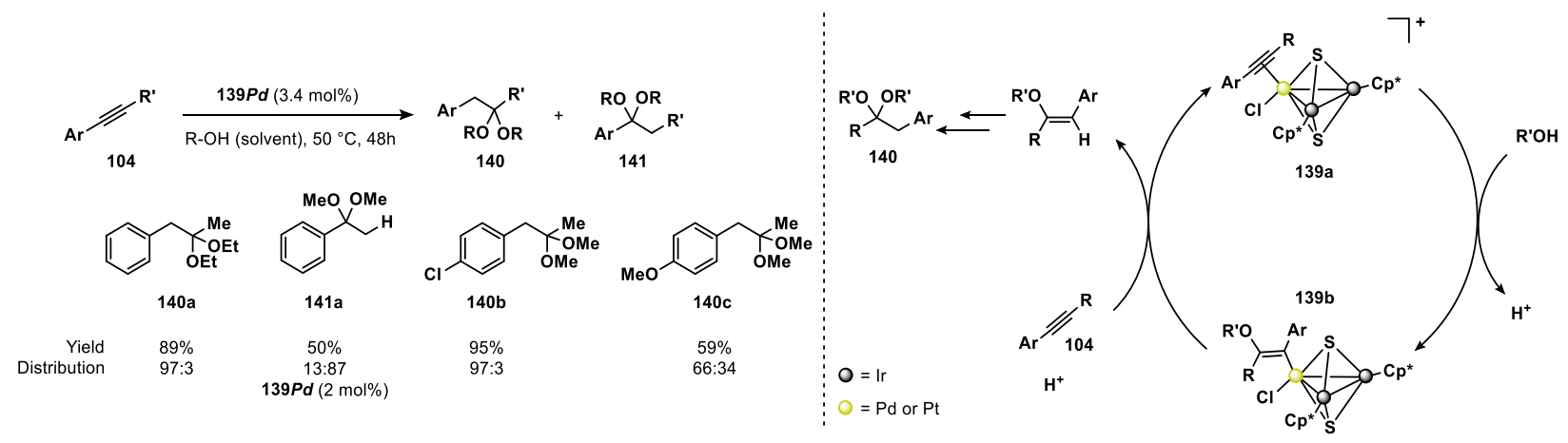

\section{Cycloaddition}

In a later study, Hidai employed cluster $\mathbf{1 3 4}$ to demonstrate its applicability in the cyclization of various alkynoic acids 142a to furanone type product 143a, Scheme 38 [166]. Cluster catalysis is strongly implied based on kinetic studies revealing a first order rate-dependence with respect to the cluster, an approximately 20 fold rate enhancement relative to mononuclear $\mathrm{Pd}$ complex, $\mathrm{PdCl}_{2}(\mathrm{PhCN})_{2}$, as well as spectroscopic measurement showing intact catalyst throughout the reaction. A TON $(19 \mathrm{~h})$ value of 100000 was reported in the cyclization of the simplest compound, using a 0.001 mol\% catalyst loading in $\mathrm{MeCN}$ at $40{ }^{\circ} \mathrm{C}$ (97\% yield).

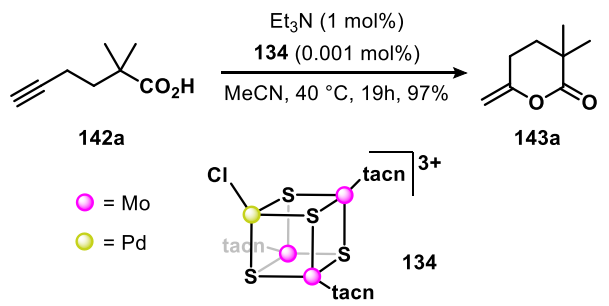

Scheme 38. Cyclization of 142a to 143a using 134 as catalyst precursor, [166].

Continued efforts to provide insight into the catalytic activity of cubane-type clusters 134 were provided by Hidai in the cyclization of aminoalkynes 144 to 146, Scheme 39 [167]. Changing the Pd-precursor to either $\operatorname{Pd}(\mathrm{dba})_{2}, \mathrm{dba}=$ bis(dibenzylideneacetone), or $\operatorname{Pd}(\mathrm{ma})(\mathrm{nbd}), \mathrm{ma}=$ maleic anhydride, and $\mathrm{nbd}=$ nobornadiene, resulted in corresponding cubane-type clusters $\left[(\mathrm{Cp} * \mathrm{Mo})_{3} \mathrm{PdS}_{4}(\mathrm{dba})\right]\left[\mathrm{PF}_{6}\right], \quad \mathbf{1 4 5 a}$ and $\left[(\mathrm{Cp} * \mathrm{Mo})_{3} \mathrm{PdS}_{4}(\mathrm{ma})\right]\left[\mathrm{PF}_{6}\right] \mathbf{1 4 5} \mathbf{b}$, respectively. Both $\mathbf{1 4 5 a}$ and $\mathbf{1 4 5 b}$ showed a high catalytic activity in the intramolecular cyclization of $\mathbf{1 4 4}$, affording up to $98 \%$ yield. These findings are in stark contrast with when employing $\mathrm{PPh}_{3}$, which afforded merely $6 \%$ yield. This observation was accounted for as to due to a difficult ligand-substrate substitution in the former systems. Insights on the mixtures was provided by UV-vis measurements substantiating an intact cluster entity. Using a $1 \mathrm{~mol} \%$ catalyst loading of $\left[(\mathrm{Cp} * \mathrm{Mo})_{3} \mathrm{PdS}_{4}(\mathrm{dba})\right]\left[\mathrm{PF}_{6}\right] \mathbf{1 4 5 a}$ in $\mathrm{THF}$ at $60{ }^{\circ} \mathrm{C}$ led to near quantitative yields. 


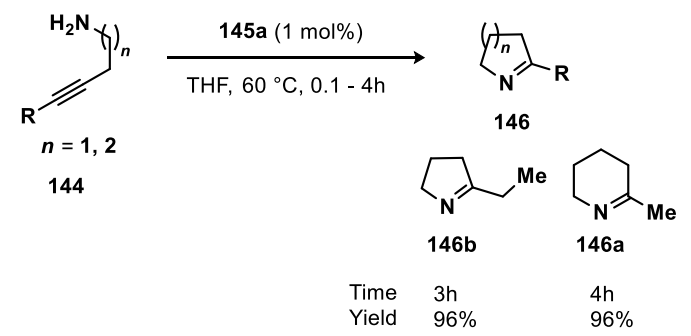

Scheme 39. Catalytic intramolecylar aminoalkyne cycloaddition of 144 leading to 146 using 145a as catalyst precursor, [167].

Substituting Ni for Pd and tacn for Cp* in 134 provided the COD-dimer of the cluster [ $\left\{(\mathrm{Cp} * \mathrm{Mo})_{3}\left(\mu_{3}-\mathrm{S}\right)_{4} \mathrm{Ni}\right\}_{2}\left(\mu, \eta^{2}: \eta^{2}-\right.$ cod) $]\left[\mathrm{PF}_{6}\right]_{2}, 147$ [168]. A monomeric cluster was generated by treating 147 with dimethyl acetylenedicarboxylate, resulting in the singly alkyne-Ni coordinated cluster 148, Scheme 40. The alkyne coordination to the Ni-center is suggested to result from the $\pi$-accepting properties of the $\mathrm{Mo}_{3} \mathrm{~S}_{4}$-framework, thus lowering the electron-density at the Ni center. While both 147 and 148 demonstrated catalytic activity, neither of the parent compounds, $\left[(\mathrm{Cp} * \mathrm{Mo})_{3}\left(\mu_{2^{-}}\right.\right.$ $\left.\mathrm{S})_{3}\left(\mu_{3}-\mathrm{S}\right)\right]\left[\mathrm{PF}_{6}\right]$ and $\mathrm{Ni}(\mathrm{COD})_{2}$, provided any activity in the cyclization. Based on the lack of catalytic activity of the parent compounds as well as prior observations, the authors propose the catalytic cycle by a single cluster shown in the Scheme 41.

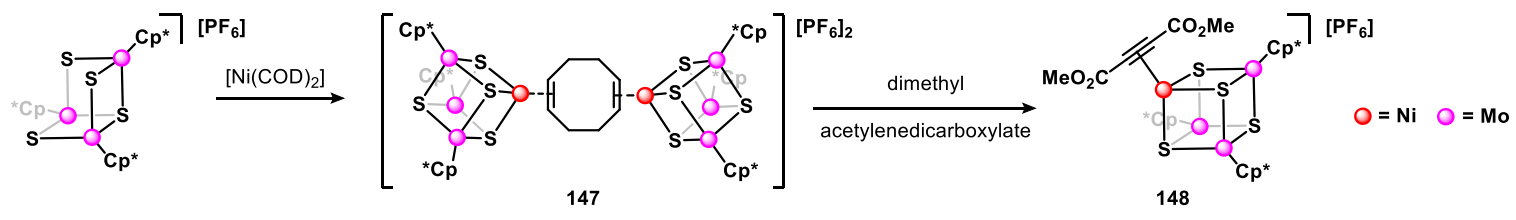

Scheme 40. Preparation of [NiMo $\left.\mathrm{S}_{4}\right]$-cubane type clusters 147 and 148, [168].
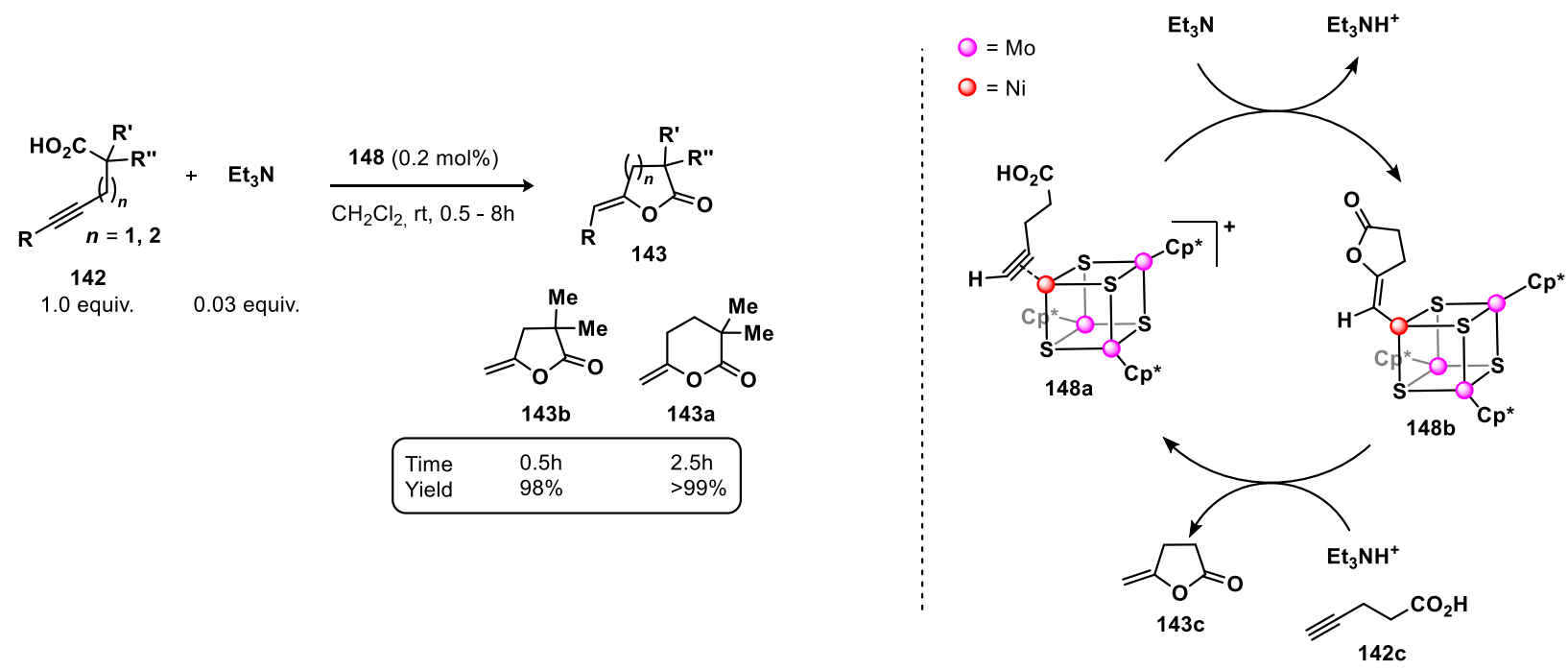

Scheme 41. Left: Intramolecular cyclization of 142 leading to 143 using 148 as catalyst precursor. Right: Catalytic cycle for the cyclization of $\mathbf{1 4 2}$ to $\mathbf{1 4 3}$ using $\mathbf{1 4 8}$ as catalyst, as proposed by Hidai, [168].

Llusar and Pérex-Prieto reported asymmetric induction in the catalytic intra- and intermolecular cyclopropanation of olefins, such as 149 and 1d, with $\alpha$-diazoketo units leading to 150 and 152, respectively, by using catalytic amounts of stereoenriched mixed-metal cubane-type $\mathrm{CuMo}_{3} \mathrm{~S}_{4}$-clusters, 153-156, Table 32 [169]. Optically pure trinuclear frameworks were prepared stereoselectively via cluster excision of the polymeric unit, $\left\{\mathrm{Mo}_{3} \mathrm{~S}_{7} \mathrm{Cl}_{4}\right\}_{n}$, using the chiral chelating phosphine ligand, $(R / S, R / S)$-Me-BPE. The resulting cluster chirality was preserved as $\mathrm{Cu}$ was introduced to the framework. Single-crystal X-ray diffraction in combination with circular dichroism was used to establish two 
enantiopure compounds. Preliminary studies of the intramolecular cylopropanation reaction showed that the parent $\mathrm{Mo}_{3} \mathrm{~S}_{4}$-framework 15 was catalytically inactive. Furthermore, spectroscopic analysis confirmed the racemic cubanecluster, 156, stayed intact throughout the reaction. Based on the preliminary results of the racemic cluster, the chiral cluster 153 was employed under the same reaction conditions, affording a low enantiomeric excess of merely $25 \%$ ee.

Additionally, clusters 153-156 were employed in an intermolecular cyclopropanation, resulting in E/Z ratio of up to 2.6 and with low enantioselectivity. The low selectivity is suggested to relate to the addition of alkenes to the $\mathrm{Cu}$ carbene species, which is insufficiently sterically encumbered. As such, the authors suggest that an increase of steric bulk at the coordination-sphere of the $\mathrm{Cu}$-center likely will be beneficial for the stereoselectivity. Pérez-Prieto proposed the involvement of the cluster $\mathbf{1 5 3}$ to occur by either of two mechanisms, namely $(i)$ halide dissociation [at the $\mathrm{Cu}$-center], or by (ii) $\mathrm{Cu}-\mathrm{S} / \mathrm{Se}$ bond cleavage [170]. To this end, analogues were prepared; substituting $\mathrm{Cl}$ with $\mathrm{Br}$, and $\mathrm{S}$ for Se. Whereas the enantiomeric ratios were effectively identical for the chloride- and bromide cluster, the rate was decreased by substitution of S for Se, Table 32, indicating that the latter mechanism is more likely.

Table 32. Chiral induction using enantiopure $\mathrm{CuMo}_{3} \mathrm{~S}_{4}$-clusters 153 and 156 as catalyst precursors for the cyclopropanation of $\mathbf{1 4 9}$ [169], as well as the intermolecular cyclopropanation of 1d [170].

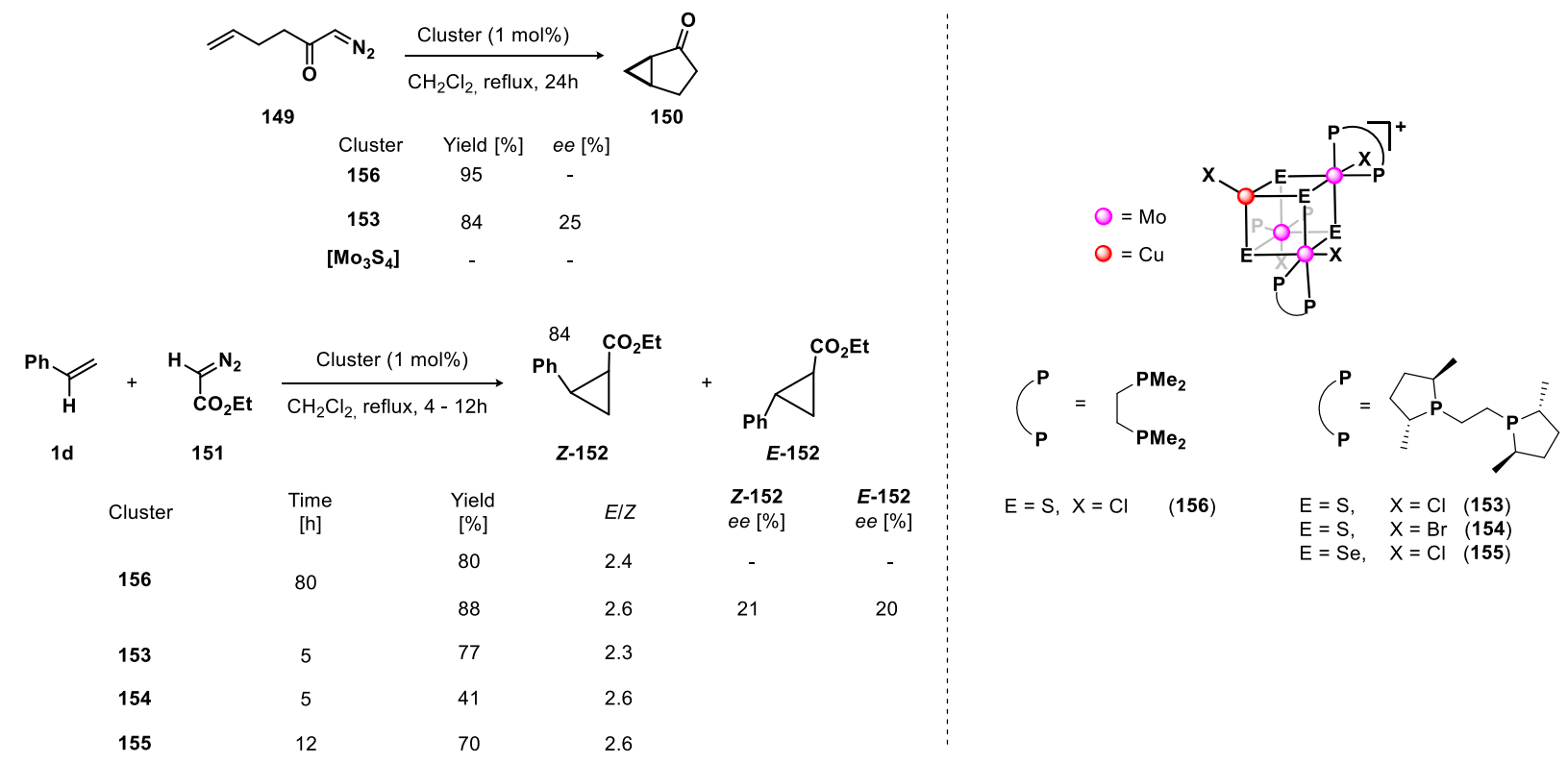

\section{Allylation}

Cluster 145 was further used to afford regioselective allyllation of amines, such as $\mathbf{4 2 h}$, leading to 158 , Scheme 42 [171]. Using $50 \mathrm{~mol} \% \mathrm{H}_{3} \mathrm{BO}_{3}$ as additive, near quantitative yields were reported within 4 hours with 5 mol\% catalyst loading. As in the aforementioned study, the ligation was found to affect the catalytic activity, and only dba afforded a catalytically active cluster. Of the mononuclear compounds, only $\mathrm{Pd}\left(\mathrm{PPh}_{3}\right)_{4}$ was able to provide any transformation albeit at lower yield (70 vs 96\%). The authors concluded that the $\mathrm{Mo}_{3} \mathrm{~S}_{4}$-framework act as a sterically encumbered ligand, thus suppressing formation of branched product. A tentative mechanism was provided by the authors, initiated by ligand substitution going from 145 to $\mathbf{1 4 5 b}$. The allylic hydroxyl group in turn coordinates to the boric acid. Subsequent nucleophilic attack to the $\pi$-allyl intermediate $145 \mathrm{c}$ regenerates $145 \mathrm{a}$ concurrently with product formation. The authors suggest the $\left[(\mathrm{Cp} * \mathrm{Mo})_{3} \mathrm{~S}_{4}\right]$ unit may be regarded in terms of an extended ligand. 


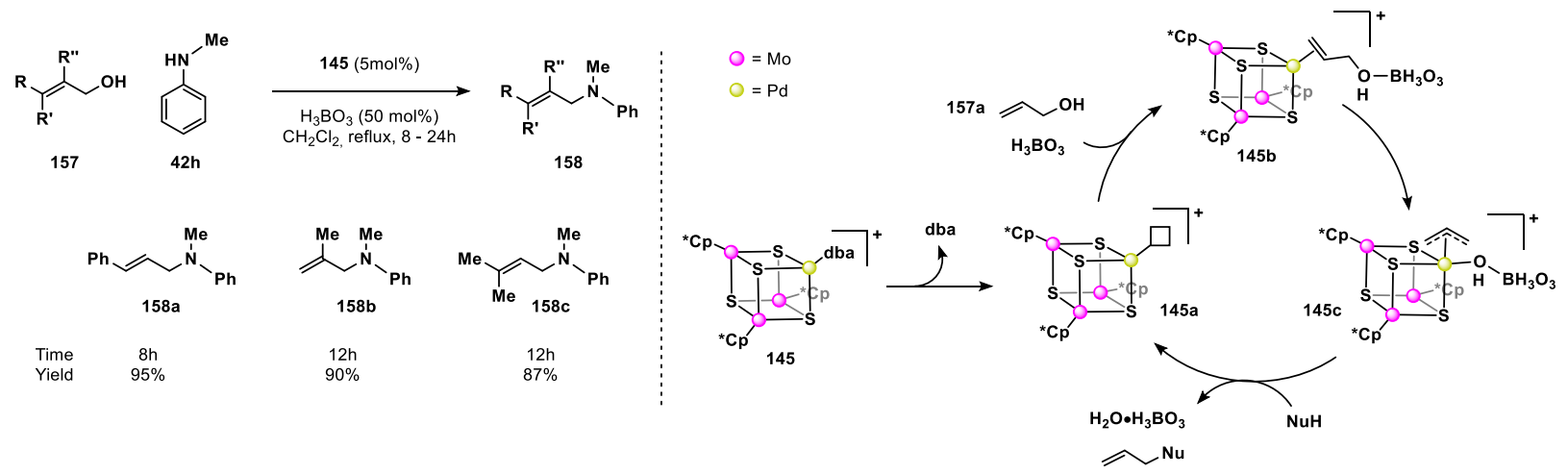

Scheme 42. Left: Allylation of $\mathbf{4 2 h}$ leading to 158 using 145 as catalyst precursor. Right: Catalytic cycle for allylation of various nucleophiles as proposed by $\mathrm{Qu},[171]$.

Continued studies of $\mathbf{1 4 5}$ was done by $\mathrm{Qu}$, who reported an extended substrate scope for the allyllation reaction, to include additional amines as well as active methylene compounds $\mathbf{1 5 9}$, such as 2-nitro-acetophenone, leading to 160 (Scheme 43, left) [172]. High yields up to $98 \%$ were obtained using a 5 mol\% catalyst loading. In a later study, they demonstrated that the same cluster is an efficient catalyst precursor for the Friedel-Crafts-type allylation of both anilines and indoles with allylic alcohols, Scheme 43, right [173]. In both studies, the lack of catalytic activity of related lower nuclearity species, combined with previous findings by Hidai, led the authors to propose cluster catalysis as shown in the scheme. Nucleophilic attack to $\mathbf{1 4 5 e}$ is directed by the $\left[(\mathrm{Cp} * \mathrm{Mo})_{3} \mathrm{~S}_{4}\right]$ unit that acts an extended ligand 145f, rather than the hindered allylic carbon, resulting. Subsequent ligand substitution with 157 forms $\mathbf{1 4 5 g}$ that undergoes protonation of the allylic alcohol moiety (145d).

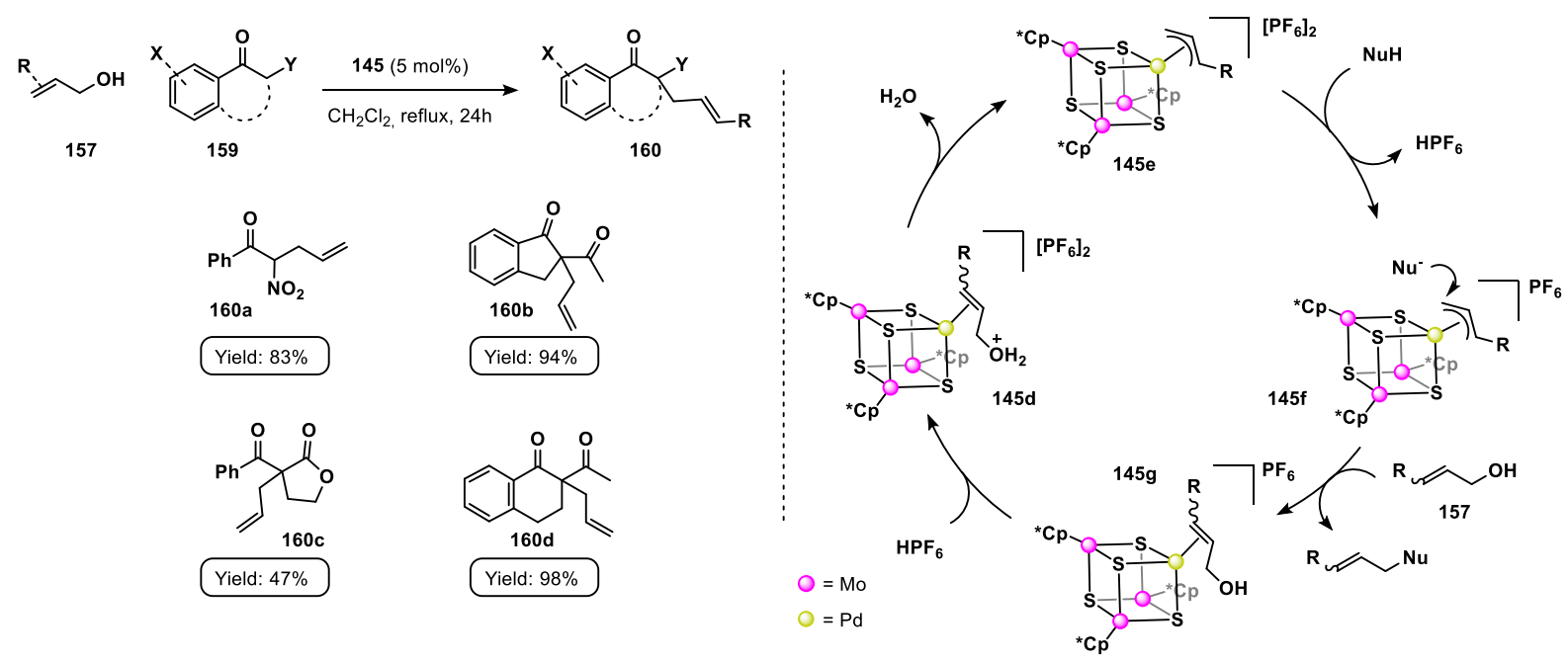

Scheme 43. Left: allylation of 159 to 160 using 145 as catalyst precursor. Right; Catalytic cycle in allylation of amines and Friedel-Crafts-type reaction as proposed by Qu, [172, 173].

\section{Disproportionation}

Hidai reported the cubane-cluster $\mathbf{1 6 1}$ containing Ru as an efficient catalyst for cleaving of N-N bonds in hydrazines [174]. Thus, catalytic disproportionation of hydrazine occurs from treatment with 161, Table 33. In addition to the disproportionation products $\left(\mathrm{NH}_{3}\right.$ and $\mathrm{N}_{2}$ ), an ammonia ligated cluster, 161a, along with a di-cubane cluster 161b bridged by both an amido and hydrazido ligand, $\mu-\mathrm{NH}_{2}$ and $\mu-\mathrm{NHNH}_{2}$, were observed. Substitution of $\mathrm{PPh}_{3}$ with $\mathrm{PCy}_{3}$ resulted in a catalytically more active cluster in the disproportionation reaction whilst suppressing the formation of 161a. The authors conclude a low reactivity of the clusters compared to a mononuclear molybdenum [175], and a dinuclear ruthenium thiolate-complex [176]. 
Table 33. [RuMo $\left.\mathrm{S}_{4}\right] 161$ in disproportionation of hydrazine and the corresponding adducts, [174].

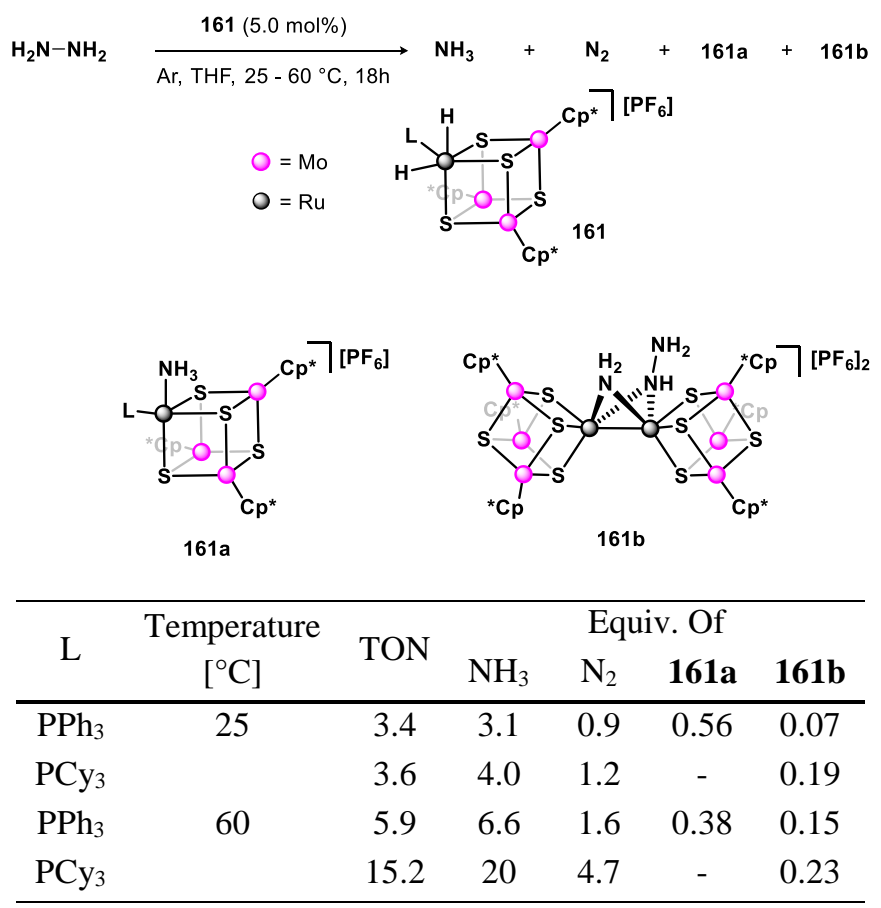

\section{Cross-alkylation}

Blum reported the triangulated mixed-metal clusters 106a and 106b as an efficient catalyst precursors for the crossalkylation of (pseudo)-halide arenes by group thirteen-stabilized alkylation agents, Table 34 [177]. The authors provide evidence in support of cluster catalysis. Thus, the use of either catalyst precursor $106 \mathbf{a}$ or $106 \mathbf{b}$, exclusively afford methylation products, whereas mononuclear Pd-compounds promote both homocoupling and hydrogenolysis. Moreover, the authors note that whereas conventional Pd-catalysts do not activate chloroarenes, both clusters demonstrated $99 \%$ yields when using $\mathbf{4 1 g}$ as substrate. The authors further suggest that side-reactions are suppressed based on a synergistic interaction between $\mathrm{Pd}$ and Mo or W.

Table 34. Methylation of aryl arenes using either 106a or 106b, [177].

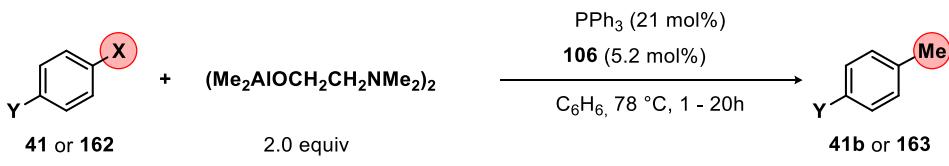

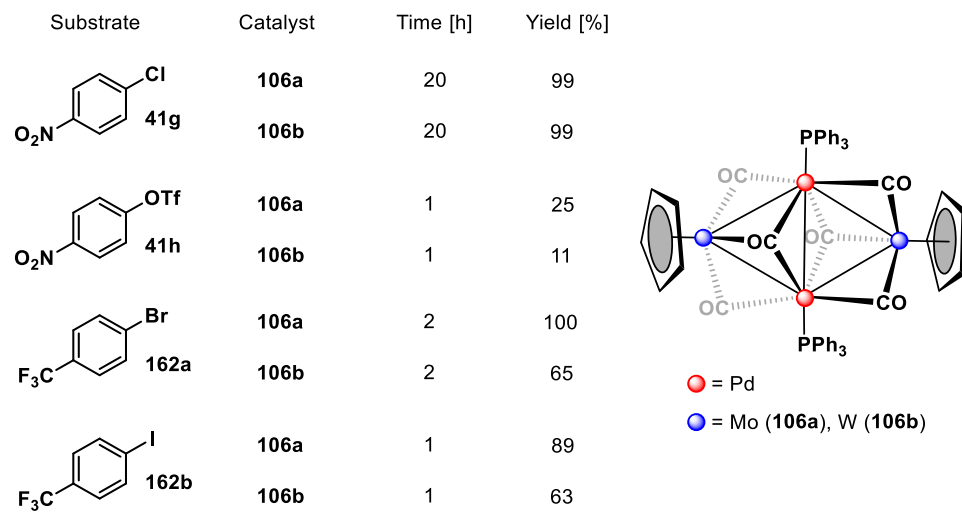




\section{Aryl homocoupling}

Shieh investigated three $N$-heterocyclic (NHC) functionalized mixed-metal pentanuclear clusters 164-166, which provided catalytic activity under Suzuki-Miyaura conditions for the homocoupling of $p$-bromoboronic acid 167 to biphenyl product 168 [178]. Comparing the reactivity the three clusters 164, 165, and 166, the authors conclude that the steric encumbering at the $\mathrm{Cu}$ center affords a greater activity in $166\left(18.2 \mathrm{~h}^{-1}\right.$ in 164 vs. $\left.36.8 \mathrm{~h}^{-1} \mathbf{1 6 6}\right)$, Table 35 . Furthermore, based on DFT and spectroscopical data $\left({ }^{13} \mathrm{C}\right.$ NMR), the authors suggest a facile oxidation of $\mathrm{Cu}(\mathrm{I})$, with the NHC groups stabilizing a $\mathrm{Cu}(\mathrm{III})$ intermediate during the catalytic cycle.

Table 35. Mixed-metal clusters 164-166 stabilized by Te in Suzuki-Miyaura homocross-copuling of 167 leading to 168, [178]. Terminal CO molecules have been omitted for clarity.

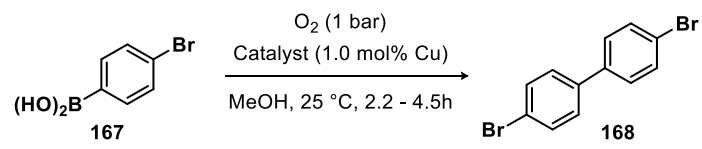

\begin{tabular}{|ccccc|}
\hline Catalyst & Time $[\mathrm{h}]$ & Yield $[\%]$ & TON & TOF $\left[\mathrm{h}^{-1}\right]$ \\
$\mathbf{1 6 4}$ & 4.5 & 82 & 82 & 18.2 \\
$\mathbf{1 6 5}$ & 3 & 80 & 80 & 26.7 \\
$\mathbf{1 6 6}$ & 2.2 & 81 & 81 & 36.8 \\
\hline
\end{tabular}

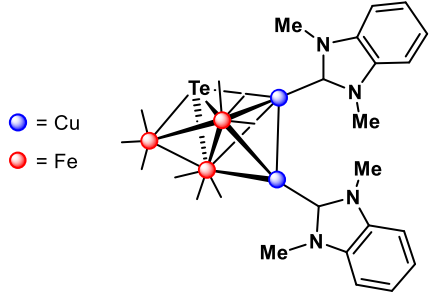

164

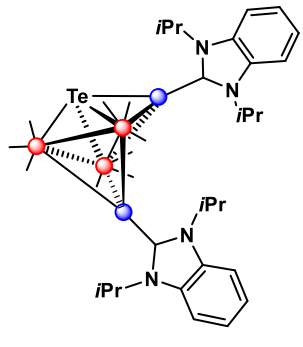

165

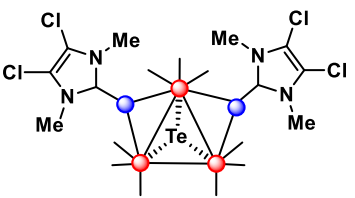

166 


\section{CONCLUSION}

During the past decades, the homogeneous catalytic research community has witnessed an impressive development within the use of polynuclear clusters as catalysts for a plethora of organic transformations. Interestingly, is has been demonstrated on numerous occasions that these clusters bear the potential to provide unique product selectivities, and thus represent a highly exciting rising methodology.

In this review, we have presented multiple examples of successes in homogeneous cluster catalysis. We have shown how the use of either homonuclear or heteronuclear clusters, respectively, may provide increased catalyst activity as well as different chemo-, regio-, and stereoselectivities than those seen with traditional mononuclear organometallic catalysts. Furthermore, several accounts shed light on the effect on catalysis when substituting among the members of a transitional metal triad of a single metal center in a heteronuclear cluster. Finally, throughout the review we have presented the Laine criteria for cluster catalysis and highlighted how the structures of the true catalysts have been addressed by use of a multitude of analytical tools. These investigations have led to several mechanistic proposals, which have been discussed here as well.

Many of the examples shown in this review demonstrate a fundamental challenge relating to cluster catalysis, namely the lack of framework stability, resulting from fluxional ligands, such as carbonyls and hydrides, often leading to cluster fragmentation. On the other hand, considerable evidence already supports that polynucleating ligands provide the necessary rigidity to retain cluster integrity while accommodating the essential geometric rearrangements during catalysis.

Cluster catalyzed reactions have the potential to open new avenues in chemical transformations stemming from the synergistic interaction between several vicinal metal centers, and their ability to mediate multiple electron transfers. Despite a wide range of cluster structures found in literature, their provision has largely relied on (serendipitous) selfassembly of appropriate metal and strong-field ligand combinations. Moreover, the majority of catalytic transformations are dictated by the parent cluster structure, thus limiting the scope. Consequently, the development of cluster catalyst that are structurally dictated by their polynucleating ligands are of high interest. 


\section{REFERENCES}

1. Shriver DF, Sailor MJ (1988). Acc. Chem. Res. 21, 374-379

2. Giordano R, Sappa E, Knox SAR (1996). J. Clust. Sci. 7, 179-190

3. Sappa E, Tiripicchio A, Braunstein P (1983). Chem. Rev. 83, 203-239

4. $\quad$ Keister JB, Shapley JR (1975). J. Organomet. Chem. 85, C29-C31

5. Muetterties EL, Stein J (1979). Chem. Rev. 79, 479-490

6. Nagashima H, Fukahori T, Aoki K, Itoh K (1993). J. Am. Chem. Soc. 115, 10430-10431

7. Nagashima H, Suzuki A, Nobata M, Itoh K (1996). J. Am. Chem. Soc. 118, 687-688

8. Yi CS, Zeczycki TN, Lindeman S V (2008). Organometallics 27, 2030-2035

9. Buchwalter P, Rosé J, Braunstein P (2015). Chem. Rev. 115, 28-126

10. Powers IG, Uyeda C (2017). ACS Catal. 7, 936-958

11. Cotton FA (1964). Inorg. Chem. 3, 1217-1220

12. Cotton FA (1966). Q. Rev. Chem. Soc. 20, 389

13. E. Rosenberg, R., M. Laine, in Catalysis by Di- and Polynuclear Metal Cluster Complexes ed. By R. D. Adams and F. A. Cotton, (Wiley-VCH, Weinheim, 1998), p. 4.

14. Adams RD, Captain B, Zhu L (2004). J. Am. Chem. Soc. 126, 3042-3043

15. Sculfort S, Braunstein P (2011). Chem. Soc. Rev. 40, 2741-2760

16. Gray TG (2003). Coord. Chem. Rev. 243, 213-235

17. Walton RA (2004). J. Clust. Sci. 15, 559-588

18. Muetterties EL, Krause MJ (1983). Angew. Chem. Int. Ed. 22, 135-148

19. Kuiper JL, Shapley PA, Rayner CM (2004). Organometallics 23, 3814-3818

20. Laine RM (1982). J. Mol. Catal. 14, 137-169

21. Anton DR, Crabtree RH (1983). Organometallics 2, 855-859

22. Hagen CM, Vieille-Petit L, Laurenczy G, Süss-Fink G, Finke RG (2005). Organometallics 24, 1819-1831

23. Lausarot PM, Vaglio GA, Valle M (1982). J. Organomet. Chem. 240, 441-445

24. Lausarot PM, Vaglio GA, Valle M (1984). J. Organomet. Chem. 275, 233-237

25. Moura FCC, Lago RM, dos Santos EN, Helena Araujo M (2002). Catal. Commun. 3, 541-545

26. Joh T, Doyama K, Onitsuka K, Shiohara T, Takahashi S (1991). Organometallics 10, 2493-2498

27. Alvila L, Pakkanen TA, Pakkanen TT, Krause O (1992). J. Mol. Catal. 73, 325-334

28. Chatani N, Kamitani A, Oshita M, Fukumoto Y, Murai S (2001). J. Am. Chem. Soc. 123, 12686-12687

29. Inoue S, Yokota K, Tatamidani H, Fukumoto Y, Chatani N (2006). Org. Lett. 8, 2519-2522

30. Driller KM, Klein H, Jackstell R, Beller M (2009). Angew. Chem. Int. Ed. 48, 6041-6044

31. Morimoto T, Chatani N, Fukumoto Y, Murai S (1997). J. Org. Chem. 62, 3762-3765

32. Kondo T, Suzuki N, Okada T, Mitsudo T (1997). J. Am. Chem. Soc. 119, 6187-6188

33. Kondo T, Nakamura A, Okada T, Suzuki N, Wada K, Mitsudo T (2000). J. Am. Chem. Soc. 122, 6319-6320 
34. Kondo T, Kaneko Y, Taguchi Y, Nakamura A, Okada T, Shiotsuki M, Ura Y, Wada K, Mitsudo T (2002). J. Am. Chem. Soc. 124, 6824-6825

35. Yamazaki H, Hong P (1983). J. Mol. Catal. 21, 133-150

36. Chatani N, Ie Y, Kakiuchi F, Murai S (1997). J. Org. Chem. 62, 2604-2610

37. Ishii Y, Chatani N, Kakiuchi F, Murai S (1997). Organometallics 16, 3615-3622

38. Chatani N, Asaumi T, Yorimitsu S, Ikeda T, Kakiuchi F, Murai S (2001). J. Am. Chem. Soc. 123, 1093510941

39. Koelliker R, Bor G (1991). J. Organomet. Chem. 417, 439-451

40. Ragaini F, Ghitti A, Cenini S (1999). Organometallics 18, 4925-4933

41. Han SH, Geoffroy GL, Dombek BD, Rheingold AL (1988). Inorg. Chem. 27, 4355-4361

42. Sanchez-Delgado RA, Bradley JS, Wilkinson G (1976). J. Chem. Soc., Dalton Trans. 399-404

43. Blazina D, Duckett SB, Dyson PJ, Lohman JAB (2001). Angew. Chem. Int. Ed. 40, 3874-3877

44. Blazina D, Duckett SB, Dyson PJ, Lohman JAB (2003). Chem. Eur. J. 9, 1045-1061

45. Park BY, Montgomery TP, Garza VJ, Krische MJ (2013). J. Am. Chem. Soc. 135, 16320-16323

46. Hasegawa N, Charra V, Inoue S, Fukumoto Y, Chatani N (2011). J. Am. Chem. Soc. 133, 8070-8073

47. Shibata K, Hasegawa N, Fukumoto Y, Chatani N (2012). ChemCatChem 4, 1733-1736

48. Hasegawa N, Shibata K, Charra V, Inoue S, Fukumoto Y, Chatani N (2013). Tetrahedron 69, 4466-4472

49. Fleischer I, Wu L, Profir I, Jackstell R, Franke R, Beller M (2013). Chem. Eur. J. 19, 10589-10594

50. Fleischer I, Dyballa KM, Jennerjahn R, Jackstell R, Franke R, Spannenberg A, Beller M (2013). Angew. Chem. Int. Ed. 52, 2949-2953

51. Liu J, Kubis C, Franke R, Jackstell R, Beller M (2016). ACS Catal. 6, 907-912

52. Rameshkumar C, Periasamy M (2000). Tetrahedron Lett. 41, 2719-2722

53. Periasamy M, Mukkanti A, Raj DS (2004). Organometallics 23, 619-621

54. Periasamy M, Mukkanti A, Raj DS (2004). Organometallics 23, 6323-6326

55. Chini P, Martinengo S (1969). Inorg. Chim. Acta 3, 315-318

56. Martinengo S, Fumagalli A, Chini P, Albano VG, Clani G (1976). J. Organomet. Chem. 116, 333-342

57. Martinengo S, Fumagalli A, Chini P (1985). J. Organomet. Chem. 284, 275-279

58. Matsuda I, Fukuta Y, Tsuchihashi T, Nagashima H, Itoh K (1997). Organometallics 16, 4327-4345

59. Longoni G, Campanella S, Ceriotti A, Chini P, Albano VG, Braga D (1980). J. Chem. Soc., Dalton Trans. 1816-1819

60. Kondo T, Akazome M, Tsuji Y, Watanabe Y (1990). J. Org. Chem. 55, 1286-1291

61. Moore EJ, Pretzer WR, O’Connell TJ, Harris J, LaBounty L, Chou L, Grimmer SS (1992). J. Am. Chem. Soc. 114, 5888-5890

62. Chatani N, Fukuyama T, Kakiuchi F, Murai S (1996). J. Am. Chem. Soc. 118, $493-494$

63. Agarwala R, Azam KA, Dilshad R, Kabir SE, Miah R, Shahiduzzaman M, Hardcastle KI, Rosenberg E, Hursthouse MB, Abdul Malik KM (1995). J. Organomet. Chem. 492, 135-144

64. Bruce MI, Goodall BL, Gordon F, Stone A (1973). J. Organomet. Chem. 60, 343-349

$$
\text { P. ii }
$$


65. Chatani N, Morimoto T, Fukumoto Y, Murai S (1998). J. Am. Chem. Soc. 120, 5335-5336

66. Chatani N, Ishii Y, Ie Y, Kakiuchi F, Murai S (1998). J. Org. Chem. 63, 5129-5136

67. Burgess K, Holden HD, Johnson BFG, Lewis J, Hursthouse MB, Walker NPC, Deeming AJ, Manning PJ, Peters R (1985). J. Chem. Soc., Dalton Trans. 85-90

68. Chatani N, Fukuyama T, Tatamidani H, Kakiuchi F, Murai S (2000). J. Org. Chem. 65, 4039-4047

69. Fukuyama T, Chatani N, Tatsumi J, Kakiuchi F, Murai S (1998). J. Am. Chem. Soc. 120, 11522-11523

70. Inoue S, Shiota H, Fukumoto Y, Chatani N (2009). J. Am. Chem. Soc. 131, 6898-6899

71. Kakiuchi F, Sato T, Tsujimoto T, Yamauchi M, Chatani N, Murai S (1998). Chem. Lett. 27, 1053-1054

72. Cabeza JA, Fernandez-Colinas JM, Llamazares A, Riera V, Garcia-Granda S, Van der Maelen JF (1994). Organometallics 13, 4352-4359

73. Cabeza JA, del Rio I, Fernández-Colinas JM, Llamazares A, Riera V (1995). J. Organomet. Chem. 494, 169177

74. Cabeza JA, del Río I, Fernández-Colinas JM, Riera V (1996). Organometallics 15, 449-451

75. Castiglioni M, Giordano R, Sappa E (1991). J. Organomet. Chem. 407, 377-389

76. Algarra AG, Guillamón E, Andrés J, Fernández-Trujillo MJ, Pedrajas E, Pino-Chamorro JÁ, Llusar R, Basallote MG (2018). ACS Catal. 8, 7346-7350

77. Bergounhou C, Fompeyrine P, Commenges G, Bonnet JJ (1988). J. Mol. Catal. 48, 285-312

78. Haupt H-J, Wittbecker R, Flörke U (1996). J. Organomet. Chem. 518, 213-219

79. Gieshoff TN, Chakraborty U, Villa M, Jacobi von Wangelin A (2017). Angew. Chem. Int. Ed. 56, 3585-3589

80. Chakraborty U, Reyes-Rodriguez E, Demeshko S, Meyer F, Jacobi von Wangelin A (2018). Angew. Chem. Int. Ed. 57, 4970-4975

81. Matteoli U, Beghetto V, Scrivanti A (1996). J. Mol. Catal. A. Chem. 109, 45-50

82. Homanen P, Persson R, Haukka M, Pakkanen TA, Nordlander E (2000). Organometallics 19, 5568-5574

83. Moberg V, Haukka M, Koshevoy IO, Ortiz R, Nordlander E (2007). Organometallics 26, 4090-4093

84. Moberg V, Duquesne R, Contaldi S, Röhrs O, Nachtigall J, Damoense L, Hutton AT, Green M, Monari M, Santelia D, Haukka M, Nordlander E (2012). Chem. Eur. J. 18, 12458-12478

85. Moberg V, Homanen P, Selva S, Persson R, Haukka M, Pakkanen TA, Monari M, Nordlander E (2006). Dalton Trans. 279-288

86. Abdel-Magied AF, Patil MS, Singh AK, Haukka M, Monari M, Nordlander E (2015). J. Clust. Sci. 26, 12311252

87. Abdel-Magied AF, Singh AK, Haukka M, Richmond MG, Nordlander E (2014). Chem. Commun. 50, 77057708

88. Abdel-Magied AF, Majeed MH, Abelairas-Edesa MF, Ficks A, Ashour RM, Rahaman A, Clegg W, Haukka M, Higham LJ, Nordlander E (2017). J. Organomet. Chem. 849-850, 71-79

89. Zhang H, Yang C-B, Li Y-Y, Donga Z-R, Gao J-X, Nakamura H, Murata K, Ikariya T (2003). Chem. Commun. $142-143$

90. Cabeza JA, da Silva I, del Río I, Gossage RA, Miguel D, Suárez M (2006). Dalton Trans. 2450-2455

91. Sorribes I, Wienhöfer G, Vicent C, Junge K, Llusar R, Beller M (2012). Angew. Chem. Int. Ed. 51, 77947798 
92. Pedrajas E, Sorribes I, Junge K, Beller M, Llusar R (2015). ChemCatChem 7, 2675-2681

93. Pedrajas E, Sorribes I, Gushchin AL, Laricheva YA, Junge K, Beller M, Llusar R (2017). ChemCatChem 9, 1128-1134

94. Pedrajas E, Sorribes I, Junge K, Beller M, Llusar R (2017). Green Chem. 19, 3764-3768

95. Nakajima Y, Suzuki H (2005). Organometallics 24, 1860-1866

96. Takao T, Horikoshi S, Kawashima T, Asano S, Takahashi Y, Sawano A, Suzuki H (2018). Organometallics 37, 1598-1614

97. Federsel C, Boddien A, Jackstell R, Jennerjahn R, Dyson PJ, Scopelliti R, Laurenczy G, Beller M (2010). Angew. Chem. Int. Ed. 49, 9777-9780

98. Federsel C, Ziebart C, Jackstell R, Baumann W, Beller M (2012). Chem. Eur. J. 18, $72-75$

99. Wesselbaum S, vom Stein T, Klankermayer J, Leitner W (2012). Angew. Chem. Int. Ed. 51, 7499-7502

100. Hull JF, Himeda Y, Wang W-H, Hashiguchi B, Periana R, Szalda DJ, Muckerman JT, Fujita E (2012). Nat. Chem. 4, 383

101. Shitaya S, Nomura K, Inagaki A (2019). Chem. Commun. 55, 5087-5090

102. Guzman-Jimenez IY, Van Hal JW, Whitmire KH (2003). Organometallics 22, 1914-1922

103. Bachman RE, Whitmire KH (1994). Inorg. Chem. 33, 2527-2533

104. Suzuki N, Kondo T, Mitsudo T (1998). Organometallics 17, 766-769

105. Süss-Fink G, Herrmann G (1985). J. Chem. Soc., Chem. Commun. 735-737

106. Süss-Fink G, Schmidt GF (1987). J. Mol. Catal. 42, 361-366

107. Diz EL, Neels A, Stoeckli-Evans H, Süss-Fink G (2001). Polyhedron 20, 2771-2780

108. Ryan RC, Pittman CU, O’Connor JP (1977). J. Am. Chem. Soc. 99, 1986-1988

109. Pitmann CU, Ryan RC (1978). Chemtech 8, 170-175

110. Pittman CU, Wilemon GM, Wilson WD, Ryan RC (1980). Angew. Chem. Int. Ed. 19, 478-479

111. Nombel P, Lugan N, Mulla F, Lavigne G (1994). Organometallics 13, 4673-4675

112. Nombel P, Lugan N, Donnadieu B, Lavigne G (1999). Organometallics 18, 187-196

113. Kim D-S, Park W-J, Lee C-H, Jun C-H (2014). J. Org. Chem. 79, 12191-12196

114. Ko S, Na Y, Chang S (2002). J. Am. Chem. Soc. 124, 750-751

115. Na Y, Ko S, Hwang LK, Chang S (2003). Tetrahedron Lett. 44, 4475-4478

116. Ko S, Lee C, Choi M-G, Na Y, Chang S (2003). J. Org. Chem. 68, 1607-1610

117. Ko S, Han H, Chang S (2003). Org. Lett. 5, 2687-2690

118. Park EJ, Lee JM, Han H, Chang S (2006). Org. Lett. 8, 4355-4358

119. Kondo T, Okada T, Mitsudo T (1999). Organometallics 18, 4123-4127

120. Yoneda E, Kaneko T, Zhang S-W, Onitsuka K, Takahashi S (2000). Org. Lett. 2, 441-443

121. Yoneda E, Zhang S-W, Zhou D-Y, Onitsuka K, Takahashi S (2003). J. Org. Chem. 68, 8571-8576

122. Tsubuki M, Takahashi K, Honda T (2009). J. Org. Chem. 74, 1422-1425

123. Nagashima H, Suzuki A, Iura T, Ryu K, Matsubara K (2000). Organometallics 19, 3579-3590

$$
\text { P. iv }
$$


124. Sasakuma H, Motoyama Y, Nagashima H (2007). Chem. Commun. 4916-4918

125. Yumino S, Hashimoto T, Tahara A, Nagashima H (2014). Chem. Lett. 43, 1829-1831

126. Hanada S, Yuasa A, Kuroiwa H, Motoyama Y, Nagashima H (2010). Eur. J. Org. Chem. 2010, 1021-1025

127. Miyamoto K, Motoyama Y, Nagashima H (2012). Chem. Lett. 41, 229-231

128. Hanada S, Motoyama Y, Nagashima H (2008). Eur. J. Org. Chem. 2008, 4097-4100

129. Nagashima H, Itonaga C, Yasuhara J, Motoyama Y, Matsubara K (2004). Organometallics 23, 5779-5786

130. Harada N, Nishikata T, Nagashima H (2012). Tetrahedron 68, 3243-3252

131. Beltrán TF, Feliz M, Llusar R, Mata JA, Safont. VS (2011). Organometallics 30, 290-297

132. Alfonso C, Beltrán TF, Feliz M, Llusar R (2015). J. Clust. Sci. 26, 199-209

133. Yi CS, Zeczycki TN, Guzei IA (2006). Organometallics 25, 1047-1051

134. Yi CS, Lee DW (2009). Organometallics 28, 947-949

135. Kim J, Pannilawithana N, Yi CS (2016). ACS Catal. 6, 8395-8398

136. Takao T, Kawashima T, Kanda H, Okamura R, Suzuki H (2012). Organometallics 31, 4817-4831

137. Haak RM, Decortes A, Escudero-Adán EC, Belmonte MM, Martin E, Benet-Buchholz J, Kleij AW (2011). Inorg. Chem. 50, 7934-7936

138. Kielland N, Escudero-Adán EC, Martínez Belmonte M, Kleij AW (2013). Dalton Trans. 42, 1427-1436

139. Li B, Park Y, Chang S (2014). J. Am. Chem. Soc. 136, 1125-1131

140. Chakraborty U, Demeshko S, Meyer F, Jacobi von Wangelin A (2019). Angew. Chem. Int. Ed. 58, 3466-3470

141. Pittman CU, Honnick W, Absi-Halabi M, Richmond MG, Bender R, Braunstein P (1985). J. Mol. Catal. 32, $177-190$

142. Castiglioni M, Giordano R, Sappa E, Tiripicchio A, Camellini MT (1986). J. Chem. Soc., Dalton Trans. 2330

143. Castiglioni M, Giordano R, Sappa E (1987). J. Organomet. Chem. 319, 167-181

144. Castiglioni M, Giordano R, Sappa E (1988). J. Organomet. Chem. 342, 111-127

145. Adams RD, Li Z, Swepston P, Wu W, Yamamoto J (1992). J. Am. Chem. Soc. 114, 10657-10658

146. Adams RD, Barnard TS, Li Z, Wu W, Yamamoto JH (1994). J. Am. Chem. Soc. 116, 9103-9113

147. Adams RD, Barnard TS (1998). Organometallics 17, 2567-2573

148. Adams RD, Barnard TS (1998). Organometallics 17, 2885-2890

149. Smirnova ES, Muñoz Molina JM, Johnson A, Bandeira NAG, Bo C, Echavarren AM (2016). Angew. Chem. Int. Ed. 55, 7487-7491

150. Richmond MG, Absi-Halbi M, Pittman CU (1984). J. Mol. Catal. 22, 367-371

151. Senocq F, Randrianalimanana C, Thorez A, Kalck P, Choukroun R, Gervais D (1984). J. Chem. Soc., Chem. Commun. 1376-1377

152. Gervais D, Jaud J, Kalck P, ChoUKroun R, Senocq F (1986). Organometallics 5, 67-71

153. Choukroun R, Gervais D, Rifaï C (1989). Polyhedron 8, 1760-1761

154. Choukroun R, Dahan F, Gervais D, Rifai C (1990). Organometallics 9, 1982-1987 
155. Casado MA, Pérez-Torrente JJ, Ciriano MA, Oro LA, Orejón A, Claver C (1999). Organometallics 18, 30353044

156. Casado MA, Ciriano MA, Edwards AJ, Lahoz FJ, Oro LA, Pérez-Torrente JJ (1999). Organometallics 18, 3025-3034

157. Haupt HJ, Wittbecker R, Florke U (2001). Z. Anorg. Allg. Chem. 627, 472-484

158. Pittman Jr. CU, Richmond MG, Absi-Halabi M, Beurich H, Richter F, Vahrenkamp H (1982). Angew. Chem. Int. Ed. 21, 786-787

159. Shapley PA, Liang H-C, Dopke NC (2001). Organometallics 20, 4700-4704

160. Nagaoka M, Kawashima T, Suzuki H, Takao T (2016). Organometallics 35, 2348-2360

161. Li Y, Pan W-X, Wong W-T (2002). J. Clust. Sci. 13, 223-233

162. Murata T, Mizobe Y, Gao H, Ishii Y, Wakabayashi T, Nakano F, Tanase T, Yano S, Hidai M (1994). J. Am. Chem. Soc. 116, 3389-3398

163. Wakabayashi T, Ishii Y, Murata T, Mizobe Y, Hidai M (1995). Tetrahedron Lett. 36, 5585

164. Masui D, Ishii Y, Hidai M (1998). Chem. Lett. 27, 717-718

165. Masui D, Kochi T, Tang Z, Ishii Y, Mizobe Y, Hidai M (2001). J. Organomet. Chem. 620, 69-79

166. Wakabayashi T, Ishii Y, Ishikawa K, Hidai M (1996). Angew. Chem. Int. Ed. 35, 2123-2124

167. Takei I, Enta Y, Wakebe Y, Suzuki T, Hidai M (2006). Chem. Lett. 35, 590-591

168. Takei I, Wakebe Y, Suzuki K, Enta Y, Suzuki T, Mizobe Y, Hidai M (2003). Organometallics 22, 4639-4641

169. Feliz M, Guillamón E, Llusar R, Vicent C, Stiriba S-E, Pérez-Prieto J, Barberis M (2006). Chem. Eur. J. 12, 1486-1492

170. Guillamón E, Llusar R, Pérez-Prieto J, Stiriba S-E (2008). J. Organomet. Chem. 693, 1723-1727

171. Tao Y, Zhou Y, Qu J, Hidai M (2010). Tetrahedron Lett. 51, 1982-1984

172. Tao Y, Wang B, Wang B, Qu L, Qu J (2010). Org. Lett. 12, 2726-2729

173. Tao Y, Wang B, Zhao J, Song Y, Qu L, Qu J (2012). J. Org. Chem. 77, 2942-2946

174. Takei I, Dohki K, Kobayashi K, Suzuki T, Hidai M (2005). Inorg. Chem. 44, 3768-3770

175. B. Hitchcock P, L. Hughes D, J. Maguire M, Marjani K, L. Richards R (1997). J. Chem. Soc., Dalton Trans. 4747-4752

176. Kuwata S, Mizobe Y, Hidai M (1994). Inorg. Chem. 33, 3619-3620

177. Shenglof M, Molander GA, Blum J (2006). Synthesis (Stuttg) 2006, 111-114

178. Shieh M, Liu YH, Li YH, Lin CN, Wang CC (2018). J. Organomet. Chem. 867, 161-169 